\title{
A European Evidence-Based Guideline for the Prevention of Type 2 Diabetes
}

Authors
B. Paulweber ${ }^{1}$, P. Valensi ${ }^{2}$, J. Lindström ${ }^{3}$, N. M. Lalic ${ }^{4}$, C. J. Greaves ${ }^{5}$, M. McKee ${ }^{6}$, K. Kissimova-Skarbek ${ }^{7}$, S. Liatis ${ }^{8}$, E. Cosson ${ }^{2}$, J. Szendroedi ${ }^{9}$, K. E. Sheppard ${ }^{5}$, K. Charlesworth ${ }^{6}$, A.-M. Felton ${ }^{10}$, M. Hall ${ }^{11}$, A. Rissanen ${ }^{12}$, J. Tuomilehto ${ }^{13}$, P. E. Schwarz ${ }^{14}$, M. Roden ${ }^{9}$, for the Writing Group* , on behalf of the IMAGE Study Group * *

* Writing Group: M. Paulweber, A. Stadlmayr, L. Kedenko, N. Katsilambros, K. Makrilakis, Z. Kamenov, P. Evans, A. GilisJanuszewska, K. Lalic, A. Jotic, P. Djordevic, V. Dimitrijevic-Sreckovic, U. Hühmer, B. Kulzer, S. Puhl, Y. H. Lee-Barkey, A. AlKerwi, C. Abraham, W. Hardeman

** IMAGE Study Group: T. Acosta, M. Adler, A. AlKerwi, N. Barengo, R. Barengo, J. M. Boavida, K. Charlesworth, V. Christov, B. Claussen, X. Cos, E. Cosson, S. Deceukelier, V. Dimitrijevic-Sreckovic, P. Djordjevic, P. Evans, A.-M. Felton, M. Fischer, R. Gabriel-Sanchez, A. Gilis-Januszewska, M. Goldfracht, J. L. Gomez, C. J. Greaves, M. Hall, U. Handke, H. Hauner, J. Herbst, N. Hermanns, L. Herrebrugh, C. Huber, U. Hühmer, J. Huttunen, A. Jotic, Z. Kamenov, S. Karadeniz, N. Katsilambros, M. Khalangot, K. Kissimova-Skarbek, D. Köhler, V. Kopp, P. Kronsbein, B. Kulzer, D. Kyne-Grzebalski, K. Lalic, N. Lalic, R. Landgraf, Y. H. Lee-Barkey, S. Liatis, J. Lindström, K. Makrilakis, C. McIntosh, M. McKee, A. C. Mesquita, D. Misina, F. Muylle, A. Neumann, A. C. Paiva, P. Pajunen, B. Paulweber, M. Peltonen, L. Perrenoud, A. Pfeiffer, A. Pölönen, S. Puhl, F. Raposo, T. Reinehr, A. Rissanen, C. Robinson, M. Roden, U. Rothe, T. Saaristo, J. Scholl, P. E. Schwarz, K. E. Sheppard, S. Spiers, T. Stemper, B. Stratmann, J. Szendroedi, Z. Szybinski, T. Tankova, V. Telle-Hjellset, G. Terry, D. Tolks, F. Toti, J. Tuomilehto, A. Undeutsch, C. Valadas, P. Valensi, D. Velickiene, P. Vermunt, R. Weiss, J. Wens, T. Yilmaz

The affiliations are listed at the end of the article

\section{Bibliography}

Dol http://dx.doi.org/ 10.1055/s-0029-1240928

Horm Metab Res 2010; 42

(Suppl. 1): S3-S36 @ Georg

Thieme Verlag KG Stuttgart

New York · ISSN 0018-5043

\section{Correspondence}

Univ. Prof. Dr. Michael Roden

Karl-Landsteiner Institute for Endocrinology and Metabolism Hanusch Hospital

1140 Vienna

Austria

and

Institute for Clinical Diabetology, German Diabetes Center, and Department of Metabolic Diseases

University Clinics

Heinrich Heine University

Düsseldorf

Auf'm Hennekamp 65

40225 Düsseldorf

Germany

michael.roden@

ddz.uni-duesseldorf.de

\section{Abstract \\ $\nabla$}

Background: The prevalence and socioeconomic burden of type 2 diabetes (T2DM) and associated co-morbidities are rising worldwide. Aims: This guideline provides evidence-based recommendations for preventing T2DM. Methods: A European multidisciplinary consortium systematically reviewed the evidence on the effectiveness of screening and interventions for T2DM prevention using SIGN criteria. Results: Obesity and sedentary lifestyle are the main modifiable risk factors. Age and ethnicity are non-modifiable risk factors. Case-finding should follow a step-wise procedure using risk questionnaires and oral glucose tolerance testing. Persons with impaired glucose tolerance and/or fasting glucose are at high-risk and should be prioritized for intensive intervention. Interventions supporting lifestyle changes delay the onset of T2DM in high-risk adults (numberneeded-to-treat: 6.4 over $1.8-4.6$ years). These should be supported by inter-sectoral strategies

\section{Abbreviations}

$\nabla$

ADA:

ADDITION: Anglo-Danish-Dutch study of intensive treatment in people with screen

AES: Androgen Excess Society

AHA: American Heart Association that create health promoting environments. Sustained body weight reduction by $\geq 5 \%$ lowers risk. Currently metformin, acarbose and orlistat can be considered as second-line prevention options. The population approach should use organized measures to raise awareness and change lifestyle with specific approaches for adolescents, minorities and disadvantaged people. Interventions promoting lifestyle changes are more effective if they target both diet and physical activity, mobilize social support, involve the planned use of established behaviour change techniques, and provide frequent contacts. Cost-effectiveness analysis should take a societal perspective. Conclusions: Prevention using lifestyle modifications in highrisk individuals is cost-effective and should be embedded in evaluated models of care. Effective prevention plans are predicated upon sustained government initiatives comprising advocacy, community support, fiscal and legislative changes, private sector engagement and continuous media communication. 
DE-Plan: Diabetes in Europe-Prevention using Lifestyle, Physical Activity and Nutritional Intervention Plan

DESIR: Data from Epidemiological Study on the Insulin Resistance syndrome detected diabetes in primary care

DPP: $\quad$ US Diabetes Prevention Program

DPS: $\quad$ Finnish Diabetes Prevention Study

DREAM: $\quad$ Diabetes REduction Assessment w/ramipril \& rosiglitazone Medication

EASD: $\quad$ European Association for the Study of Diabetes

EPIC: $\quad$ European Prospective Investigation into Cancer and Nutrition study

FINDRISC: $\quad$ FINnish Diabetes Risk Score

FPG: $\quad$ Fasting plasma glucose concentration

GDM: Gestational diabetes

GWAS: $\quad$ Genome-wide association studies

HR: Hazard ratio

IDF: International Diabetes Foundation

IDPP: Indian Diabetes Prevention Program

IFG: Impaired fasting glucose

IGLOO: Impaired Glucose tolerance and Long-term Outcomes Observational

IGT: Impaired glucose tolerance

MetSy: $\quad$ Metabolic syndrome

MRF: $\quad$ Multiple Risk Factor Intervention Trial

NCEP-ATP III: National Cholesterol Education Program

NGT: $\quad$ Normal glucose tolerance

NHANES III: Third National Health and Nutrition Examination

Survey

NNT: $\quad$ Number needed to treat

OGTT: $\quad$ Oral glucose tolerance test

OR: $\quad$ Odds ratio

PCOS: $\quad$ Polycystic ovary syndrome

PG: $\quad$ Plasma glucose concentration

PIPOD: $\quad$ Pioglitazone In Prevention of Diabetes

QALY: Quality adjusted life years

RCT: $\quad$ Randomized controlled trial

RIO: $\quad$ Rimonabant-In-Obesity

RR: $\quad$ Relative risk

SES: $\quad$ Low socioeconomic status

SMOMS: $\quad$ Scandinavian Multicenter on Orlistat in Metabolic Syndrome

SOS: $\quad$ Swedish Obesity Surgery

STOP-NIDDM: Study To Prevent Non-Insulin-Dependent Diabetes Mellitus

T2DM: $\quad$ Type 2 diabetes mellitus

TRIPOD: $\quad$ Troglitazone In Prevention of Diabetes

WHO: World Health Organisation

XENDOS: XEnical in the prevention of Diabetes in Obese Subjects

\section{Introduction}

$\nabla$

It is estimated that the number of people with diabetes will reach 285 million people worldwide in 2010 , with almost half of those affected in the 20-60 age group. In Europe about 55 million people aged 20-79 will have diabetes in 2010 and this number is expected to rise to 66 million by 2030 unless effective preventive strategies are implemented. Type 2 diabetes (T2DM) accounts for about $90 \%$ of diabetes cases. People with T2DM have a 2 - to 4-fold increased risk of cardiovascular disease (CVD) and at least two thirds die from CVD. Increased CVD risk is already present in prediabetic states, particularly in individuals with impaired glucose tolerance (IGT) [1,2] and/or the metabolic syndrome (MetSy) [3]. Diabetes and its complications represent an enormous burden not only for patients but also for society. Direct healthcare costs, which represent about $30 \%$ of total costs to society, will be about 70 billion $€$ per year in 2010. It has been estimated that if an individual is diagnosed as having diabetes at the age of 40 years, men will lose on average 11.6 life-years and 18.6 quality adjusted life years (QALY) and women will lose 14.3 lifeyears and 22.0 QALYs [4]. Thus, primary prevention of T2DM and its complications is a major public health issue.

Despite the fact that inherited factors predispose to T2DM, environmental and lifestyle factors are held mainly responsible for the increasing prevalence of the disease over the past decades. There is now strong evidence from controlled trials that T2DM can be prevented by interventions that deliver relatively modest lifestyle changes. Thus, the potential to prevent T2DM represents a major opportunity for European governments and healthcare systems.

In order to address the challenge of reversing the epidemic of T2DM, a European multidisciplinary consortium (the IMAGE project: www.image-project.eu) developed this guideline for the prevention of T2DM which provides evidence based recommendations for health care practitioners, organizations, and funders on the prevention of type 2 diabetes in European healthcare settings.

\section{Definition of Risk and Target populations \\ $\nabla$}

Definition of risk

The risk for T2DM is predominantly determined by number and severity of non-modifiable and modifiable risk factors ( Table 1).

\section{Non-modifiable risk factors}

Age. Age is one of the strongest risk factors for T2DM (A). Epidemiological data for diabetes and impaired glucose regulation from 13 European countries have been published by the DECODE study group [5]. The prevalence of diabetes rises with age up to the 8 th decade in both men and women. It is less than $10 \%$ in subjects below 60 years and exceeds $20 \%$ above 80 years. The mean plasma glucose concentration at 2 hours (2-h PG) of the oral glucose tolerance test (OGTT) rises with age in European populations, particularly after 50 years. Women have higher mean 2-h PG levels than men, particularly above 70 years. Mean fasting plasma glucose (FPG) levels increase only slightly with age. They are higher in men than in women aged 30-69 years and become higher in women after 70 years. Among middle aged subjects, the prevalence of impaired glucose regulation (impaired glucose tolerance [IGT] and impaired fasting glucose [IFG], or both) is about $15 \%$, whereas in the elderly, 35-40\% of Europeans have impaired glucose regulation. Over the last years, the age of onset of diabetes has decreased considerably in countries in which the prevalence of obesity has increased significantly [610]. T2DM now accounts for as many as $50 \%$ of cases of newly diagnosed cases of diabetes in pediatric populations [11]. Earlier onset of T2DM leads to earlier onset of the complications. Markers of increased CVD risk may appear even before the diagnosis of the MetSy among obese children and adolescents [12] 


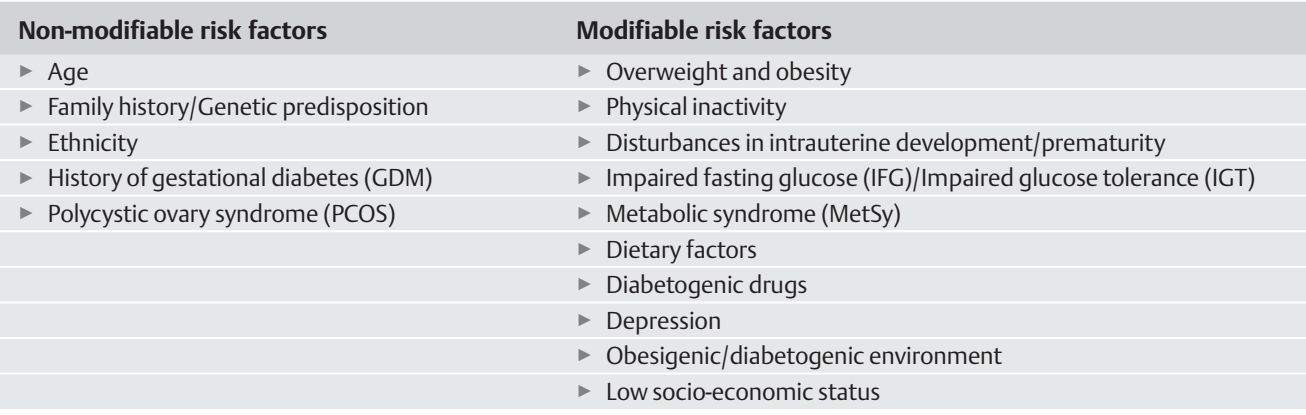

Table 1 Risk factors for T2DM

and metabolic abnormalities diagnosed in the adolescence tend to persist into adulthood [13].

Family history/genetic predisposition. Occurrence of the disease is highly concordant (60-90\%) in monozygotic twin pairs, but less so (17-37\%) in dizygotic twins [14-17] (A). The child of a parent with T2DM has a $40 \%$ chance of developing the disease, whereas the risk in the general population is about 7\% [18]. In the Botnia study, a positive family history with at least one affected first degree relative was associated with a hazard ratio (HR) of 2.2 for development of the disease [19]. In recent years a large number of genetic variants have been identified, which increase the risk for T2DM [20]. Genome-wide association studies provided by far the biggest increment to our knowledge of the genetics of T2DM [21-26]. At least 25 gene loci have been identified so far affecting susceptibility for T2DM [27] (A). The effect on T2DM risk per susceptibility allele ranges from about $10 \%$ to $40 \%$. The majority of these genes appear to play a role in beta-cell function rather than in insulin sensitivity. Collectively, however, these variants explain less than $10 \%$ of the genetic component of diabetes risk. Therefore despite the encouraging progress in our understanding of the genetic basis of T2DM, it is too early to use genetic information as a tool for targeting preventive efforts [19].

Ethnicity. Studies in multiethnic populations suggest that some ethnic groups have a particular predisposition, most likely on a genetic basis, to develop insulin resistance and T2DM, when exposed to adverse conditions [20]. There are wide differences in the prevalence of diabetes between ethnic groups (A) [28]. The prevalence of diagnosed diabetes among Hispanics is 1.9 times higher than that among Caucasians. Diabetes is diagnosed at an earlier age and Hispanics suffer from higher rates of diabetes-related complications and mortality [29]. Afro-Caribbeans and Asian Indians also exhibit higher prevalence of T2DM than Caucasians [30]. One important factor contributing to increased T2DM risk in Asian Indians is the greater insulin resistance compared to Caucasians [31].

Gestational diabetes (GDM). GDM is defined in terms of having glucose intolerance in the diabetic range as assessed from OGTT and/or FPG that begins or is first diagnosed during pregnancy $[32,33]$. It is estimated to affect between 3 and $5 \%$ of all pregnancies [32] There is a strong correlation between a history of GDM and later development of T2DM and its co-morbidities [34]. A recent meta-analysis of 20 studies reported that women with a history of GDM had about a 7.5-fold increased risk for T2DM compared with women with normoglycemic pregnancy [35] (A). Ethnicity has been proven to be an independent risk factor for GDM [36]. In the DPP women with a history of GDM randomized to placebo had an incidence rate of T2DM about $70 \%$ higher than that of women without such a history, despite equivalent levels of glucose intolerance at baseline [37]. Metabolic assessments recommended after GDM are $[33,38]$ (D): post delivery $(1-3$ days): FPG or random PG to detect persistent or overt diabetes, 6-12 weeks postpartum: OGTT, 1 year postpartum: OGTT, annually: fasting plasma glucose, tri-annually and pre-pregnancy: OGTT to classify glucose metabolism.

Polycystic ovary syndrome (PCOS). PCOS affects about one in 15 women worldwide with up to $10 \%$ of women of reproductive age [39] and shows familial aggregation and ethnic variation in its prevalence. At present, there are three main definitions for PCOS. The National Institutes of Health (NIH) criteria require the presence of hyperandrogenism and/or hyperandrogenemia, chronic anovulation, and exclusion of related disorders such as hyperprolactinemia, thyroid disorders, and congenital adrenal hyperplasia [40]. The 2003 Rotterdam criteria include two or more of the following in addition to exclusion of related disorders: oligo-anovulation or anovulation, clinical and/or biochemical signs of hyperandrogenism, polycystic ovaries [41]. The most recent criteria was defined by a task force of the Androgen Excess Society (AES) in 2006, which recommended the following criteria: hirsutism and/or hyperandrogenemia, oligo-ovulation and/or polycystic ovaries, exclusion of other androgen excess or related disorders [42]. Using the NIH criteria in unselected populations of women of the reproductive age the prevalence of PCOS is 6.5-8.0\% [43]. The 2003 Rotterdam criteria result in a 1.5 fold higher prevalence of PCOS [44].

The etiology of PCOS is incompletely understood, but studies suggest a strong genetic component influenced by gestational environment and lifestyle factors. Most women with PCOS have increased insulin resistance and impaired $\beta$-cell function compared with age- and BMI-matched controls [45]. Approximately $30 \%$ of women with PCOS have IGT and up to $10 \%$ are diabetic [46]. In the United States up to $40 \%$ of all women with PCOS have developed T2DM or IGT by the age of 40 years [47]. More pronounced endocrine disturbances conferring a particularly high risk for T2DM are observed in women with PCOS and obesity as compared with normal weight women with this condition [48]. Women with PCOS have a higher incidence of GDM, pregnancyinduced hypertension, and preeclampsia [49]. A recent metaanalysis revealed an approximately 3-fold increased risk as assessed from the odds ratio of 2.94 [95\% confidence interval, CI $1.70,5.08]$ for GDM among women with PCOS [50].

\section{Modifiable risk factors}

Overweight and obesity. Obesity (BMI $\geq 30 \mathrm{~kg} / \mathrm{m}^{2}$ ) and overweight (BMI $25-30 \mathrm{~kg} / \mathrm{m}^{2}$ ) increase the risk for developing both 
Table 2 Classification of glucose homeostasis based on fasting blood glucose and 2-hour blood glucose after a 75-g oral glucose tolerance test (OGTT)

\begin{tabular}{ll} 
Fasting glucose & Venous plasma $(\mathbf{m m o l} / \mathbf{l} / \mathbf{m g} / \mathbf{d l})$ \\
\hline Normal fasting glucose & $<6.1 /<110$ \\
\hline Impaired fasting glucose & 6.1 and $<7.0 / 110$ and $<126^{* *}$ \\
Diabetes & $7.0 / 126$ \\
\hline $\mathbf{2}$ glucose* & $<7.8 / 140$ \\
Normal glucose tolerance & 7.8 and $<11.1 / 140$ and $<200$ \\
Impaired glucose tolerance & $11.1 / 200$
\end{tabular}

Capillary whole blood $(\mathbf{m m o l} / / / \mathbf{m g} / \mathbf{d l})$
$<5.6 /<100$
5.6 and $<6.1 / 100$ and $<110$
$6.1 / 110$
$<7.8 / 140$
7.8 and $<11.1 / 140$ and $<200$
$11.1 / 200$

* Glucose level $2 \mathrm{~h}$ after ingestion of $75 \mathrm{~g}$ oral glucose load; if $2 \mathrm{~h}$ glucose is not measured, status remains uncertain as diabetes or IGT cannot be excluded; ** according to the classification recommended by the ADA impaired fasting glucose is defined as fasting plasma glucose levels between 5.6 and $7.0 \mathrm{mmol} / \mathrm{l}(100-126 \mathrm{mg} / \mathrm{dl})$

IGT and T2DM at all ages [51]. They act, at least in part, by inducing insulin resistance [52]. More than $80 \%$ of cases of T2DM can be attributed to obesity. Reversal of obesity also decreases the risk for T2DM (A) [53] and improves glycemic control in patients with established diabetes (A) [54]. A strong curvilinear relationship between BMI and the risk for T2DM was found in women in the Nurses' Health Study (B) [55]. The age-adjusted relative risk for diabetes was 6.1 times higher for people with BMI $>35 \mathrm{~kg} / \mathrm{m}^{2}$ than for people with BMI $<22 \mathrm{~kg} / \mathrm{m}^{2}$. The degree of insulin resistance and the incidence of T2DM are highest in those subjects with upper body or abdominal adiposity, as assessed from waist circumference [56,57]. Adiposity of the "gynoid" type, which primarily affects the gluteal and femoral region is not associated with glucose intolerance or increased CVD risk. However, studies trying to discern the relative importance of waist circumference (or waist-to-hip ratio) compared to BMI regarding risk for T2DM development have not shown a major advantage of one over the other (A) [58].

Physical inactivity. Recent data from the Nurses Health Study indicate that both obesity and physical inactivity independently contribute to the development of T2DM: the magnitude of risk contributed by obesity, seems to be greater than that imparted by lack of physical activity $[59,60]$. The benefit of physical activity in preventing diabetes has been demonstrated in several studies (A) [61-69].

Disturbances in intrauterine development/prematurity. There is an inverse association between birth weight and risk for T2DM. Specifically, subjects who had a low birth weight for gestational age have, as adults, reduced $\beta$-cell function [70], insulin resistance [71] and an increased incidence of T2DM (B) [72]. Small-for-gestational-age babies are those whose birth weights lie below the 10th percentile for their gestational age. Low birth weight $(<2500 \mathrm{~g})$ is sometimes used synonymously. Thinness at birth and in adult life have opposing effects on insulin resistance, such that subjects who were underweight at birth, but who become overweight in middle age, have the most severe insulin resistance and the greatest risk for T2DM [73]. Higher birth weight (>4000 g) may also be associated with an increased risk for T2DM (B) [74]. Large-for-gestational-age babies are those whose birth weights lie above the 90th percentile for their gestational age. A meta-analysis of 14 studies demonstrated a U-shaped relationship between birth weight and diabetes risk [75]. Both high and low birth weight were similarly associated with increased risk for diabetes later in life (OR: 1.36 and 1.47). Children born prematurely, whatever their weight, may also be at increased risk for T2DM (B) [76, 77].
Impaired fasting glucose (IFG) and impaired glucose tolerance (IGT). IFG and IGT are early abnormalities of glucose metabolism that precede diabetes. These are often called prediabetes. IFG is defined as an elevated FPG concentration between 6.1$6.9 \mathrm{mmol} / \mathrm{l}$. In 2003 the lower cut-off value was reduced to $5.6 \mathrm{mmol} / \mathrm{l}$ by the American Diabetes Association (ADA) [78], which was not accepted by the WHO in 2006 [79] (O Table 2). IGT is defined as an elevated PG between 7.8 and $11.1 \mathrm{mmol} / \mathrm{l}$ at 2 hours after a 75-g OGTT, in the presence of an FPG $<7 \mathrm{mmol} / \mathrm{l}$ $[78,80]$. It is clear that with the definitions above, there is overlap between the two groups. Thus, additional groups have been created, namely isolated IFG (i-IFG), isolated IGT (i-IGT) and IFG plus IGT (IFG + IGT).

The prevalence of IFG and IGT varies considerably among different ethnic groups and increases with age (B). IGT is more common in women. IFG and IGT are believed to represent different metabolic abnormalities. The reported estimates of diabetes development in IFG and IGT individuals vary widely, depending on the ethnicity of the population studied, with a higher incidence of T2DM noted in non-Caucasian populations (B).

Two recent meta-analyses found no evidence of a difference in T2DM risk among people with either IGT, IFG, i-IGT or i-IFG $[81,82]$, but both concluded that individuals with IFG + IGT have a substantially increased risk of T2DM compared to all other groups (B). The first meta-analysis included 44 studies and calculated the unadjusted annualized relative risk (RR) for progression to diabetes at 6.02 for IGT, 5.55 for IFG and 12.21 for IFG + IGT. The second meta-analysis included 40 studies and the RR was found to be 6.35 for IGT, 4.66 for IFG and 12.13 for IFG + IGT. Of note, most of the literature on IFG is based upon the older cut-off point (6.1-6.9 mmol/l) while the risk associated with IFG as more recently defined by the ADA (5.6-6.9 mmol/l) in 2003 remains to be evaluated.

According to the available data, it has been estimated that the majority of individuals (probably up to $70 \%$ ) with these prediabetic conditions will eventually develop diabetes [83]. However, studies of shorter duration have shown that during a period of $3-5$ years about $25 \%$ of individuals progress to diabetes, $25 \%$ return to a normal glucose tolerance status and $50 \%$ remain in the prediabetic state $(\mathbf{B})[84,85]$.

Metabolic syndrome (MetSy). MetSy is defined as a cluster of metabolic risk factors for cardiovascular disease which are associated with insulin resistance $[86,87]$. It is associated with an up to 2-fold elevated risk for CVD [3]. Although several diagnostic criteria have been proposed by different organizations, there is an ongoing debate regarding the existence of unique underlying pathophysiology [88-90]. The most widely used criteria were defined 
by the National Cholesterol Education Program (NCEP-ATP III) and include central obesity, high fasting plasma glucose, high triglycerides, low HDL-cholesterol and high blood pressure [86]. A harmonized definition of the MetSy has recently been suggested in a joint statement issued by several international organizations [91]. Despite the fact that the MetSy strongly predicts progression to T2DM [92], several reports [93-95] show that a single measure of blood glucose is a better predictor of incident diabetes than the complex definition of the MetSy. In a recent analysis from the San Antonio heart study, however, the metabolic syndrome as defined by the NCEP criteria predicted T2DM independently of the presence of elevated FPG [96]. The MetSy was as good a predictor for the occurrence of T2DM as iIFG (OR: 5.03 versus 7.07). If both conditions occurred simultaneously, the risk for T2DM was much higher (OR: 21.0).

Dietary factors. Diet is thought to play an important role, and some data suggest that certain dietary factors may predict T2DM but confounding factors limit many nutritional clinical studies. Even randomized nutritional clinical trials often suffer from several short-comings as they may start too late in the disease process, not be continued for sufficient duration or be inadequately powered. In addition, the protective (or deleterious) effect of a certain nutrient may only operate in conjunction with other nutrients or at a particular intake level. Finally, poor dietary compliance is another common problem of dietary trials. It is clear however that diet can influence the development of T2DM by affecting body weight. It has been shown that a dietary pattern promoting weight loss reduces the risk of T2DM (A) $[61,65,68]$. More recently, higher T2DM risk was also found to be associated with diet composition, particularly with low fibre intake.

Low fibre intake [97-100]. Individuals with low intake of dietary fibre, particularly of insoluble cereal fibre, have been found to be at increased risk for T2DM in several epidemiologic studies (B) $[101,102]$. In studies aimed at diabetes prevention by lifestyle modification, an increase in fibre consumption was often part of the intervention $[61,65]$. Fibre has a low glycemic index, which may contribute to T2DM risk reduction. However, the evidence for an increased risk associated with high glycemic index and high glycemic load diets is mixed [98-100,103]. Nevertheless, a recent meta-analysis of 37 prospective cohort studies (B) showed, in fully adjusted models, that both high glycemic load (RR 1.27 [95\% CI 1.12, 1.45]) and high glycemic index (RR 1.40, [95\% CI 1.23, 1.59]) diets are associated with increased risk for T2DM [104]. It must be emphasized that fibre rich foods generally have a low GI, although not all foods with a low GI necessarily have high fibre content.

Low unsaturated/saturated fat ratio [105-107]. Shifting from a diet based on animal fat to a diet rich in vegetable fat might reduce the risk for T2DM (B) [61,65]. An increased intake of monounsaturated fat appears to be of particular benefit (C) [108]. Recent studies revealed a weak positive correlation between intake of long chain omega-3 fatty acids (LCFA) and diabetes risk $[109,110]$.The beneficial effects of LCFA on other health outcomes, however, are well established $[108,111]$. The consumption of trans fatty acids has consistently been found to be associated with increased risk for T2DM [112] and CVD [113] (A).

Other nutrients. A less consistent but still significant body of evidence suggests that the risk for T2DM is lowered by regular con- sumption of moderate amounts of alcohol $(\mathbf{B})[114,115]$, fruits and vegetables (B) [116], nuts (B) [117] and coffee (B) [118]. It must be emphasized that people do not consume nutrients in isolation but rather ingest a variety of nutrients at the same time as they eat their food [119]. The study of different dietary patterns such as the "Mediterranean diet" is an alternative approach to examining the possible relationships between diet and T2DM [120].

Diabetogenic drugs. A large number of drugs may worsen in glycemic control in diabetic patients, or even cause diabetes in predisposed people. These drugs include various classes of agents [121], such as glucocorticoids, antihypertensive drugs (beta blockers, thiazide diuretics) [122], niacin, immunosuppressive drugs, gonadotropin releasing hormone agonists, pentamidine, diazoxide, atypical antipsychotic agents [123], the antineoplastic agent asparaginase, danazole, and anti-retroviral drugs used for the treatment of HIV infection [124].

Obesogenic/diabetogenic environment. The recent increase in T2DM seems to be strongly linked to unfavorable changes in the environment (B) [125]. The abundant availability of energy dense and highly palatable food and changes in transport, work and leisure infrastructure and opportunities decreasing physical activity are the main obesogenic and diabetogenic environmental factors [126]. To change this environment in a beneficial way is a major challenge for T2DM prevention $[127,128]$.

Smoking increases the risk for T2DM by adversely affecting insulin sensitivity and beta-cell function $[129,130]$. The potential of xenobiotics to disturb glucose and lipid metabolism in mammals is well established [131].

A strong correlation between insulin resistance and serum concentrations of persistent organic pollutants (POPs), especially organochlorine compounds has been reported [131-136]. It has also been proposed that modern food processing can generate diabetogenic compounds, such as glycation end products or oxidized ascorbic acid and lipoic acid [125].

Depression. Psychosocial factors may play a causal role in the chain of events leading to development of the MetSy [137]. Depression has been considered as a risk factor for T2DM and its complications $[138,139]$ and an increased risk for developing T2DM in adults with depression has been demonstrated in a meta-analysis of 9 longitudinal studies [140] (B). A recent analysis of the DPP found that baseline antidepressant use was associated with diabetes risk in the placebo and intensive lifestyle arms, but not in the metformin arm [141]. Potential mediators of the effects of depression on diabetes risk have been summarized elsewhere [139].

Low socio-economic status. Several studies have recognized the adverse influence of low socioeconomic status (SES) on general health, prevalence of obesity, smoking, CVD, and early mortality [142-148]. There is also an inverse association between SES and T2DM, with a higher prevalence among less-advantaged groups. This appears to be consistent across several developed countries and across different ethnic groups (B) [149-157]. An inverse graded association between diabetes prevalence, metabolic disorders and different measures of SES such as education, occupation, income, poverty income ratio, and measures of material deprivation and poverty has been found (B) [158-162]. Although T2DM prevalence is increasing in the population at large, the in- 
crease is more pronounced among people with lower SES [163]. In some, but not all studies an independent association between lower SES in childhood and increased risk for T2DM and cardiovascular disease in adulthood has been observed [163-168]. The underlying processes are not yet fully understood, but associations between lower SES and diabetes risk factors like obesity, waist circumference, smoking, inappropriate diet, and leisure time inactivity appear to be important [169-171].

\section{Definition of target populations}

For successful prevention of T2DM both a whole population approach and an individual (targeted high-risk) approach are recommended.

\section{Whole population approach}

The IDF consensus [172] recommends a population as well as an individually targeted approach for diabetes prevention. Simply distributing information about T2DM risk and available strategies for risk reduction, however, is not sufficient to reverse the T2DM epidemic. For successful prevention it is important to create environmental conditions that are conducive to achieving and maintaining a healthy lifestyle. The health sector on its own cannot accomplish such population-wide changes. National diabetes prevention plans are required, which should include the components proposed in the IDF consensus, namely advocacy, community support, fiscal and legislative measures, engagement of the private sector, media communication, and improving level of knowledge and motivation of the population [172].

Unlike interventions that focus on high-risk individuals, the population approach is not supported by a large database of clinical studies. A UK cohort study found that diabetes incidence was inversely related to the achievement of five "healthy behaviour goals for diabetes prevention" (BMI $<25 \mathrm{~kg} / \mathrm{m}^{2}$, fat intake $<30 \%$ of energy intake, saturated fat intake $<10 \%$ of energy intake, fibre intake $\geq 15 \mathrm{~g} / 4,184 \mathrm{~kJ}$, physical activity $>4 \mathrm{~h} /$ week) [173]. The incidence of T2DM was inversely and linearly related to the number of goals achieved. None of the participants who met all five goals developed diabetes, whereas the highest incidence was observed in subjects who did not meet any of the goals. $(2++, \mathbf{B})$.

\section{High-risk approach}

It is current practice in several countries (e.g. UK, USA, Finland and France) to recommend targeted or opportunistic screening to identify high risk individuals. The IDF consensus document [172] recommends the use of opportunistic screening by health care personnel, particularly those working in primary care. Risk for T2DM and CVD may be assessed quantitatively by appropriate methods such as blood testing (fasting plasma glucose, OGTT, lipid profile, and $\mathrm{HbA} 1 \mathrm{c}$ ) and searching for the presence of other risk factors like family history of premature CVD, hypertension, visceral obesity, physical inactivity, unhealthy diet and smoking. Appropriate interventions (e.g. antihypertensive and lipid therapy, aspirin, smoking cessation, dietary changes, exercise, weight loss) targeting all identified risk factors should subsequently be initiated.

The IDF recommends the following criteria for opportunistic screening (or targeted screening) [172]: obesity (including visceral), family history of diabetes, age, history of raised blood pressure and/or heart disease, history of GDM, and drug history. Recently best practice guidelines for vascular risk assessment and management have been issued by the UK National Health Service (www.dh.gov.uk/publications). According to these guidelines tar- geted screening for T2DM risk by measuring either FPG or HbA1c is recommended in asymptomatic subjects aged $40-74$ years with obesity and/or elevated blood pressure $(\geq 140 / 90 \mathrm{mmHg})$. In subjects with FPG (6-7 mmol/l) or HbA1c (6-6.5\%) in the prediabetic range, an OGTT is recommended.

\section{Target populations for interventions}

It is thought that most patients pass through a prediabetic phase before developing T2DM [174]. Subjects with IGT are at highest risk for T2DM, but individuals with isolated IFG and the MetSy $[95,96,175]$ are also at increased risk $[96,176]$. Particularly high conversion rates ( $>10 \%$ per year) have been observed in subjects with a combination of 2 or 3 prediabetic conditions (IGT \pm IFG, \pm MetSy) $[83,96]$. Therefore a hierarchical approach is proposed starting with subjects with IGT \pm IFG, \pm MetSy (A), IFG and/or MetSy (C), (overweight, obesity, hypertension, or physical inactivity) (C) and finally the general population (C) $[177,178]$ ( $\odot$ Table 6). It has to be emphasized that the major prevention trials [120] have all focused on patients with IGT ( \pm IFG). Given the fact that resources are limited, the intensity of the intervention should be adjusted to the level of risk, implying that subjects at highest risk should receive the most intensive intervention (B).

\section{Recommendations}

A hierarchical approach for prevention of T2DM is proposed:

A starting with subjects at highest risk for T2DM (IGT \pm IFG, \pm MetSy) with highest priority,

C followed by subjects at high risk (IFG and/or MetSy) with high priority,

C subjects with overweight, obesity, hypertension, or physical inactivity with medium priority and

C finally the general population with low priority.

B Given the fact that resources are limited, the intensity of the intervention should be adjusted to the level of risk, implying that subjects at highest risk should receive the most intensive intervention.

\section{Screening Tools, Diagnosis and Detection \\ $\nabla$ \\ Categorization of abnormal glucose metabolism}

In practice, the glucometabolic category depends on whether FPG is measured alone or combined with a 2-h PG. For example an individual falling into the IFG category may also have IGT or diabetes, which would only be discovered by a post-load BG measurement. In the text, IFG and/or IGT will be defined as prediabetes. As to HbA1c, a high HbA1c level may only identify a fraction of asymptomatic people with diabetes. HbA1c is insensitive in the low range and a normal HbA1c level cannot exclude the presence of diabetes or prediabetes.

\section{Epidemiological arguments}

Several epidemiological studies have challenged the practice of not using the 2-h PG and have showed that a substantial number of people who do not meet the FPG criteria for glucose disorders will satisfy the criteria when exposed to an OGTT [180-182]. Thus, the OGTT is more sensitive than FPG for detecting diabetes and the only way to detect IGT. The probability of false negative results is substantial, when measuring FPG only. But there are some important arguments against OGTT. OGTT needs to be performed in appropriate conditions and should be standardized (Appendix 1). In particular, OGTT should be carried out after at 
least 3 days of unrestricted (> $150 \mathrm{~g}$ ) carbohydrate intake daily. This test has been considered to be less appropriate at a population level, mainly because it takes more than $2 \mathrm{~h}$ to perform, is costly and has a low reproducibility. However, the true primary prevention of diabetes requires the identification of high-risk subjects and treatment to prevent their transition to overt diabetes. This needs a definite categorization of glycemic states.

\section{Arguments based on the natural history of glucose abnormalities}

The rate of conversion to diabetes is very high in people with IGT or IFG, and even higher in those with IGT + IFG, as discussed earlier. Approximately $30 \%$ of people with IGT will convert to T2DM within 5 years [183] implying that at-risk individuals should be screened for both IFG and IGT.

\section{Arguments based on prevention trials}

To date, prevention trials mainly included patients with IGT, whereas only one trial included also patients with IFG only [61, $65,68,184-187]$. This trial showed that prevention of the transition from IFG to diabetes is possible so that IFG may also be considered a target for intervention [188].

\section{Arguments based on CVD risk}

Patients with IGT are at high risk for developing CVD. The most convincing evidence of increased CVD risk was provided by the DECODE (Diabetes Epidemiology: Collaborative analysis Of Diagnostic criteria in Europe) study, which showed that IGT is more predictive of CVD mortality than FPG levels [5]. Many individuals with prediabetes have a cluster of other cardiovascular risk factors, i.e. abdominal adiposity, elevated triglycerides, low HDLcholesterol, elevated blood pressure, known as components of the MetSy, as well as raised LDL-cholesterol levels [189].

Taking all of the above arguments into account, it is strongly suggested that clinicians categorize the type of glycemic abnormalities as precisely as possible to identify people with IFG and IGT and, in those with IGT, to screen for associated CVD risk factors, in order to achieve the goals of both diabetes and CVD prevention. However this step should be preceded by a screening phase in order to select subjects with a high chance of having prediabetes or developing T2DM.

\section{Detection of people at high risk for diabetes}

Detection programmes may be targeted widely or restricted to higher risk populations. They may use risk scores and/or blood glucose measurement. Scoring systems based on the presence and extent of a number of aetiological factors may be helpful to identify people at high risk for T2DM. They need to be reliable, simple and practical. A number of tools have been developed to screen for undiagnosed diabetes and/or diabetes and for the risk of incident diabetes ( Tables 3, 4).

Several risk scores based on large cohort studies are available [85, 190-196]. However, few of these rely on factors that are measurable with non-invasive methods and are not therefore applicable outside of clinical practice. Most were developed to rate the risk for developing T2DM ( $\odot$ Table 4 ) and some seem to be valuable for detecting current undiagnosed diabetes ( $\triangle$ Table 3 ), and for identification of patients with MetSy, insulin resistance and at risk for CVD. Therefore such questionnaires are able to select populations in whom blood glucose could be measured and/ or lifestyle advice provided in order to prevent diabetes. Some scores directly require a diagnostic test, such as random capillary glucose measurement (interpreted according to time since last meal) [197].

\section{European population}

The Finnish risk test (FINDRISC) takes only a couple of minutes, can be taken online (www.diabetes.fi or http://care.diabetesjournals.org for an English version) and provides a measure of the probability of developing T2DM over the following 10 years. The FINDRISC test is based on a representative random sample of the Finnish population, aged 35-64 years and their 10-year incidence of drug-treated T2DM. It includes 8 items: age, BMI, waist circumference, antihypertensive medication, history of elevated blood glucose (including GDM), meeting the criterion for daily physical activity and daily intake of fruit or vegetables. The last 2 variables were introduced to increase awareness about the importance of lifestyle modifications, although they were not associated with increased diabetes risk. The performance of this scoring test as a screening tool was assessed in a cross-sectional, population-based survey of subjects aged 45-74 years. The risk score was associated with the presence of previously undiagnosed T2D, IGT, MetSy and CVD risk factors. Using a cut-off score of 11 (maximum: 20), the sensitivity to identify undiagnosed diabetes was $66 \%$ in men and $70 \%$ in women, with false-negative rates of $31 \%$ and 39\% [198]. The performance was also satisfactory in an Italian cohort [122].

A simplified version of the FINDRISC consisting of 6 questions was validated in a German population aged $41-79$ years with a family history of T2D, obesity, or dyslipoproteinemia and found to be a simple tool with high performance to predict diabetes risk but less efficient to identify asymptomatic T2DM [199]. In the IGLOO (Impaired Glucose tolerance and Long-term Outcomes Observational) study in an Italian cohort aged 55-75 years with one or more CVD risk factors, the FINDRISC score had a sensitivity of $77 \%$ and a specificity of $45 \%$ to detect people with T2DM [122].

A Danish diabetes risk score including six questions (age, sex, BMI, family history of diabetes, known hypertension, physical activity at leisure time) has been developed in a population-based sample of individuals aged 30-60 years who underwent an OGTT. This simple score which can be completed at home identified $76 \%$ of individuals with previously undiagnosed T2DM, with a specificity of $72 \%$, reducing the proportion of individuals in the population that need subsequent testing to $29 \%$ [200].

The Cambridge risk score comprises data routinely available in UK general practice (age, sex, BMI, family history of diabetes, smoking habits, and prescribed anti-hypertensive drugs or steroids) [201] and allows to identify individuals with undiagnosed diabetes in different ethnic groups [202-204]. It has also been validated in a Danish population where a risk score above the threshold of 0.246 provided a sensitivity of $71 \%$, a specificity of $81 \%$, and a positive predictive value of $8 \%$ to detect diabetes [205]. The QDS score has been developed from data of 2540753 patients aged 25-79 years collected by 355 GPs in UK and Wales, of whom 78081 had an incident diagnosis of type 2 diabetes. This score includes ethnicity, age, sex, BMI, smoking status, family history of diabetes, Townsend deprivation score, treated hypertension, cardiovascular disease, and current use of corticosteroids. It can be applied systematically to computerised patient databases [196].

A questionnaire including readily available information (age, sex, presence of obesity, use of anti-hypertensive medication) has been developed from a sample of participants aged 55-75 years who were recruited in the Rotterdam Study, to screen for preva- 


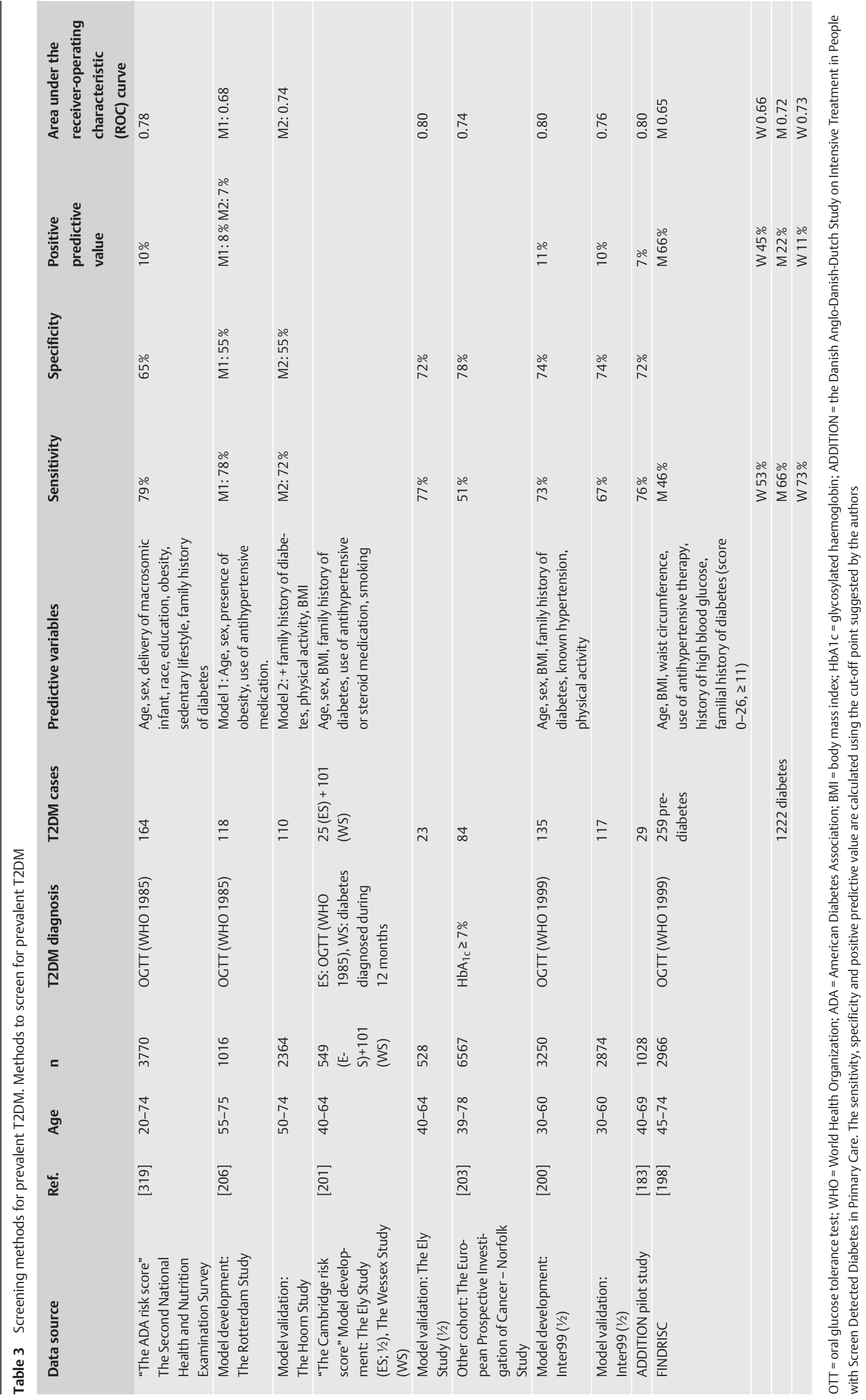



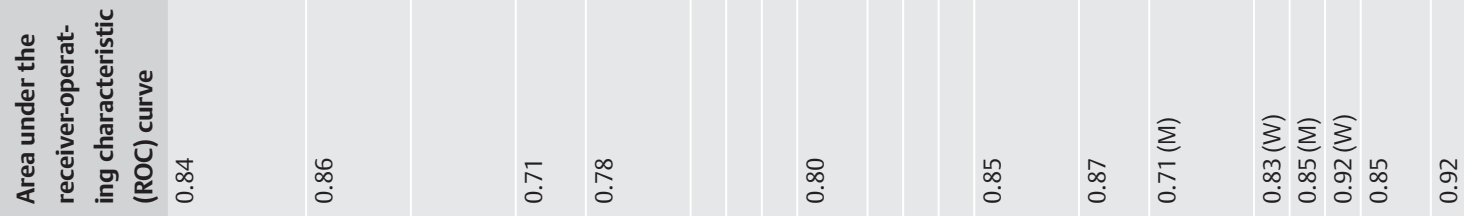

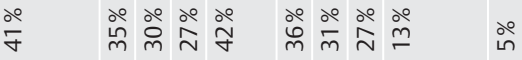

जั:

ळ’

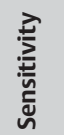

ڤ̊
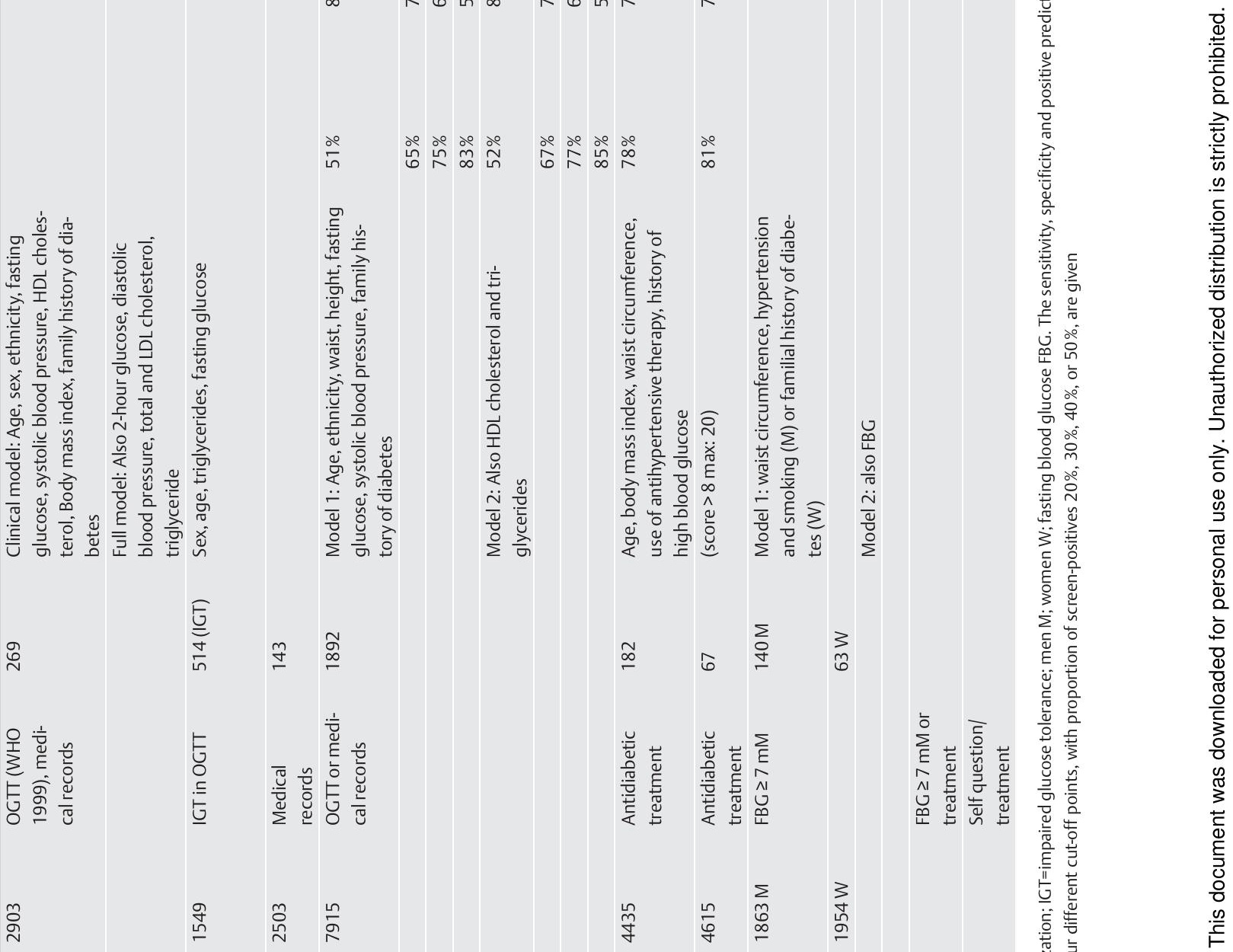

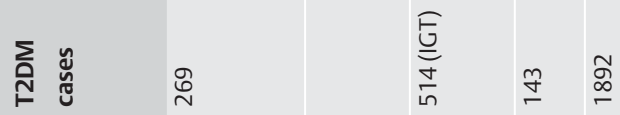

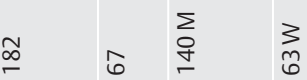

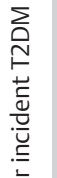

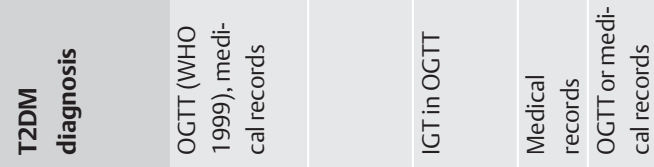

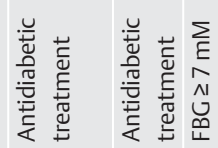

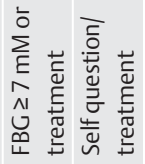

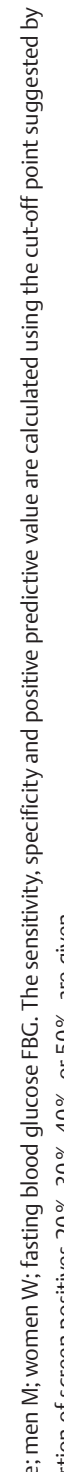

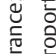

严焉

ํㅡㅁ

旁告

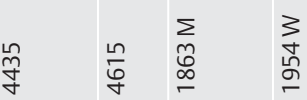

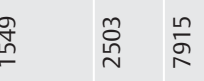

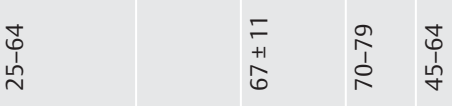

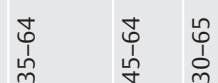

范

产 盛

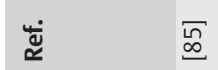

$\stackrel{\bar{N}}{\stackrel{一}{\Xi}}$

స్

$\stackrel{\check{g}}{\Xi}$

$\stackrel{\infty}{\stackrel{\infty}{ }}$

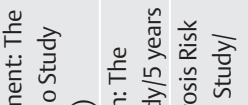

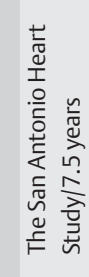

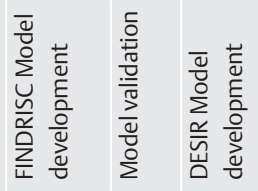

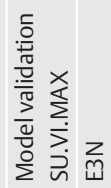

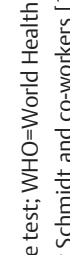

氜 方

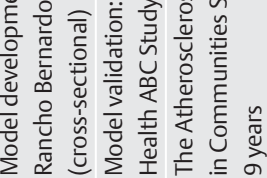

竞 蓄

嵌 产 
lent T2DM. This simple questionnaire has been tested in the Dutch Hoorn Study and provides good performance at the cutoff point of $>6$ with a sensitivity $78 \%$, specificity $55 \%$, negative predictive value $98 \%$, positive predictive value $8 \%$ [206].

The German Diabetes Risk Score which includes information on age, waist circumference, height, history of hypertension, physical activity, smoking, and consumption of red meat, whole-grain bread, coffee, and alcohol is also publicly available (http://www. dife.de). This score has been developed in the prospective Potsdam cohort of the EPIC (European Prospective Investigation into Cancer and Nutrition) study of individuals aged 35-65 years. It was further shown to be an accurate tool to identify individuals at high risk for undiagnosed T2DM and to correlate well with measures of insulin resistance and impaired insulin secretion in three other German cohorts [207].

The Data from Epidemiological Study on the Insulin Resistance syndrome (DESIR) study produced a risk score from a French cohort followed up over 9 years, and validated in two other French cohorts [208]. It includes waist circumference and hypertension in both sexes, and smoking in men and family history of diabetes in women. A risk score of 5 confers a $>30 \%$ chance of diabetes in the following 9 years.

In conclusion, the FINDRISC score meets the requirements of being a simple, non-invasive and inexpensive tool. It has been used in several European cohorts, and shown to be a reliable tool both for detecting undiagnosed diabetes and for predicting future diabetes risk. The DESIR score also meets the same criteria but has not been tested for detecting undiagnosed diabetes. It is simpler than the FINDRISC score, but that latter provides more opportunities for lifestyle discussion and has been validated in several European populations.

\section{US population}

The ADA risk test is a simple, user-friendly risk test based on age, weight, family history of diabetes, and for women, having a baby weighing more than 9 pounds at birth (www.diabetes.org).

The score, derived from the San Antonio Heart Study, includes age, sex, ethnicity, BMI, family history of diabetes and systolic blood pressure, and two biological parameters (FPG and HDLcholesterol) but does not perform better than FPG alone [85].

The ARIC risk score demonstrated low validity in the testing sample [100]. Furthermore its applicability to European Caucasian populations may be limited because it was derived from a US population.

The Diabetes Risk Calculator has been developed as a screening tool for undiagnosed diabetes and prediabetes, based on the Third National Health and Nutrition Examination Survey (NHANES III) dataset (7092 participants $\geq 20$ years with FPG being measured in all at fasting, and an OGTT being performed in approximately half of those aged 40-75 years). This tool includes simple questions and performed well [209].

\section{Asian population}

An Indian Diabetes Risk Score has been developed from the Chennai Urban Rural Epidemiological Study (CURES) in India for screening for undiagnosed diabetes. This simple test uses four risk factors (age, waist circumference, family history of diabetes and physical activity), and has a sensitivity of $72 \%$ and a specificity of $60 \%$ with a positive predictive value of $17 \%$ and a negative predictive value of $95 \%$ [210].
A simple risk equation (including age, BMI, and hypertension) has been described in a high-risk Thai population and allowed to detect $87 \%$ of undiagnosed diabetes [211].

\section{Applicability of screening tools}

Screening tests using questionnaires also need to be performed in appropriate conditions. The FINDRISC score may be used as a self-administered test (as it was in the first validation study). However it is recommended that the answers should be checked by a nurse or a physician.

More importantly, four published screening tests (Rotterdam Diabetes Study, Cambridge Risk score, San Antonio Heart Study and FINDRISC score) have been applied to detect undiagnosed diabetes in a German population (KORA Survey 2000). These tests yielded low validity when applied to that new population, most likely due to differences in population characteristics [212]. Low performances were also demonstrated in German subjects with a family history of T2DM [199] and in the population of Oman [213]. This suggests that performance of diabetes risk questionnaires or scores must be assessed in the target population where they will be ultimately applied. However, all these screening tools had a high negative predictive value (94-98\%), and thus may be helpful when the findings are negative rather than positive.

The DETECT-2 project, an international data pooling collaboration, on screening for T2D specifically addressed ethnicity and population differences [214]. Nine datasets were selected, which were representative of people from a diverse range of ethnic backgrounds. The use of the Rotterdam Predictive Model [206], yielded a wide variation of the performance with sensitivity, specificity, and percentage needing further testing ranging between 12 and 57\%, 72 and 93\%, and 2 and 25\%, with a worse performance in non-Caucasian populations. Thus, a risk score developed in Caucasian populations cannot be applied to other populations of more diverse ethnic origins.

After scoring for diabetes risk, it is mandatory to inform patients about their elevated risk and to take time to deliver explanations, in particular to low educated individuals, as recently stressed in a study carried out in the US that included a large number of minority populations [215]. This needs to be done appropriately in order to raise the awareness and understanding of T2DM and its risk factors, while avoiding or minimizing negative effects, such as emotional distress and denial [216].

\section{Strategies for detection of people at high risk for diabetes \\ Community based strategies}

Various approaches exist: (i) measuring PG in specified population groups (e.g. age over 40 ) to determine prevalent prediabetes (a strategy that will detect undiagnosed diabetes as well); (ii) using computer database searches/risk-scoring algorithms or collecting questionnaires to provide an estimate of the risk for incident diabetes (a strategy that leaves the current glycemic state undetermined); (iii) using risk scores or questionnaires as primary screening tools to identify sub-groups of the population in whom glycemic testing may be targeted efficiently.

Alternative (iii) has been tested in the IGLOO study [122]. In that study, the use of the FINDRISC score as initial instrument, followed by the measurement of FPG in individuals with a score $\geq 9$ and by the OGTT in individuals with FPG between 5.6 and $6.9 \mathrm{mmol} / \mathrm{l}$, would have led to the identification of $83 \%$ of T2DM cases and $57 \%$ of IGT cases, at a cost of an OGTT in $38 \%$ of the sam- 


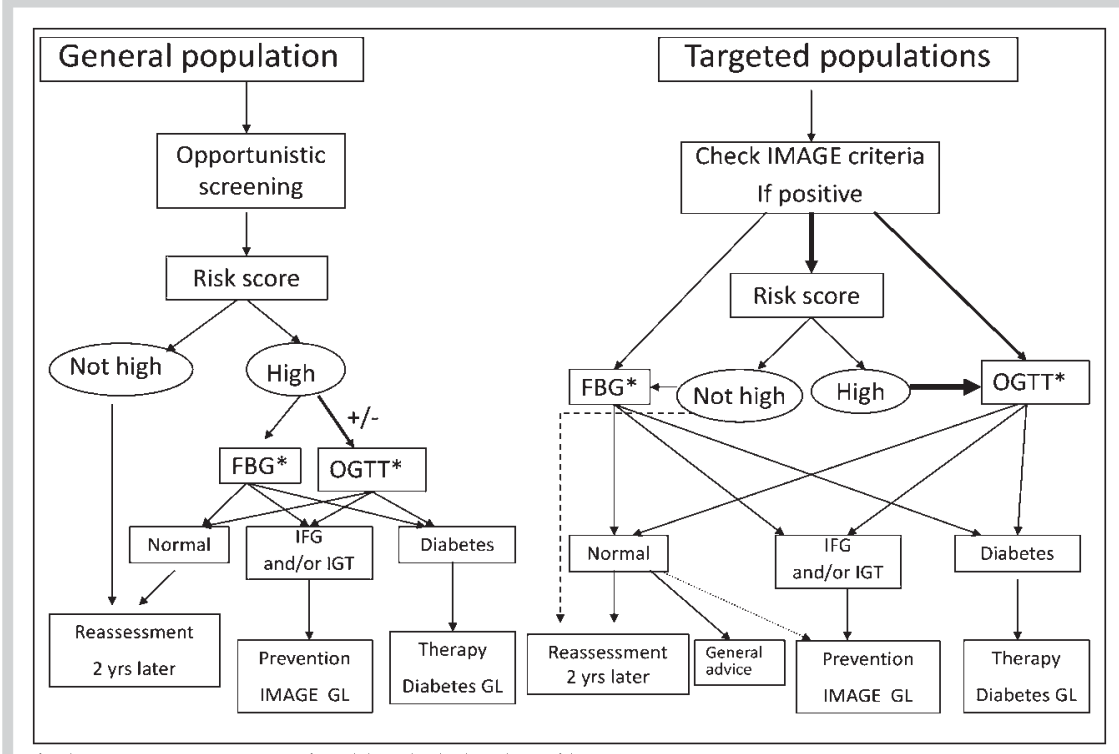

Fig. 1 Community based strategies for detection of people at high risk for type 2 diabetes.

* Blood measurements should include lipid profiling

ple and a FPG in 64\% [122]. Therefore, a multiple step approach may be proposed, consisting of using first a risk score, then measuring fasting BG, and if FPG is increased, lastly performing an OGTT. An alternative may be performing an OGTT in all individuals with a high test score.

A similar approach was tested in the Anglo-Danish-Dutch study of intensive treatment in people with screen-detected diabetes in primary care (ADDITION [183]). Stepwise screening strategies were performed using risk questionnaires and routine clinical practice data plus random blood glucose, HbA1c and fasting blood glucose measurement. Diabetes was diagnosed using the 1999 WHO criteria and estimated 10-year coronary heart disease risk was calculated using the UK Prospective Diabetes Study risk engine. Out of 76308 people aged 40-69 years, a total of 3057 individuals with screen-detected diabetes were identified.

A community-based strategy ( Fig. 1) should consist of a screening test as a first step in order to estimate the risk for current diabetes or prediabetes and the risk for future diabetes (A). In agreement with the IDF, we recommend the use of opportunistic screening by health-care personnel including those working in general practice, nurses and pharmacists [172] (A). Self-adminis- tered questionnaires may also be used to identify people at risk (e.g. by anyone on the Internet, or in pharmacies, or as part of national health surveys) and used to prompt further diagnostic testing by a health care provider. If a person is considered to be at increased risk for diabetes, they will proceed to PG measurements (either fasting or preferably using an OGTT). At the very least, measurement of random capillary blood glucose can be used with an improved performance if measurement is done in the postprandial period [217]. A high HbA1c level may also identify a subset of asymptomatic people with diabetes. Indeed, the sensitivity of HbA1c measurement for the screening of undiagnosed diabetes was found to be fairly good as compared to FPG [218]. HbA1c was less sensitive for detecting prediabetes or diabetes when compared to OGTT results [219]. The available resources may define the testing regime used in each country/locality.

\section{Clinical practice-based strategies}

A diagnostic test may be used in routine clinical practice but as it is time-consuming, one may propose to select the patients with at least one obvious risk factor for diabetes, such as age $>40$ years, overweight or obesity, components of the MetSy, family history

\section{Criteria for screening for diabetes and prediabetes within targeted populations}

a) White people aged over 40 years or people from Black, Asian and minority ethnic groups aged over 25 years with 1 or more of the following risk factors:

- a first degree family history of diabetes and/or

- BMl over $25 \mathrm{~kg} / \mathrm{m}^{2}$ and/or

- waist measurement of over $\geq 94 \mathrm{~cm}$ for White and Black men and $\geq 80 \mathrm{~cm}$ for White, Black and Asian women, and $\geq 90 \mathrm{~cm}$ for Asian men and/or

- systolic blood pressure $\geq 140 \mathrm{mmHg}$ or diastolic blood pressure $\geq 90 \mathrm{mmHg}$ or treated hypertension and/or

- HDL-cholesterol $\leq 0.35 \mathrm{~g} / \mathrm{l}(0.9 \mathrm{mM})$ or triglycerides $\geq 2 \mathrm{~g} / \mathrm{l}(2.2 \mathrm{mM})$ or treated dyslipidemia

b) Women with a history of gestational diabetes or with a child weighing $>4 \mathrm{~kg}$ at birth,

c) People with history of temporarily induced diabetes, e.g. steroids,

d) People who have ischaemic heart disease, cerebrovascular disease, peripheral vascular disease,

e) Women with polycystic ovary syndrome who have a BMI $\geq 30 \mathrm{~kg} / \mathrm{m}^{2}$,

f) People who have severe mental health problems and/or receiving long term anti-psychotic drugs,

g) People with a history of IGT or IFG.
Table 5 IMAGE criteria for screening for diabetes and prediabetes within target populations 
of GDM, polycystic ovary syndrome or ethnicity (migrants). Such factors are identified in the sections above, and have been considered in other recent guidelines, including IDF [172], Diabetes UK [220], France [221], American Diabetes Association [222], that all recommend targeted or opportunistic screening of high risk individuals. Some of these recommendations have already been validated [223]. O Table 5 summarizes the populations we recommend for targeted screening (Evidence I, B). Systematically targeted screening programmes may be possible here. For example, GPs or health insurance companies with computerised databases can pro-actively identify all people with various combinations of risk factors and post the questionnaires to these targeted groups. A screening strategy may consist of PG measurement at fasting or even better of OGTT due to its higher sensitivity. One alternative may be a stepped approach including an initial screening questionnaire in the process ( Fig. 1). Two risk factors, obesity and $\mathrm{CVD}$, provide some examples for the operation of a targeted screening process.

Cosson et al. [224] performed OGTT in 933 overweight or obese patients with mean age of 39 years and free of known glycemic abnormalities. Their FINDRISC score was retrospectively calculated using the clinical files. Prediabetes or diabetes was diagnosed in $26 \%$ of the subjects of whom $75 \%$ would not have been diagnosed with FPG alone. Selecting the subjects with a FINDRISC $\geq 11$ to be screened directly with an OGTT had a sensitivity of $78 \%$, a specificity of $44 \%$ and limited the number of OGTTs to 575 (60\% of the study sample) [224] (B).

In patients with established CVD but without known diabetes: the percentage of those who have IFG or unknown diabetes according to FPG is higher than $17 \%$, but the percentage of those with prediabetes or diabetes according to OGTT is far higher (>50\%). In other words among patients with CVD and glucose abnormalities, in most cases it is the 2-hour PG which is elevated, whereas FPG is often normal [225]. Therefore, in patients with CVD a scoring diabetes risk test can be applied but an OGTT should be carried out in all patients [226] (B).

In practice, the screening strategy depends on local possibilities. However, due to the very high number of obese subjects, OGTT is perhaps best reserved for those with higher scores, whereas the very high prevalence of diabetes or prediabetes in CVD patients suggests that performing OGTT routinely in these patients is the best strategy ( Table 6 ).

\section{Recommendations}

A As OGTT has a higher sensitivity than FPG for detecting diabetes and is the only test to detect IGT, a definite categorization of glycemic state needs an OGTT.

A Several risk scores are available and valuable for detecting current undiagnosed diabetes and/or to rate the risk for developing T2DM. The FINDRISC meets the requirements of being a simple, non-invasive and inexpensive tool and has been shown to be a reliable tool both for detecting undiagnosed diabetes and for predicting future diabetes risk in several European cohorts.

B Performance of diabetes risk scores must be assessed in the target population where they will be ultimately applied.

A After scoring for diabetes risk, it is mandatory to inform participants about their risk and to take time to deliver explanations, in particular to low educated individuals. This needs to be done appropriately in order to raise the awareness and understanding of T2DM and its risk factors, while avoiding or minimizing negative effects, such as emotional distress and denial [216].
Table 6 Suggested priorities for diabetes prevention

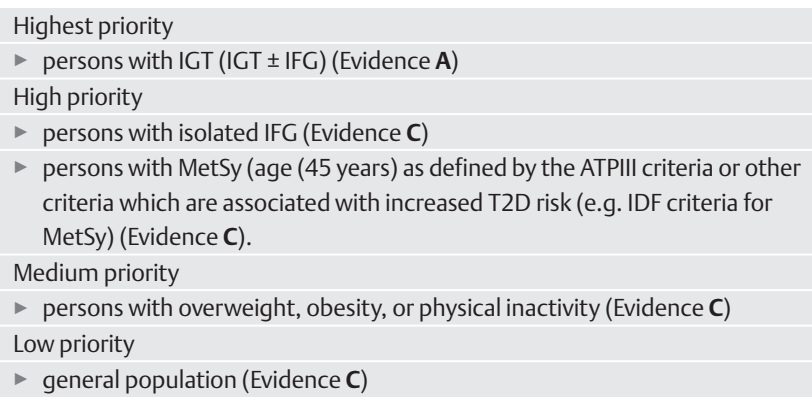

A A community-based strategy should consist of using a screening test as a first step in order to estimate the risk for current diabetes or prediabetes and the risk for future diabetes. It is recommended the use of opportunistic screening by health-care personnel including those working in general practice, nurses and pharmacists. If after this first step a person is considered to be at increased risk for diabetes, they will proceed to PG measurements (either fasting or preferably using an OGTT) in order to determine more precisely their glycemic status.

B In routine clinical practice, a screening strategy should be targeted to patients with at least one obvious risk factor for diabetes. It may consist of PG measurement at fasting or even better of OGTT due to its higher sensitivity. One alternative may be a stepped approach including an initial screening questionnaire (score of risk for diabetes) in the process. As examples, due to the very high number of obese subjects, OGTT is best reserved for those with higher scores, whereas the very high prevalence of diabetes or prediabetes in CVD patients suggests that performing OGTT routinely in these patients is the best strategy.

\section{Prevention of T2DM and its Comorbidities}

$\nabla$

\section{Methodology}

This section was compiled following a systematic search for primary studies, systematic reviews and meta-analyses $[69,178]$ of research on preventing the onset of T2DM. The initial search was undertaken using MEDLINE with follow-up of cited references. The final selection was limited to randomized controlled trials (RCTs) published in English between1979 and 2008, which featured development of T2DM as a study endpoint and used standard criteria for the diagnosis of diabetes mellitus. Key data from the major studies are summarized in ( $\odot$ Tables $7,8,9$ ).

\section{Findings for prevention by lifestyle modification \\ Major T2DM prevention studies}

Da-Qing Study (CDQDPS) [184,227]. Cluster randomisation was used to allocate 577 people with IGT attending 33 participating clinics to diet alone, exercise alone, diet-and-exercise combined or no intervention. The participants in the dietary intervention were encouraged to reduce weight aiming at $<24 \mathrm{~kg} / \mathrm{m}^{2}$, otherwise high-carbohydrate (55-65 E\%) and moderate-fat (25-30 E $\%$ ) diet was recommended. Participants were encouraged to consume more vegetables, reduce simple sugar intake and control alcohol intake. The participants in the exercise intervention were encouraged to increase their level of leisure-time physical activity by at least 1-2 "units" per day, one unit corresponding for in- 
Table 7 Characteristics of lifestyle intervention studies to prevent type 2 diabetes

\begin{tabular}{|c|c|c|c|c|c|}
\hline Ref. & Acronym & Design & Intervention (int, $\mathrm{D}=$ diet, $\mathrm{PA}=$ physical activity) & Follow-up (years) & DROP out \\
\hline \multirow[t]{3}{*}[184,227]{} & CDQDPS & $\begin{array}{l}\text { Cluster } \\
\text { randomized }\end{array}$ & $\begin{array}{l}\text { D: increase vegetables, decrease alcohol and sugar, } \\
\text { caloric and weight reduction if overweight }\end{array}$ & $6[104]$ (int) & $44 / 577(8 \%)$ at 6 years \\
\hline & & & $\begin{array}{l}\text { PA: } 1-2 \text { units/day; } 1 \text { unit = } 30 \text { min slow walking/house } \\
\text { cleaning, } 20 \text { min fast walking/cycling, or } 5 \text { min jumping } \\
\text { rope/swimming), }\end{array}$ & & \\
\hline & & & $\begin{array}{l}\mathrm{D}+\mathrm{PA} \text { : individual counselling + compliance evaluation } \\
\text { by physician/nurse every } 3 \mathrm{~m}+\text { small groups weekly for } \\
1 \mathrm{~m} \text {, monthly for } 3 \mathrm{~m} \text { and every } 3 \mathrm{~m} \text { thereafter }\end{array}$ & $\begin{array}{l}20[105] \\
\text { (int + follow-up) }\end{array}$ & $\begin{array}{l}14 / 577(2 \%) \text { at } 20 \\
\text { years }\end{array}$ \\
\hline \multirow[t]{2}{*}{$\begin{array}{l}{[231,232} \\
320,321]\end{array}$} & DPS & RCT & $\begin{array}{l}\mathrm{D}+\mathrm{PA} \text { : weight reduction } 5 \% \text { or more; } \mathrm{D}:<30 \mathrm{E} \% \mathrm{fat} \text {, } \\
<10 \mathrm{E} \% \text { sat fat, } 15 \mathrm{~g} \text { fibres } / 1000 \mathrm{kcal} ; \mathrm{PA}: \geq 30 \mathrm{~min} / \text { day }\end{array}$ & 3.2 [193] (int) & $\begin{array}{l}42 / 522(8 \%) \text { at } 3.2 \\
\text { years }\end{array}$ \\
\hline & & & $\begin{array}{l}\text { Individual, personalized dietary counselling; } 7 \text { sessions } \\
\text { during the first year and every } 3 \mathrm{~m} \text { thereafter voluntary } \\
\text { gym } 1-2 \text { sessions/w }\end{array}$ & $\begin{array}{l}7[195] \\
\text { (int + follow-up) }\end{array}$ & $47 / 522(9 \%)$ at 7 years \\
\hline \multirow[t]{5}{*}[234,322]{} & DPP & RCT & $\mathrm{D}+\mathrm{PA}$ : weight reduction $7 \%$ & 2.8 & $7.5 \%$ \\
\hline & & & D: $25 \mathrm{E} \%$ fat & & \\
\hline & & & PA (e.g. brisk walking) 150 min/week (700 kcal/w) & & \\
\hline & & & $\begin{array}{l}\text { Goal-based behavioural intervention; case-managers } \\
\text { (1/20-26 participants) }\end{array}$ & & \\
\hline & & & $\begin{array}{l}\text { 16-session core curriculum in groups during the first } \\
24 \text { w; individual session every } 2 \mathrm{~m} \text { thereafter + "toolbox } \\
\text { funds" ( } \$ 100 / \text { participant/year) for expenses (cook- } \\
\text { books, personal trainer, aerobic tapes, reinforcers for } \\
\text { fulfilling behavioural contracts etc.) }\end{array}$ & & \\
\hline \multirow[t]{4}{*}[186,235]{} & IDPP & RCT & $D+P A$ & 2.5 & $1.5 \%$ (con) \\
\hline & & & $\begin{array}{l}\text { D: decrease energy, refined carbohydrates and fats, } \\
\text { avoidance of sugar and inclusion of fibre-rich foods }\end{array}$ & & $9 \%$ (int) \\
\hline & & & $\begin{array}{l}\text { Face-to-face counselling at baseline and every } 6 \mathrm{~m} \text {; tele- } \\
\text { phone contacts at two weeks and monthly thereafter }\end{array}$ & & \\
\hline & & & $\begin{array}{l}\text { PA: Brisk walking } 30 \mathrm{~min} / \text { day or more (or comparable } \\
\text { physical labour or other activity) }\end{array}$ & & \\
\hline \multirow[t]{5}{*}{ [187] } & $\begin{array}{l}\text { Japanese trial in } \\
\text { IGT males }\end{array}$ & $\mathrm{RCT}(1: 4)$ & Intensive vs. standard intervention: & 4 & $\begin{array}{l}5.6 \%(\text { con), } 4.7 \% \text { (int) } \\
\text { at year } 1\end{array}$ \\
\hline & & & BMl goal $<22 \mathrm{~kg} / \mathrm{m}^{2}$ & & \\
\hline & & & $\begin{array}{l}\text { D: reduce amount by } 10 \% \text { (smaller rice bowl etc.), } \\
\text { increase vegetables; total fat }<50 \mathrm{~g} / \text { day, alcohol }<50 \mathrm{~g} / \\
\text { day; eating out } \leq 1 / \text { day }\end{array}$ & & \\
\hline & & & PA: walking $30-40 \mathrm{~min} /$ day & & \\
\hline & & & Face-to-face counselling in hospital every $2-3 \mathrm{~m}$ & & \\
\hline
\end{tabular}

stance for 30 minutes of slow walking, 20 minutes of cycling, 10 minutes of slow running, or 5 minutes of swimming. The cumulative 6-year incidence of T2DM was lower in all intervention groups (41-46\%) compared with the control group (68\%). A 20year follow-up [184] found that the incidence of T2DM was persistently lower in the combined intervention group compared with the control group. There were no statistically significant differences in CVD events, CVD mortality, or total mortality between the control group and the combined intervention groups, on the other hand, the study was under-powered to detect such effects. Although the non-significant $17 \%$ reduction in death from CVD is suggestive of an effect, lifestyle intervention has not yet been proven to prevent CVD morbidity and mortality in persons at high risk for T2DM and further, well-powered studies are needed to confirm this. Nevertheless, there is preliminary evidence from CDQDPS [228] and other studies $[229,230]$.

Finnish Diabetes Prevention Study (DPS) [185, 231,232]. A total of 522 middle-aged, overweight individuals with IGT were allocated either to a the intensive lifestyle intervention or to the control group. The intervention included individualized advice and behavioural support to achieve the intervention goals: body weight reduction of $\geq 5 \%$, total fat intake $<30 \%$ of energy, saturated fat intake $<10 \%$ of energy, fibre intake of $\geq 15 \mathrm{~g} / 1000 \mathrm{kcal}$, and moderate exercise for $\geq 30 \mathrm{~min} /$ day. Consumption of wholemeal products, vegetables, berries and fruit, low-fat milk and meat products, soft margarines, and vegetable oils rich in monounsaturated fatty acids were recommended. The participants were also individually guided to increase their level of physical activity and individually tailored circuit-type resistance training sessions were also offered to improve the functional capacity and strength of the large muscle groups. The control group received only general advice about healthy lifestyle at baseline. Body weight reductions from baseline to years 1 and 3 were $4.5 \mathrm{~kg}$ and $3.5 \mathrm{~kg}$ respectively in the intervention group and $1.0 \mathrm{~kg}$ and $0.9 \mathrm{~kg}$ in the control group. The cumulative incidence of T2DM was $11 \%$ [CI 6, 15\%] in the intervention group and $23 \%[95 \%$ CI 17, 29\%] in the control group after 4 years, with $58 \%$ relative risk reduction. None of those achieving all five lifestyle goals developed T2DM. Post hoc analyses showed that adopting a diet with moderate fat and high fibre content [233], as well as increasing physical activity [97] were independently associated with a reduced risk of T2DM. After a median of seven years follow-up, the marked reduction in the cumulative incidence of T2DM was sustained. 
Table 8 Population characteristics (means) of lifestyle intervention studies to prevent type 2 diabetes

\begin{tabular}{|c|c|c|c|c|c|c|c|c|}
\hline Ref. & Acronym & $\begin{array}{l}\text { Age } \\
\text { (years) }\end{array}$ & $\begin{array}{l}\text { BMI } \\
\left(\mathrm{kg} / \mathrm{m}^{2}\right)\end{array}$ & $\begin{array}{l}\text { Waist }(\mathrm{cm}) \\
\text { (male/female) }\end{array}$ & $\begin{array}{l}\text { Blood pressure } \\
\text { (mmHg) }\end{array}$ & $\begin{array}{l}\text { Lipids TC } \\
\text { (mmol/l) }\end{array}$ & $\begin{array}{l}\text { MetSy } \\
\text { (\%) }\end{array}$ & $\begin{array}{l}\text { FPG } \\
(\mathrm{mmol} / \mathrm{l})\end{array}$ \\
\hline \multirow[t]{2}{*}[184,227]{} & CDQDPS & 45 & 26 & - & 134/89 (con) & 5.3 & - & 5.5 \\
\hline & & & & & $132 / 87$ (int) & 5.2 & & 5.6 \\
\hline $\begin{array}{l}{[231,232} \\
320,321]\end{array}$ & DPS & 55 & 31 & 101 & $138 / 86$ & 5.6 & $74 \%$ & 6.1 \\
\hline$[234,322]$ & DPP & 50 & 34 & 105 & - & - & $53 \%$ & 5.9 \\
\hline \multirow[t]{2}{*}[186,235]{} & IDPP & 45 (con) & 26 & $91 / 86$ & $124 / 76$ & 5.1 & $46 \%$ & \\
\hline & & 46 (int) & 26 & $89 / 88$ & $122 / 74$ & 5.2 & & \\
\hline \multirow[t]{2}{*}{ [187] } & $\begin{array}{l}\text { Japanese trial in } \\
\text { IGT males }\end{array}$ & $30-60$ & 24 & - & 124/79 (con) & TC & - & 6.2 \\
\hline & & & & & $123 / 78$ (int) & 5.5 & & 6.3 \\
\hline
\end{tabular}

Table 9 Main results and outcome of lifestyle intervention studies to prevent type 2 diabetes

\begin{tabular}{|c|c|c|c|c|}
\hline Ref. & Intervention & $\begin{array}{l}\text { Number of T2DM cases } \\
\text { (per } 100 \text { person years) }\end{array}$ & Risk reduction & $\begin{array}{l}\text { Numbers- } \\
\text { needed-to-treat }\end{array}$ \\
\hline \multirow[t]{8}{*}{ [184-227] } & CDQDPS & At 6 years: & At 6 years: & $4.2(\mathrm{D})$ \\
\hline & & $90 / 133($ con $)=15.7$ & DRR (adjusted): & $3.8(\mathrm{PA})$ \\
\hline & & $57 / 130(D)=10.0$ & $0.69(D), p<0.3$ & $4.6(D+P A)$ \\
\hline & & $58 / 141(P A)=8.3$ & $0.54(\mathrm{PA}), \mathrm{p}<0.0005$ & for 6 years \\
\hline & & $58 / 126(D+P A)=9.6$ & 0.58 (diet + PA), $p<0.005$; no diff. between ints & \\
\hline & & At 20 years: & At 20 years: & \\
\hline & & 11.3 (con) & Adjusted HRR: & \\
\hline & & 6.9 (combined int) & 0.57 (combined int) & \\
\hline \multirow[t]{6}{*}[231,232,320,321]{} & DPS & At 3.2 years: & At 3.2 years: & 22 for 1 year \\
\hline & & $59 / 257($ con $)=7.8$ & HRR $0.42, p<0.001$ & \\
\hline & & $27 / 265$ (int) $=3.2$ & & \\
\hline & & At 7 years: & At 7 years: & \\
\hline & & $110 / 257$ (cont) $=7.4$ & HRR $0.57, p<0.001$ & \\
\hline & & $75 / 257$ (int) $=4.3$ & & \\
\hline \multirow[t]{2}{*}[234,322]{} & DPP & 11.0 (con) & HRR 0.42 & 6.9 for 3 years \\
\hline & & 4.8 (int) & & \\
\hline$[186,235]$ & IDPP & $\begin{array}{l}\text { 3-years cumulative incidence: } \\
55.0 \% \text { (con), } 39.3 \% \text { (int) }\end{array}$ & RRR $28.5 \%, p=0.018$ & 6.4 for 3 years \\
\hline [187] & $\begin{array}{l}\text { Japanese trial in } \\
\text { IGT males }\end{array}$ & $\begin{array}{l}\text { 4-years cumulative incidence: } \\
9.3 \% \text { (con), } 3.0 \% \text { (int) }\end{array}$ & RRR $67.4 \%, p<0.001$ & \\
\hline
\end{tabular}

United States Diabetes Prevention Program (DPP) [229,234]. The DPP compared the efficacy of intensive lifestyle intervention and standard lifestyle recommendations; the study also had a metformin arm. A total of 3234 high-risk individuals with IGT and slightly elevated FPG were recruited. Lifestyle intervention in DPP was primarily undertaken by "case managers". The goals were to achieve and maintain $7 \%$ weight reduction by consuming healthy, low-calorie, low-fat diet and to engage in physical activities of moderate intensity (such as brisk walking) 150 minutes per week or more. Compared with placebo, lifestyle intervention reduced T2DM risk by $58 \%$ at 2.8 years mean follow-up. Among the lifestyle intervention group, $74 \%$ achieved the physical activity goal of $>150$ minutes/week at 24 weeks. At one-year the mean weight loss was $7 \mathrm{~kg}$ (about 7\%). Body weight at baseline and weight reduction during intervention were most important predictors of T2DM risk [60]. For each kilogram lost, the risk of T2DM was reduced by $16 \%$.

Indian DPP (IDPP) [186,235]. A total of 531 subjects with IGT were randomized into four groups (control, lifestyle modification, metformin, and combined lifestyle modification and metformin). Lifestyle modification included advice on physical activity
(30 minutes of brisk walking per day) and reduction in total calories, refined carbohydrates and fats, avoidance of sugar, and inclusion of fibre-rich foods. After a median follow-up of 30 months, the relative risk reduction was $29 \%$ with lifestyle modification, $26 \%$ with metformin and $28 \%$ with lifestyle modification and metformin, as compared with control.

Japanese Prevention Trial [187]. This trial randomized 458 men with IGT to receive either an intensive lifestyle intervention or standard management. Participants in the intensive intervention group visited hospital every $2-3$ months to receive detailed advise to reduce body weight if BMI was $\geq 22 \mathrm{~kg} / \mathrm{m}^{2}$ (by consuming large amount of vegetables and reducing the total amount of other food by $10 \%$. Intake of fat ( $<50 \mathrm{~g}$ per day) and alcohol $(<50 \mathrm{~g}$ per day) were limited and physical activity recommended (3040 min per day of walking). The intervention group achieved a $67.4 \%$ reduction in risk compared with controls. Body weight decreased by $2.2 \mathrm{~kg}$ and by $0.4 \mathrm{~kg}$ in the intervention and control groups during 4 years.

Other studies relevant to prevention of T2DM by lifestyle modification. The following studies are not included with the "major" 
prevention studies because of a variety of limitations including low power, inadequate randomization or insufficient description of the methodology or content of the lifestyle intervention. Some studies, although not primarily focusing on prevention of T2DM, have also published findings related to T2DM incidence and are summarised below.

An early randomised intervention study, the Malmöhus study [236] included 267 men with IGT and found lower rates of development of T2D (13\% vs. 29\%) in those receiving dietary intervention, although the published report neither defined clearly what type of diet was advocated nor the degree of adherence.

The "Whitehall Borderline Diabetes Study" [237] assessed the effectiveness of carbohydrate restriction in the prevention of T2DM. A total of 204 men with IGT were randomized to one of four treatment groups: (i) carbohydrate $120 \mathrm{~g} /$ day + placebo, (ii) "control diet" with sucrose limitation + placebo, (iii) $120 \mathrm{~g} /$ day carbohydrate $+50 \mathrm{mg}$ phenformin and (iv) sucrose limitation $+50 \mathrm{mg}$ phenformin. After 5 years, the incidence of T2DM cases in each group was as follows: $18 \%, 13 \%, 18 \%$, and $9 \%$, with none of the differences significant.

The feasibility of a diet and exercise intervention was assessed in 217 men with IGT in the Malmö feasibility study [238]. Effects of exercise training (twice weekly 60-min with various dynamic activities) and diet (reduction in refined sugar, simple carbohydrates, fat, saturated fat, energy, alcohol and increase in complex carbohydrates and vegetables) were compared with a non-randomized group receiving no intervention. After 5 years, $11 \%$ of the intervention and $29 \%$ of the reference groups had developed T2DM. The 12-year follow-up [154] revealed that mortality in the former IGT intervention group was lower than in those who received "routine care" only (6.5 and 14.0/1000 person years, $\mathrm{p}=0.009$ )

In 200 women with IGT and previous GDM, intensive versus routine dietary advice and emphasizing the importance of regular exercise was tested at the University of Melbourne [240]. Advice was delivered using a diet sheet and reinforced during frequent telephone contacts. Annual incidence rates for T2DM were $6.1 \%$ in the intervention group versus $7.3 \%$ in controls, with no difference between groups.

In Auckland [241], 176 subjects with IGT or newly diagnosed T2DM were randomized to dietary intervention designed solely to reduce total dietary fat and "usual diet" controls. Despite lower 2-hour glucose, insulin and incidence of T2DM or IGT at one year in the intervention group, there was no difference after 5 years. The SLIM Study $[177,178]$ assessed the effect of a diet and exercise intervention based on general public health recommendations on glucose tolerance, insulin resistance, and CVD risk factors in individuals with IGT. Altogether 147 participants with IGT were randomised to receive either intensive lifestyle intervention or standard care. After three years, mean weight changes were greater in the intervention than in the control group $(1.1 \mathrm{~kg}$ and $+0.2 \mathrm{~kg} ; \mathrm{p}=0.011$ ). Desired changes in insulin resistance and 2-h glucose were observed only in the intervention group. Among the 106 who completed the intervention, the cumulative incidence of T2DM was $18 \%$ in the intervention group and $38 \%$ in the control group, a relative risk $0.42(p=0.025)$, representing a $58 \%$ risk reduction. However an intention-to-treat analysis, which included 121 participants, attenuated the effect with a non-significant relative risk (RR) of 0.58 ( $p=0.07$ ).

The primary aim of The Multiple Risk Factor Intervention Trial (MRFIT) [242] was prevention of coronary heart disease (CHD) among 12866 men at high CHD risk, followed up over 6-7 years.
The intervention included dietary counselling aimed at reducing saturated fat and cholesterol and increasing polyunsaturated fat, and body weight reduction if needed. In the intervention group, $11.5 \%$ developed T2DM, compared with $10.8 \%$ of the control group with a HR of 1.08 [95\% CI: 0.96, 1.20]. However, among smokers HR was 1.26 [95\% CI 1.10, 1.45] and among non-smokers $0.82[95 \%$ CI 0.68, 0.98] $(\mathrm{p}=0.0003)$. Thus, the intervention reduced the risk of T2DM only among non-smokers.

A one-year trial in Italy [243] compared the effectiveness of a structured lifestyle intervention program in reducing the onset of the MetSy or T2DM in 375 persons with metabolic disorders recruited from a population-based cohort. Intervention consisted of general information from family physician (control group), followed by 5 training sessions with structured core but flexible contents (intervention group only) in line with general dietary recommendations (50-60\% of energy as carbohydrates, $<30 \%$ energy as fat, $<10 \%$ energy as saturated fat, $15-20 \%$ energy as protein, and 20 to $30 \mathrm{~g}$ fibre/day) and with individualized exercise and weight loss goals. After one year, $1.8 \%$ of the intervention group and 7.2 of the control group had developed T2DM, with an odds ratio (OR) of 0.23 [95\% CI 0.06, 0.85] ( $\mathrm{p}=0.03$ ).

\section{Prevention of T2DM in children and adolescents}

Applying the predefined search criteria failed to identify any RCTs designed to prevent the onset of T2DM in children or adolescents and there is a need for "long-term studies of multi-ethnic cohorts followed into adulthood to determine the natural history and effectiveness of intervention strategies, particularly lifestyle“ [10]. Expert opinion, drawing mainly on evidence in adults, identifies weight loss and/or prevention of weight gain as the best way to prevent T2DM. The American Academy of Pediatrics has made the following recommendations: supporting breast feeding, promoting healthy eating habits and physical activity, i. e. discouraging sedentary activities such as watching TV or playing video games, screening for family readiness for change, education about complications of obesity, maintaining normal, healthy body weight, and avoidance of smoking [244,245]. At present, the evidence for the long-term effectiveness of obesity prevention programs in children and adolescents is insufficient. The best results have been obtained when schools and family are involved [246]. Nevertheless, on the basis of evidence on the determinants of obesity, lifestyle changes are strongly recommended for all children and adolescents at risk for overweight, IGT and T2DM.

\section{Recommendations}

A Intensive lifestyle interventions that encourage people to change their diet and to increase their level of physical activity should be used to prevent or delay the onset of T2DM in adults with IGT. The NNT for prevention of one case of T2DM of 6.4 [95\% CI 5.0, 8.4] at mean follow up ranging from 1.83 to 4.62 years [247].

A Weight reduction is an essential element of prevention of T2DM prevention. Sustained weight reduction by $5-7 \%$ is sufficient to substantially lower the risk of T2DM.

B An increase in physical activity even at a level of 30 minutes per day of moderate exercise reduces the risk of T2DM and is therefore recommended.

B A diet with high fibre ( $\geq 15 \mathrm{~g}$ per $1000 \mathrm{kcal})$, moderate fat $(\leq 35 \%$ of total energy) reduced saturated and trans fat $(<10 \%$ of total energy) can lower body weight and reduce the risk of T2DM and is therefore recommended. 
Table 10 Characteristics of pharmacological intervention studies to prevent type 2 diabetes

\begin{tabular}{|c|c|c|c|c|c|c|}
\hline Ref. & Acronym & Design & $\begin{array}{l}\text { Intervention }(\mathrm{D}=\text { diet, } \mathrm{PA}=\text { physical } \\
\text { activity, } \mathrm{P}=\text { placebo })\end{array}$ & $\begin{array}{l}\text { Follow up } \\
\text { (years) }\end{array}$ & $\begin{array}{l}\text { Drop } \\
\text { out }\end{array}$ & Adverse effects \\
\hline \multirow[t]{3}{*}{ [249] } & SMOMS & $\mathrm{RCT}, \mathrm{DB}, \mathrm{PC}$ & 8-w very-low-calorie $D$, then $D+P A$ & 3 & & gastrointestinal \\
\hline & & & + Orlistat, $0,3 \times 120 \mathrm{mg} / \mathrm{d},(n=153)$ & & $33 \%$ & $88 \%$ \\
\hline & & & $+P(n=156)$ & & $37 \%$ & $63 \%$ \\
\hline \multirow[t]{3}{*}{ [250] } & XENDOS & RCT, DB, PC & Low caloric D + PA & 4 & & gastrointestinal \\
\hline & & & + Orlistat, $O, 3 \times 120 \mathrm{mg} / \mathrm{d},(n=1640)$ & & $48 \%$ & $36 \%$ \\
\hline & & & $+P(n=1637)$ & & $66 \%$ & $23 \%$ \\
\hline \multirow[t]{3}{*}{ [258] } & BOTNIA & $\begin{array}{l}\mathrm{RCT}, \mathrm{DB}, \mathrm{PC},+12 \mathrm{~m} \\
\text { wash out }\end{array}$ & & 1.5 & & hypoglycemia \\
\hline & & & Glipizide, G, 2.5 mg7d, ( $=17)$ & & 1 & $41 \%$ \\
\hline & & & $P(n=17)$ & & & $32 \%$ \\
\hline \multirow[t]{3}{*}{ [255] } & $\begin{array}{l}\text { STOP- } \\
\text { NIDDM }\end{array}$ & $\begin{array}{l}\text { RCT, DB, 3-m wash- } \\
\text { out: data not avail- } \\
\text { able }\end{array}$ & $D+$ PA prescription & & & gastrointestinal \\
\hline & & & + Acarbose, $A, 3 \times 100 \mathrm{mg} / \mathrm{d},(\mathrm{n}=682)$ & 3.3 & $30 \%$ & $13 \%$ \\
\hline & & & $+P(n=686)$ & 3.5 & $18 \%$ & $3 \%$ \\
\hline \multirow[t]{5}{*}[65,260]{} & DPP & $\begin{array}{l}\text { RCT, DB, intention- } \\
\text { to-treat }\end{array}$ & Standard lifestyle recommendation & 2.8 & $7.5 \%$ & $\begin{array}{l}\text { gastrointestinal } \\
\text { (events/100 person-yr) }\end{array}$ \\
\hline & & & + Metformin, M, $2 \times 850 \mathrm{mg} / \mathrm{d},(\mathrm{n}=1037)$ & & & $\mathrm{M}: 78, \mathrm{D}+\mathrm{PA}: 24, \mathrm{p}: 31$ \\
\hline & & & + Intensified D + PA $(n=1079)$ & & & \\
\hline & & & $+P(n=1082)$ & & & \\
\hline & & & + Troglitazone, T, discontinued due to safety & & & 31 \\
\hline \multirow[t]{5}{*}{ [186] } & IDPP & RT & Individual D modification & 2.5 & 26 & gastrointestinal \\
\hline & & & + Standard lifestyle advice (con, $n=136$ ) & & & $M, D+P A+M: 5$ \\
\hline & & & $+D+P A(n=133)$ & & & $\begin{array}{l}\text { hypoglycemic } \\
\text { symptoms: }\end{array}$ \\
\hline & & & + Metformin, M, $2 \times 500 / 250 \mathrm{mg} / \mathrm{d},(n=133)$ & & & $M, D+P A+M: 22$ \\
\hline & & & + Combined D + PA + M $(n=129)$ & & & \\
\hline \multirow[t]{3}{*}{ [262] } & TRIPOD & $\begin{array}{l}\text { RCT, DB,PC, open- } \\
\text { label follow-up }\end{array}$ & Lifestyle (standard D + PA) & & & - \\
\hline & & & + Troglitazone, T, 400 mg/d, $(n=133)$ & 2.6 & 19 & \\
\hline & & & $+D+P A(n=133)$ & 2.3 & 11 & \\
\hline \multirow[t]{4}{*}{ [188] } & DREAM & $\begin{array}{l}\mathrm{RCT}, \mathrm{DB}, \mathrm{PC}, 2 \times 2 \\
\text { factorial design } \\
+2-3 \text { m wash out }\end{array}$ & $\begin{array}{l}\text { 17-d SB P run-in, compliant patients enrolled, } \\
\text { D + PA }\end{array}$ & 3 & & CV events/HF \\
\hline & RO & & + Rosiglitazone, RO, 8 mg/d, $(\mathrm{n}=2635)$ & & & $75 / 14$ \\
\hline & & & $+P+$ lifestyle $(n=2634)$ & & 772 & $55 / 2$ \\
\hline & & & & & 658 & $\mathrm{~ns} / \mathrm{p}=0.01$ \\
\hline \multirow[t]{2}{*}{ [264] } & DREAM & $\begin{array}{l}\text { RCT, DB, PC, } 2 \times 2 \\
\text { factorial design } \\
+2-3 \text { m wash out }\end{array}$ & + Ramipril, RA, -15 mg/d, $(n=2623)$ & 3 & $27 \%$ & $\begin{array}{l}\text { cough/angioedema: } \\
9.7 \% / 0.1 \%\end{array}$ \\
\hline & RA & & $+P+$ lifestyle $(n=2646)$ & & $22 \%$ & $1.8 \% / 0.2 \%$ \\
\hline
\end{tabular}

C Comorbidities, particularly MetSy, should be monitored and taken into account while planning the diet $[119,248]$.

C Currently there is no evidence from long-term prevention studies that reducing total dietary carbohydrate prevents T2DM. Carbohydrate sources should mainly be whole-grain cereal, fruit, vegetables, and legumes.

D There is no evidence from clinical trials of the effectiveness of interventions to prevent the onset of T2DM among children and adolescents. However, on the basis of physiological evidence and research in adults it can reasonably be assumed that maintaining a healthy weight through physical activity and balanced/healthy nutrition is the key factor will be important to prevent or postpone the onset of T2DM among youth.

Findings for prevention by pharmaceutical treatment Studies of the effectiveness of drug treatment in preventing or delaying the onset of T2DM have been performed mostly in persons at high-risk of T2DM, such as those who are obese and/or exhibit IGT, or women with a history of GDM. Key data of these studies are summarized in 0 Tables 10, 11, 12.

\section{Antiobesity treatment}

Orlistat. The Scandinavian Multicenter Orlistat in Metabolic Syndrome (SMOMS) study was performed in obese subjects with the MetSy ( $n=309$ ). After 8-weeks on a very-low caloric diet, participants were given the intestinal lipase inhibitor, orlistat or placebo in addition to lifestyle modification. Over 36 months the incidence of diabetes was $58 \%$ lower in the orlistat group compared with placebo, with no differences in insulin secretion and activity [249].

The XEnical in the prevention of Diabetes in Obese Subjects (XENDOS) study was conducted in 3277 obese subjects, of whom 694 had IGT. They received orlistat or placebo in addition to lifestyle modification. After a median follow up of 48 months, the HR for all patients was $0.59(p=0.028)$, for those with IGT it was 0.55 
Table 11 Population characteristics (means) of pharmacological intervention studies to prevent type 2 diabetes

\begin{tabular}{|c|c|c|c|c|c|c|c|c|c|}
\hline Ref. & Acronym & $\begin{array}{l}\text { Age } \\
\text { (years) }\end{array}$ & $\begin{array}{l}\text { BMI } \\
\left(\mathrm{kg} / \mathrm{m}^{2}\right)\end{array}$ & $\begin{array}{l}\text { Waist (cm) } \\
\text { (male/ } \\
\text { female) }\end{array}$ & $\begin{array}{l}\text { Blood } \\
\text { pressure } \\
(\mathrm{mmHg})\end{array}$ & $\begin{array}{l}\text { Lipids } \\
\text { HDL-C } \\
\text { (mmol/I) }\end{array}$ & $\begin{array}{l}\text { Lipids TG } \\
\text { (mmol/l) }\end{array}$ & $\begin{array}{l}\text { MetSy or } \\
\text { diabetes risk }\end{array}$ & $\begin{array}{l}\text { FPG } \\
(\mathrm{mmol} / \mathrm{l})\end{array}$ \\
\hline \multirow[t]{2}{*}{ [249] } & SMOMS & $47(0)$ & 37 & 119 & $144 / 91$ & 1.1 & 2.4 & 309 Obese + MetSy & 6.4 \\
\hline & & $47(P)$ & 38 & 119 & $144 / 91$ & 1.2 & 2.5 & & 6.3 \\
\hline \multirow[t]{2}{*}{ [250] } & XENDOS & $43(0)$ & 37 & 115 & $131 / 82$ & 1.2 & 1.9 & 3277 Obese, 694 IGT & 4.6 \\
\hline & & $44(P)$ & 37 & 115 & $130 / 82$ & 1.2 & 1.9 & & 4.6 \\
\hline \multirow[t]{2}{*}{ [258] } & BOTNIA & $58(G)$ & 28 & 88 & $143 / 88$ & 1.0 & 1.8 & $\begin{array}{l}\text { First-degree relatives + } \\
\text { IGT }\end{array}$ & 5.3 \\
\hline & & $53(P)$ & 29 & 90 & $134 / 83$ & 1.1 & 1.6 & & 5.3 \\
\hline \multirow[t]{2}{*}{ [255] } & $\begin{array}{l}\text { STOP- } \\
\text { NIDDM }\end{array}$ & $54(\mathrm{~A})$ & 31 & 102 & 131 & 1.2 & 2.1 & 1429 IGT + IFG & $6 \cdot 2$ \\
\hline & & $55(\mathrm{P})$ & 31 & 102 & 131 & 1.2 & 2.1 & & 6.2 \\
\hline [65] & DPP & 51 & 34 & 105 & $125 / 79$ & 1.0 & - & 3234 IGT + IFG & 6.0 \\
\hline \multirow[t]{4}{*}{ [186] } & IDPP & $35-55$ & 26 & & 124 (con) & & $1,1.9$ & $531 \mathrm{IGT}$ & \\
\hline & & & & & $122(\mathrm{D}+\mathrm{PA})$ & & $2,2.0$ & & \\
\hline & & & & & $121(\mathrm{M})$ & & $3,1.7$ & & \\
\hline & & & & & $\begin{array}{l}123 \\
(D+P A+M)\end{array}$ & & $4,1.8$ & & \\
\hline \multirow[t]{2}{*}{ [262] } & TRIPOD & $35(\mathrm{~T})$ & 31 & - & - & - & - & 266 pGDM, 63\% IGT & 5.3 \\
\hline & & $34(\mathrm{P})$ & 30 & & & & & & 5.2 \\
\hline \multirow[t]{2}{*}{ [188] } & $\begin{array}{l}\text { DREAM- } \\
\text { Rosi }\end{array}$ & 55 (Ro) & 31 & $101 / 96$ & $136 / 83$ & - & - & 739 IFG, 4530 IGT & 5.8 \\
\hline & & $55(\mathrm{P})$ & 31 & $102 / 96$ & $136 / 84$ & & & & 5.8 \\
\hline \multirow[t]{2}{*}{ [264] } & $\begin{array}{l}\text { DREAM- } \\
\text { Rami }\end{array}$ & $55(\mathrm{Ra})$ & 31 & & $136 / 83$ & & & $\begin{array}{l}\text { IGT: } 1513 \text { (Ra), } 1515 \\
\text { (P) }\end{array}$ & 5.9 \\
\hline & & $55(P)$ & 31 & - & $136 / 83$ & - & - & IFG: 366 (Ra), 373 (P) & 5.9 \\
\hline
\end{tabular}

a $90 \%$ family history of diabetes, $78 \%$ BMI > $27 \mathrm{~kg} / \mathrm{m}^{2}, 53 \%>1$ risk factor for T2DM, $51 \%$ high blood pressure, $48 \%$ dyslipidemia, $23 \%$ women with a history of gestational diabetes

$(\mathrm{p}=0.0024)$, but there was no difference in the rate of progression from NGT to IGT [250].

Rimonabant. One sub-group analysis of the Rimonabant-In-Obesity (RIO)-Europe study compared effects of the endocannabinoid receptor antagonist rimonabant $(\mathrm{n}=399)$ with placebo $(\mathrm{n}=123)$ as part of a lifestyle intervention in healthy obese subjects with a mean BMI of $36 \mathrm{~kg} / \mathrm{m}^{2}$ [251]. Within 24 months, rimonabant treatment achieved weight reduction and improvement of HDL-C and triglycerides. Although only $0.5 \%$ of the rimonabant group, compared with $4.1 \%$ of the control group, developed diabetes, the high drop-out rates (58\% and 55\%) and low incidence of T2DM limit the relevance of the study. In October 2008, rimonabant was withdrawn from the market because of concerns about risk-benefit ratios so that it cannot be used for diabetes prevention [251].

Bariatric surgery. The Swedish Obesity Surgery (SOS) trial studied 2010 severely obese subjects (BMI $>35 \mathrm{~kg} / \mathrm{m}^{2}$ ) who underwent surgery for obesity (gastric banding, gastroplasty, gastric bypass) and 2037 patients who chose conventional treatment in a matched pairs-design non-randomized study. Subjects undergoing surgery achieved a reduction in body weight of 20$30 \mathrm{~kg}$, accompanied by a reduction in cardiovascular risk factors. After 8 years, the surgical group had a greatly reduced risk of developing diabetes (OR: 0.16) [252]. Two recent reviews analyzed the available evidence for the use of bariatric surgery in overt diabetic and in obese patients. While surgery improved T2DM in $87 \%$ and resolved it in $79 \%$ of cases [253] and was more efficient than conventional treatment to induce weight loss in obese patients [254], the evidence on safety is less clear due to limited number and quality of studies [254].

\section{Oral glucose lowering drugs}

Alpha glucosidase inhibitors. In the Study-To-Prevent-NIDDM (STOP-NIDDM), persons with IGT $(\mathrm{n}=1.429)$ were randomized in a double-blind trial to either the alpha glucosidase inhibitor, Acarbose, or placebo. After a mean follow-up of 3.3 years, the acarbose-treated group achieved 25\% and 36\% RR reduction based on one or two OGTTs in progression to diabetes compared with placebo. The effect of acarbose was observed across all ages, at all BMIs, and in both sexes, while there was some evidence of an accompanying improvement in CVD risks [255-257].

Sulfonylurea. Within the BOTNIA study, 34 first-degree relatives of patients with T2DM and IGT were assigned randomly to either glipizide or placebo. At 6 months of treatment, measures of insulin secretion/action such as fasting plasma insulin and measures of insulin resistance and HDL-C had improved in the glipizide group. Thereafter, the treatment was withdrawn and the participants observed for another 12 months of washout. At 18 months, both FPG and 2-h PG were lower in the glipizide than in the placebo group. The prevalence of T2DM was $29.4 \%$ in the placebo group and $5.9 \%$ in the glipizide group, corresponding to an $80 \%$ relative risk reduction at 18 months. However, although not reaching statistical significance in this study, there was some evidence suggesting a need for caution in the use of glipizide because of an increased frequency of symptoms suggesting hypoglycemia [258].

Biguanides. As described above, the Whitehall Borderline Diabetes Study examined the ability of carbohydrate restriction to prevent the onset of diabetes in men with IGT $(n=204)$ with or without treatment with phenformin, but detected no difference in the 
Table 12 Main results and outcome of pharmacological intervention studies to prevent type 2 diabetes

\begin{tabular}{|c|c|c|c|c|}
\hline Ref. & Acronym & Number of T2DM cases per group & Risk reduction & Number needed to treat \\
\hline \multirow[t]{2}{*}{ [249] } & SMOMS & O: $8(5.2 \%)$ & HR: 0.63 & - \\
\hline & & P: $17(10.9 \%)$ & & \\
\hline \multirow[t]{2}{*}{ [250] } & XENDOS & O: $102(6.2 \%)$ & HR for all: $0.59, p=0.028$ ) & 10 IGTs/4years \\
\hline & & P: $147(9.0 \%)$ & HR for IGT: $0.55, p=0.0024^{c}$ & \\
\hline \multirow[t]{2}{*}{ [258] } & BOTNIA & V: $5.9 \%$ & ARR: $23.5 \%$ & - \\
\hline & & P: $29.4 \%$ & $\mathrm{HR}=0.30$ & \\
\hline \multirow[t]{2}{*}{ [255] } & STOP-NIDDM & V: $105(15 \%)$ & ARR: $8.7 \%$ & - \\
\hline & & P: $165(24 \%)$ & HR: $0.64, p=0.0003$ & \\
\hline \multirow[t]{4}{*}{ [65] } & DPP & Incidence/100 person-years: & RRR: & \\
\hline & & $D+P A: 4.8$ & $D+P A$ vs. $P: 58 \%$ & $6.9 / 3$ years $(D+P A)$ \\
\hline & & M: 7.8 & M vs. P: $31 \%$ & $13.9 / 3$ years $(\mathrm{M})$ \\
\hline & & P: 11.0 & D + PA vs. M: $39 \%$ & \\
\hline \multirow[t]{3}{*}{ [186] } & IDPP & $D+P A: 0.623, p=0.018$ & $H R: D+P A: 0.62, p=0.018$ & $6.4 / 3$ years \\
\hline & & $M: 0.651, p=0.029$ & M: $0.65, p=0.029$ & $6.9 / 3$ years \\
\hline & & $D+P A+M: 0.629, p=0.022$ & $D+P A+M: 0.63, p=0.022$ & $6.5 / 3$ years \\
\hline \multirow[t]{2}{*}{ [262] } & TRIPOD & $\mathrm{T}: 30 \%(12.1 \% / \mathrm{y})$ & HR: 0.45 (non-adjusted), 0.44 (adjusted) & - \\
\hline & & P: $14 \%(5.4 \% / y)$ & & \\
\hline \multirow[t]{2}{*}{ [188] } & DREAM-RO & RO: $280(10.6 \%)$ & HR: $0.38, p<0.0001^{b}$ & $6.9 / 3$ years \\
\hline & & P: $658(25.0 \%)^{a}$ & & \\
\hline \multirow[t]{2}{*}{ [264] } & DREAM-RA & RA: $17.1 \%(449)$ & HR: 0.91 & - \\
\hline & & P: $18.5 \%$ (489) & & \\
\hline
\end{tabular}

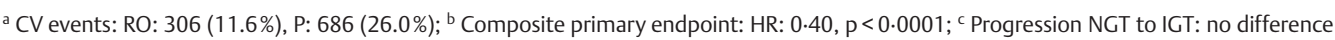

incidence of diabetes between the different groups after 45 years [259].

As decribed above, the US DPP, a multicenter RCT, tests an intensive lifestyle intervention with metformin (850 mg twice daily), or troglitazone (400 $\mathrm{mg}$ daily) or placebo [260] in high-risk persons with IGT $(\mathrm{n}=3.234)$ and slightly elevated fasting plasma glucose ( $>5.5 \mathrm{mmol} / \mathrm{l}$ ), with about $45 \%$ of the study population from Non-Caucasian groups such as African-American and Hispanic. After a mean follow-up of 2.8 years, the relative reductions in the progression to diabetes were $58 \%$ in the lifestyle group and $31 \%$ in the metformin vs. placebo-treatment. As these data were based on an OGGT performed during ongoing treatment, another OGTT was performed after a 1-2-weeks washout period. After the washout, diabetes was slightly but not significantly more common in the metformin group with a OR of $1.49([0.93,2.38]$ $\mathrm{p}=0.098$ ). Comparison of the probabilities of developing diabetes during the DPP and during the wash out period revealed that $26 \%$ of the metformin effect did not persist upon drug withdrawal. Nevertheless, metformin still reduced the incidence of diabetes by $25 \%$ [65].

The IDPP studied persons with IGT $(n=531)$ who were slightly younger and less overweight than in DPP and DPS. They received the following interventions: control, lifestyle modification, metformin or combined lifestyle modification + metformin. After median follow-up of 30 months, the relative risk reductions versus control were between $26-29 \%$ for all study arms. The lifestyle intervention was less intensive and the diabetes incidence was higher (55.0\% in 3 years) than in the DPP and DPS. Of note, as in the Indian Diabetes Prevention Study, metformin, when added to lifestyle intervention exerted no benefit beyond that of the lifestyle intervention [186].

Thiazolidendiones. "Insulin sensitizer" such as thiazolidinediones which are agonists at the peroxisome proliferator activator receptor-gamma have been also tested in prevention. The troglitazone arm of the DPP was discontinued because of concerns about liver toxicity. Before discontinuation (at a mean of 0.9 years), the incidence of diabetes was 3.0/100 person-years was not different versus intensive lifestyle intervention, but lower than in the placebo and metformin arms. During the 3 years after troglitazone withdrawal, the incidence of diabetes was comparable to that in the placebo group indicating that its effect did not persist upon withdrawal [261].

In the Troglitazone In Prevention of Diabetes (TRIPOD) study, Hispanic women with previous gestational diabetes $(n=235)$ were randomized to receive the troglitazone, since withdrawn from sale, or placebo. After a median follow-up of 30 months, the incidence of T2DM was $5.4 \%$ and $12.1 \%$ with troglitazone and placebo. Thus, troglitazone treatment was associated with a $56 \%$ relative reduction in progression to diabetes which remained even after an 8-m washout period [262].

The Pioglitazone In Prevention of Diabetes (PIPOD) study was performed as an open-label observational trial using pioglitazone ( $45 \mathrm{mg}$ daily) in 89 women participating in TRIPOD, of whom 30 had received verum during the previous study. After a median follow-up of 36 months, 65 women had completed all study visits: The rates of annual and cumulative incidence of diabetes were $5.2 \%$ and $17 \%$. It is noteworthy that parameters of insulin resistance were not affected, whereas body weight increased [263].

In the Diabetes REduction Assessment with ramipril and rosiglitazone Medication (DREAM) Study, 5.269 adults with IFG or IGT, or both, and no previous cardiovascular disease were randomly assigned to receive rosiglitazone ( $8 \mathrm{mg}$ daily) vs. placebo or ramipril (up to $15 \mathrm{mg}$ ) vs. placebo. After a median follow up of 3 years, rosiglitazone treatment reduced the incidence of T2DM as assessed from a HR of 0.38 [95\% CI 0.33, 0.44] ( $p<0.0001)$ and of the composite primary end point (death or onset of diabetes: hazard ratio (HR: $0.40[0.35 ; 0.46])(\mathrm{p}<0.0001)$. In addition, rosiglitazone for 3 years increased the likelihood of regression to normoglycemia in adults with IFG or IGT, or both $[188,264]$.

Antihypertensive and lipid-lowering drugs. Several meta-analyses and reviews of studies on angiotensin receptor (AT1) blockers 
or angiotensin converting enzyme inhibitors (ACEI) report an association with reduced risk of T2DM $[265,266]$. However, occurrence of diabetes was not a primary endpoint in these studies and the methods used to diagnose and detect diabetes were heterogeneous. No prospective RCT had examined the ability of antihypertensive drugs to prevent diabetes prior to the DREAM study.

After a median follow up of 3 years, ramipril treatment was not associated with lower incidence of diabetes at a HR of 0.91 [0.80, 1.03 ] or death, but with increased probability ("HR" $1.16, \mathrm{p}=$ 0.001 ) of regression to normoglycemia compared with placebo. At the end of the study, the median 2-h PG but not FPG was slightly lower in the ramipril than in the placebo group $(\mathrm{p}=$ 0.01) [264].

Post hoc analyses of placebo-controlled statin trials show conflicting results on associations between statin therapy and diabetes incidence [267-270]. However, currently, there is no prospective RCT investigating the effect of lipid lowering drugs on diabetes onset.

\section{Recommendations}

A In persons with IGT, metformin and acarbose can be used as second line strategies for prevention of T2DM, provided that the drugs are tolerated (gastrointestinal side-effects), and contraindications to metformin therapy (kidney, liver diseases, hypoxic conditions) are considered [65,179,186,255].

A In obese people with or without IGT, carefully monitored antiobesity treatment with orlistat, in addition to intensive lifestyle modification, can be used as a second line strategy for obese patients to prevent T2DM.

C In severely obese patients at high risk of T2DM and CVD, bariatric surgery in addition to careful monitoring and lifestyle change can induce sustained weight loss for [252,271], but longterm safety is less clear so that it cannot be recommended for diabetes prevention at present.

C Glucose lowering drugs such as glipizide or thiazolidendiones may reduce the risk of T2DM in certain high risk groups, but either long-term efficacy or safety are unclear so that these drugs cannot be recommended for diabetes prevention at present [179].

C Antihypertensive and lipid-lowering drugs cannot be recommended for the prevention of T2DM at present.

\section{Considerations of societal and public health aspects}

International organizations (IDF, EASD, WHO) have issued consensus statements on prevention programs [172,272] and a number of national or regional programs are already implemented at the societal level $[273,274]$. The pan-European DEplan project further described public health approaches for implementing prevention of T2DM at the primary care level [239]. The majority of the prevention programs designed at community and national levels are based on implementation of lifestyle interventions in public health and primary healthcare settings [185]. Data on the efficiency of the population approach are scarce, but public health surveys demonstrate its utility if based on the promotion of healthier lifestyle $[185,275]$. This suggests that the combination and coordination of individualized and population approaches at the societal level would be useful [172]. The health sector cannot implement the population approach on its own, so other stakeholders (e.g. schools, communities, politicians, industry/employers) need to be involved [172], particularly for coordinated prevention in adolescents [276]. Prevention programs also need to address cultural differences in di- etary habits and physical activity patterns, particularly in minorities [277,278]. Governments should develop and implement national diabetes prevention plans including a wide range of initiatives in different segments of societies such as advocacy (providing support for relevant associations and organizations and a favorable economic environment), community support (to produce a favorable environment for adequate nutrition by education and for physical activity by sport facilities and urban design), fiscal and legislative changes (food pricing labeling and advertising as well as environmental and infrastructure regulation), engaging of the private sector (promotion of health at workplace and ensuring healthy policies in food industry) and media support [172].

\section{Recommendations}

A Interventions to prevent T2DM should be implemented at the societal level though a structured public health plan which should take into account both high-risk/targeted approach and population approaches.

C The structured plan should also include specific approaches to meet the needs of subpopulations, e.g. adolescents, minorities and disadvantaged groups.

B The establishment and implementation of an effective plan for the prevention of T2DM at national levels requires government initiatives comprising advocacy, community support, fiscal and legislative changes involving infrastructure, engagement of private sector and continuous media communication.

A This plan should be part of a network with other relevant prevention programs and public educational activities.

\section{Supporting Change in Lifestyle Behaviour for Adults at Risk of T2DM \\ $\nabla$}

Changing an existing habit requires people to establish a motivation or intention to change, make decisions and action plans, recognise and overcome barriers (both practical and psychological), initiate the new routine, and then to maintain the new routine, resisting temptations to relapse back to former habits. Approaches for supporting changes in diet and physical activity vary from simple information-giving to more intensive programmes, which may or may not be based on theoretical models of behaviour change [279-283].

\section{Methodology}

The recommendations on this topic are based on a systematic review, which summarised the available scientific evidence on the relationship between increased intervention effectiveness and: (i) theoretical basis, (ii) behaviour change techniques used, (iii) mode of delivery, (iv) intervention provider, (v) intervention intensity, (vi) characteristics of the target population (e.g. gender, ethnicity), (vii) setting. Our systematic "review of reviews" of the scientific evidence base on dietary and/or physical activity interventions is published separately and will be available to download from the IMAGE website (http://www.image-project.eu). Only the key recommendations and a summary of the evidence are presented here. The review examined systematic reviews, published between 1998 and 2008, which focused primarily on populations of adults at risk of developing T2DM and/or CVD. Articles were identified by searching multiple electronic databases of published evidence and other sources. The methodological quality of studies was systematically assessed using an estab- 
Table 13 Evidence underlying the recommendations on supporting behaviour change

\section{Evidence}

Evidence grade ${ }^{a}$

\section{Overall intervention effectiveness}

Dietary or diet plus physical activity interventions can have effects on weight loss. Mean net weight loss in successful interventions varies from $3-5 \mathrm{~kg}$ at 12 months and from $2-3 \mathrm{~kg}$ at 36 months

Weight loss from dietary or diet plus physical activity interventions can be sustained for 48 months and 7 years $(2-3 \mathrm{~kg})$.

Physical activity interventions can have effects at up to 18 months of follow up. The increase for successful interventions is 30-60 minutes of moderate activity per week.

Physical activity interventions can also have small effects on weight at up to 12 months of follow up (decrease $1-2 \mathrm{~kg}$ ).

Dietary and/or physical activity interventions can strongly reduce progression to T2DM (49\% relative reduction in risk) at 3.4 years of follow up. Interventions need to pay more attention to behaviour maintenance, once the active phase of intervention is completed. During the active phase of interventions the net weight loss at $3-12$ months was on 0.08 body mass index units per months. During the maintenance phase (from 6-60 months), patients regained weight at a rate of 0.03 body mass index units per month.

\section{Theoretical basis}

Interventions for weight loss (diet or physical activity) which stated a theoretical model as their foundation delivered no greater weight loss than interventions that did not state their theoretical underpinnings.

\section{Behaviour change techniques}

The planned use of established behaviour change techniques in dietary and/or physical activity interventions increases the amount of weight loss and physical activity produced at 6 months of follow up.

Interventions with diet plus physical activity produce greater weight loss than those with dietary change only at up to 24 months of follow up. Interventions based on motivational interviewing are more effective than traditional advice at least in the short-term ( 3 to 6 months of follow up).

Using social support (usually from a family member) increases effectiveness of weight loss interventions at 12 months of follow up.

Interventions which include the use of pedometers to self-monitor walking activity produce moderate weight loss and moderate increases in moderate levels of physical activity at up to 4 months of follow up.

Dietary and/or physical activity interventions which include prompting of self-monitoring alongside other "self-regulatory techniques"

(Specific goal setting; Providing feedback on performance; Review of behavioural goals) produce an average weighted effect size more than twice that of other interventions.

Prompting self-monitoring of behaviour and/or outcomes and prompting self-talk, alongside other intervention techniques (i.e. not in isolation), are associated with increased intervention effectiveness for both dietary and physical activity interventions.

Providing instruction and the use of relapse prevention techniques (for dietary change), prompting practice, individual tailoring, setting goals and time management (for physical activity) may also enhance intervention effectiveness.

\section{Mode of delivery}

Successful physical activity and/or dietary interventions have been delivered using group, individual or combined (individual and group) modes of delivery.

There is no strong evidence of any difference in the effectiveness of physical activity and/or dietary interventions between individual, group and mixed modes of delivery at up to 12 months of follow up.

\section{Intervention provider}

Successful physical activity and/or dietary interventions have been delivered by doctors, nurses, dieticians/nutritionists, exercise specialists and lay people. It should be noted however that these providers were often working within a multi-disciplinary team.

There is no strong evidence of any difference in the effectiveness of physical activity and/or dietary interventions delivered by medically trained health professionals (doctors, nurses), other professionals (psychologists, counsellors, dieticians, health educators), public health students, or lay people at up to 12 months of follow up.

\section{Intensity}

When intensity is considered in terms of intervention duration or total contact time, there is insufficient evidence to draw any clear conclusions about its impact on the effectiveness of dietary and/or physical activity interventions.

A greater frequency of meetings, particularly in the active phase of the intervention is associated with greater effectiveness in dietary and/or physical activity interventions at up to 15 months of follow up.

A greater total number of personal contacts/intervention sessions is associated with greater intervention effectiveness at up to 36 months of follow up.

\section{Different populations}

Gender:

There seems to be no substantial difference between men and women in responsiveness to dietary and/or physical activity interventions (once recruited) at up to 16 months of follow up. [However, strong gender imbalances in recruiting are reported, so there may be some types of intervention which suit women more than men.]

Older people:

Dietary and/or physical activity interventions can produce weight loss in older populations at up to 34 months of follow up.

There is evidence suggesting that older people (over age 45) are more responsive to dietary and/or physical activity interventions at up to 34 months of follow up.

Black and minority ethnic groups:

Combined dietary and physical activity intervention can be effective for a wide range of ethnicities, including Caucasian, Afro-Caribbean, Hispanic, American Indian and Asian (mainly East Asian) populations at up to 34 months of follow up.

Disability groups:

The basic effectiveness of interventions is not yet established in adults with physical limitations. High quality evidence focusing on the effec tiveness or relative effectiveness of dietary and/or physical activity interventions in adults with physical limitations or other disabilities is urgently needed.

$1++$

$1+$

$1+$

$1++$ 
Table 13 Continued

\section{Evidence \\ Settings}

Successful interventions have been delivered in a wide range of settings, including health care settings, the workplace, the home, and in the community. However, evidence on the differential impact of different settings on effectiveness is lacking.

There is tentative evidence that remotely delivered walking support interventions (using internet or phone-based delivery) can produce shortterm effects on physical activity (at 3 months of follow up).

a Based on SIGN evidence grading system; * Evidence grading is explained in the methods section and in Appendix 2

Table 14 Definitions of established behaviour change techniques

\begin{tabular}{ll} 
Source & Basis for categorisation of whether studies used established behaviour change techniques or not \\
Avenell et al. [323] & $\begin{array}{l}\text { Definitions of behaviour therapy varied by study but include self-monitoring, stimulus control, problem solving, relapse } \\
\text { prevention management, cognitive restructuring, self-assertion, social support, goal setting, self-reinforcement. }\end{array}$ \\
\hline McTigue et al. [324] & $\begin{array}{l}\text { Behavioural interventions are strategies to help patients acquire the skills, motivations, and support to change diet and exer- } \\
\text { cise patterns. These include barrier identification, problem solving, self-monitoring, social support, goal-setting, developing } \\
\text { action plans, relapse prevention, stimulus control, cognitive restructuring. }\end{array}$ \\
Bhaw et al. [325] & $\begin{array}{l}\text { Behavioural therapy aims to provide the individual with coping skills to handle various cues to overeat and to manage lapses in } \\
\text { diet and physical activity when they occur and to provide motivation essential to maintain adherence to a healthier lifestyle } \\
\text { once the initial enthusiasm for the program has waned. Therapeutic techniques in studies relating to the benefit of using } \\
\text { "established behaviour change techniques" include stimulus control, self-control and therapist-controlled contingencies, self- } \\
\text { monitoring, problem solving, goal setting, behaviour modification, reinforcement. }\end{array}$ \\
NiCE Obesity Guidance [308] & $\begin{array}{l}\text { This guidance document comprises a summary of/expansion of reviews by Shaw et al. [325], McTigue et al. [324], and Avenell } \\
\text { et al. [323]. Definitions vary by analysis but typically include cue avoidance, self-monitoring, stimulus control, social support, } \\
\text { planning problem solving, cognitive restructuring, modifying thoughts, relapse prevention, reinforcement of change, coping } \\
\text { strategies, coping imagery, goal setting, social assertion, reinforcement techniques for enhancing motivation. }\end{array}$
\end{tabular}

lished rating system [284] and data were only extracted from reviews meeting a pre-set quality standard. Selection and data extraction were undertaken independently by two reviewers and any disagreements resolved by discussion. We identified 3856 potentially relevant articles, of which 30 met the quality and selection criteria. We systematically extracted data relevant to the specific aims above, rated each piece of evidence, using the SIGN evidence rating system and produced detailed evidence tables. Further discussion of the evidence in workshops of experts in primary care, behavioural science and diabetes prevention (the IMAGE study group) helped to derive the recommendations below.

\section{Findings}

The evidence showed that interventions to promote lifestyle changes are more likely to be effective if they target both diet and physical activity, mobilise social support, involve the planned use of established behaviour change techniques (as defined in Table 14) and provide a higher frequency of contacts. Specific techniques to support behaviour change and maintenance were also associated with increased effectiveness. Table 13 provides a concise summary of the evidence we examined.

\section{Recommendations}

Individual level interventions for people at risk of T2DM should: A Aim to promote changes in both diet and physical activity A Use established, well defined behaviour change techniques (e.g., specific goal-setting, relapse prevention, self-monitoring, motivational interviewing, prompting self-talk, prompting practice, individual tailoring, time management), as defined in $\bigcirc \mathrm{Ta}$ ble 14.
D A clear plan of intervention should be developed based on a systematic analysis of factors preceding, enabling and supporting behaviour change in the social/organisational context in which the intervention is to be delivered. The plan should also identify the processes of change and the specific techniques and method of delivery designed to achieve these processes. Such planning should ensure that the behaviour change techniques and strategies used are mutually compatible and well-adapted to the local delivery context. Following the procedures of the PRECEDE-PROCEED model [285], Intervention Mapping [286], or a similar intervention-design procedure is recommended.

A Work with participants to engage social support for the planned behaviour change (i.e. engage important others such as family, friends, and colleagues).

B Maximize the frequency or number of contacts with participants (within the resources available).

A Include a strong focus on maintenance. It is not clear how best to achieve this, but behaviour change techniques designed to address maintenance include establishing self-monitoring of progress, providing feedback (e.g. on changes achieved in blood glucose and other risk factors), reviewing of goals, engaging social support, use of relapse prevention/relapse management techniques and providing follow-up prompts.

C Building on a coherent set of 'self-regulatory' intervention techniques (Specific goal setting; Prompting self-monitoring; Providing feedback on performance; Review of behavioural goals) may provide a good starting point for intervention design. However, this is by no means the only approach available and It is worth noting that self-regulation techniques are not normally used in isolation (e.g. techniques designed to explore and en- 
hance initial motivation would normally be applied prior to goalsetting).

A Interventions to prevent T2DM may be delivered by a wide range of people/professions, subject to appropriate training (including the use of established behaviour change techniques). There are examples of successful physical activity and/or dietary interventions delivered by doctors, nurses, dieticians/nutritionists, exercise specialists and lay people, often working within a multi-disciplinary team.

A Interventions to prevent T2DM may be delivered in a wide range of settings. There are examples of successful physical activity and/or dietary interventions delivered, in health care settings, the workplace, the home, and in the community.

A Interventions to prevent T2DM may be delivered using group, individual or mixed modes (individual and group). There are numerous examples of successful physical activity and/or dietary interventions using each of these delivery modes.

C No specific intervention adaptations are recommended for men or women, although steps may be needed to increase engagement/recruitment of men.

D People planning interventions should consider what adaptations may be needed for different ethnic groups (particularly with regard to culturally-specific dietary advice), people with physical limitations and people with mental health problems.

\section{Models of Care and Economic Aspects of T2DM Prevention}

\section{Methodology}

This section updates and extends a recent systematic review that focused on environmental determinants of cardiovascular disease, which shares many risk factors with diabetes [287]. The initial review employed an iterative process, in which PubMed and Google were searched, initially using the following search terms: (environment or community) and (measures or index or risk factors or determinants), (built environment or nutrition environment or obesogenic environment or social environment) and cardiovascular (risk factors or disease), subsequently complemented by diabetes.

For the review of the economic aspects of diabetes prevention strategies, PubMed was searched using the terms: (economics of preventing diabetes), (economics diabetes prevention) and (economic evaluation diabetes prevention), with follow up of references cited.

To guide the review of health systems issues, a questionnaire was sent to all IMAGE partners seeking their input as to how they might implement a model of diabetes prevention in their own country. It was supplemented by a review of tabled results from the IMAGE questionnaire "Analyses of Type 2 Diabetes Prevention Programmes at national level" sent to all IMAGE partners. The results were then interpreted in the light of a series of studies undertaken by the European Observatory on Health Systems and Policies on the health system response to chronic diseases $[288,289]$, human resources in the health sector [290,291], social insurance systems [292], and primary care in Europe [293]. This used, as a conceptual framework, the Chronic Care Model [294], which was developed in the USA but is now forming the basis of innovative models of care in several other countries. The components of the Chronic Care Model are support for self-management, appropriate delivery system design, decision support methods, and clinical information systems.

\section{Findings}

Health in all policies

A comprehensive policy response to the growing challenge of T2DM will require action at two levels. The first is action at the societal or community level, to create environments that are less obesogenic. The second is action at the individual level, to identify and intervene in those at risk.

The marked increase in prevalence of T2DM has mirrored the epidemic of its major modifiable risk factor - obesity. Large scale societal changes, and in particular the industrialisation of food production and the growth in motorised transport, both coupled with rising incomes, have contributed to a situation in which people are consuming more calories than they expend, and subsequently gaining weight at an alarming rate. This phenomenon is seen in its most extreme form in populations that have evolved over generations in settings at risk of periodic famine, who now have access to secure and plentiful food supplies and where motorised transport has brought about greatly reduced physical activity [225]. This has led researchers to coin the term "obesogenic environment" [295]. This is defined as "the sum of influences that the surrounding opportunities or conditions of life have on promoting obesity in individuals or populations" [296]. Thus the increasing prevalence of T2DM has its origins in policies that lie far outside the health sector. These have recently been reviewed elsewhere [287], but in brief, obesity is correlated with both objective measures of the environment, such as "walkability" [297] and urban sprawl [298] or the structure of the retail food market [299] as well as how individuals perceive the environment in which they live (for example, fear of violence as a deterrent to physical activity) [300]. Many of these factors are modifiable, for example by incorporating health considerations into urban planning [262] or fiscal or legislative changes affecting food marketing (such as advertising bans or taxes on "junk" foods [233]). Consequently, no matter how intensive they are, individualised interventions within the health sector can only begin to overcome the pervasive forces arising from the environments within which people work, as recognised by the IDF [172] and the American Heart Association (AHA) [301]. Similarly, a key element of the European Union's public health strategy is Health in All Policies [302]. However, while there is a large volume of evidence correlating characteristics of the environment with levels of obesity, and thus T2DM, there are no population-based intervention studies (for example to change the built environment or retail food sector) that have been shown to reduce obesity. This is unsurprising given the complexity and scale of such potential interventions. However, on the basis of the clearly demonstrated association between the environment and obesity, we recommend that any individualised model of care for diabetes prevention is accompanied by other policy responses to address obesity prevalence in the population. $\mathbf{A}$

The economic aspects of diabetes prevention strategies Using data from 2001 and 2002, the average annual cost of health care in Italy for T2DM were estimated to be $1910 € /$ patient, with $52 \%$ of costs accounted for by medication, $28 \%$ by hospitalisation, and $11 \%$ by diagnostic procedures [303] (2).

An earlier Swedish study calculated the annual direct and indirect costs of diabetes per person to be approximately $6338 € /$ year. $28 \%$ of the costs were for healthcare, $41 \%$ for lost productivity and $31 \%$ fell on the municipality and relatives [304]. The recent IDF Diabetes Atlas [305] estimates that, in 2010, USD 105.5 billion will be spent on healthcare for diabetes in Europe, equating to a 
mean expenditure of USD 2046 per person with diabetes in the region [306]. Evidently, the cost is high, emphasising the importance of identifying cost-effective strategies for prevention.

The DPP group evaluated the progression of disease, costs and quality of life of their own program using a Markov simulation model. They estimated that, compared with placebo, the lifestyle intervention delayed the onset of T2DM by 11 years and decreased the absolute incidence by $20 \%$. This translated into a cost per QALY of approximately 1100 US\$; or $\$ 8800$ from a societal perspective; and the intervention was cost-effective across all age groups. Further, in a sensitivity analysis, cost-effectiveness improved.

However, the DPP group's analysis was later challenged by independent researchers who found the cost-effectiveness to be more modest: concluding that "lifestyle modification ... should be recommended to all high-risk people." but that the DPP may be, "too expensive for health plans or a national program to implement" and suggested that lower cost methods would be needed for "real world" delivery [307] (2).

One study examined cost-effectiveness in a European context, modelling the application of the intervention used in the DPS to a hypothetical Swedish population of 60 year olds [308]. It assumed that those at risk, on the basis of IGT, had already been identified (so a more comprehensive evaluation would need to incorporate these costs). It took a societal perspective and reported a cost per QALY of $2363 €$.

In a separate study, a group in the UK conducted a cost-effectiveness analysis of: screening for T2DM and IGT and then implementing lifestyle interventions in those found to have IGT [309] (2). They used a hybrid decision tree/Markov model to simulate the long term (50 year time horizon) effects of the strategy, both in terms of clinical and cost-effectiveness outcomes. For each QALY gained, the estimated cost of the strategy was $6242 £$ $(7802 €)$. They found that, given a willingness-to-pay threshold of $20000 £(25000 €)$, the probability of the intervention being cost-effective was $93 \%$ and so concluded that, in a population aged 45 at above-average risk, the strategy seemed to be cost effective.

However, a quite different conclusion emerged from a recent meta-analysis [310] (2+). This noted that most of the available evidence came from research settings, among high-risk populations and that, despite encouraging evidence of effectiveness, so far the economic case for a widespread lifestyle or drug intervention to prevent development of T2DM has not been made.

\section{Adapting a model of care to the circumstances of each country}

In considering which model of care to adopt, it is necessary to take account of the tremendous diversity of health care systems across Europe. There is a need for flexibility, with the model adopted being tailored to the circumstances of individual countries.

Ten responses to the survey among IMAGE partners conducted for this work package were obtained, from Bulgaria, Finland, Greece, Latvia, The Netherlands, Poland, Spain, Switzerland, Ukraine and the United Kingdom. The responses, along with those to the IMAGE "Analyses of T2DM Prevention Programmes at national level" questionnaire, identify very few examples of existing national diabetes (or obesity) prevention programs.

The Finnish DPS model, which has attracted moderate overall support, is viewed as facing several obstacles, mainly in gaining financial support, although there are a variety of possible sources of funding, including pharmaceutical companies, health insurance agencies and local and regional authorities, as well as national governments. In terms of settings, there was most support for primary health care, with university hospitals and endocrinologists also mentioned. There were few precedents for the delivery of such a program in the patient's home.

Two examples of potentially national level programmes were identified. The Krakow (Poland) "City" project for the prevention of CVD and T2DM, which commenced in 2002, is described as being very similar to the DPS model, with screening based on the FINDRISK and simple biochemical indices, while those at risk are offered lifestyle intervention in the form of individual consultations. Since 2005 Poland has also participated in the DE-PLAN project and there is local enthusiasm for scaling this up to national level.

In Finland, FIN-D2D, an implementation project (in the primary health care setting) of the Finnish national program for the prevention of T2DM, ran from 2003 to 2007 [274]. It was conducted in 5 hospital districts - covering a total population of 1.5 million. Subjects at high risk (identified using the FINDRISC) were offered lifestyle modification, which although drawn directly from the DPS seemed to be somewhat more flexible in terms of its approach. There were individual, self-acting and group interventions. At enrolment, subjects underwent a global risk assessment including a questionnaire; and then, together with their health professional, agreed on the level of intervention required. Further, there was flexibility as to the setting: interventions could also be implemented outside the health care system by private or third sector organisations. At the time of writing the evaluation of FIN-D2D is not yet published but will be extremely important as it is one of the first projects to actually implement lifestyle interventions to prevent diabetes in the primary care setting. Similarly, the results of the "Diabetes in Europe-Prevention using Lifestyle, Physical Activity and Nutritional Intervention Plan" (DE-Plan), which involved 25 institutions from 17 European countries, will be invaluable. The DE-Plan project is testing models of lifestyle modification intervention in individuals at high risk of T2DM. Since the programmes are being implemented in existing health care systems, they will provide important evaluations of the cost-effectiveness and feasibility of the models used [239].

\section{Recommendations}

A Any model of care for diabetes prevention should be accompanied by other policy responses to address the determinants of obesity in a population.

D Any model of care must be able to be adapted to the specifics of each health care system. From the evidence available to date, FIN-D2D appears to provide the most flexible approach. The evaluations of FIN-D2D, DE-PLAN and other programs such as the Dutch "Roadmap" will be invaluable in providing evidence for future recommendations on model of cares. The cost-effectiveness of "real world" T2DM prevention programs has not yet been clearly established.

\section{Recommendations for Economic Evaluation of T2DM Prevention Strategies \\ $\nabla$}

Effective interventions to prevent T2DM diabetes, to treat its symptoms and delay its complications will reduce the burden of disease to society and to patients, but require new resources so 
there is a need to analyze the cost-effectiveness of these interventions.

A The recommended perspective of economic evaluation is a large societal perspective including: payer's (state and local governments, health insurance companies), provider's and participant's perspectives of analysis [311,312] (1++), [307,313] (2++).

A The economic costs of the intervention, not financial costs have to be assessed. All resources used, not only paid for, should be considered.

A The ingredient approach for costs analysis is recommended which consists of the following steps: (i) measurement of all resources used by resource category (e.g. personnel, materials \& supplies, laboratory tests, equipment etc.), (ii) eliciting unit costs (prices) of resources used (for the year of evaluation) and (iii) multiplying quantity of resources used by their prices. The ingredients approach allows comparability between different intervention settings. The evaluation for another year can be easily undertaken using revised prices of the resources used.

A It should be ensured that the time of personnel allocated to the intervention is netted out from the remaining activities.

D Where exact measurement of costs such as office materials, utilities, office space, computer etc. is difficult, the estimated standard values of these costs per person-month of personnel time involved can be applied.

B To support future planning of the necessary resources for intervention, the costs should be assessed for two periods: (i) start-up (pre-implementation phase of the programme, costs spent once), (ii) post start-up (actual program running) [239,311,314], and for two levels: (i) management level (costs by health care provider and authorities involved in planning, organizing, continuous training of the intervention managers, monitoring and supervision of the intervention) and (ii) participant level (all costs at the individual level of delivery of the intervention).

A Two type of costs are to be analysed: (i) direct and (ii) productivity (indirect) costs. Direct medical costs comprise costs of identifying high-risk groups, laboratory testing, implementing and maintaining the intervention, costs of care incurred by the intervention that are captured by costs of medical care outside the analysed intervention. Direct non-medical costs include outof-pocket payments (e.g. traveling) and purchases, costs of change of food due to the intervention, as well as value of leisure time physical activities. It is recommended to estimate the value of time spent on intervention by the participant using the average hourly wage in this country in the year of evaluation. Indirect costs represent the value of production lost due to absence from work or usual activity resulting from the intervention as well as present value of future productivity lost due to premature death either caused or averted by intervention. The human capital approach is recommended, applying the average annual wage and unemployment rate of the country in the year of evaluation.

A Three groups of effects of the intervention are to be analysed: (i) benefits achieved, measured in monetary units; (ii) effects measured in specific units such as number of cases of T2DM avoided; (iii) outcomes measured in time gained, adjusted for quality of life - Quality Adjusted Life Years (QALYs) [315]. The weights are then aggregated across time periods. The costs associated with the added years of life can be excluded from analyses [316] (2++).

B We recommend excluding from the analysis the costs associated with longer life achieved with intervention.

A Present the cost-effectiveness ratios for strategies applied. Provide an incremental cost-effectiveness analysis, comparing costs and effects with lack of intervention or with current standard of practice.

A In order to estimate the full economic impact of the intervention, the lifetime health and economic consequences of preventing T2DM (progression of disease, costs and quality of life) should be quantified. The modeling approach is recommended when direct primary or secondary empirical evaluation is not possible [198, 307,315,317,318].

\section{Affiliations}

${ }^{1}$ Paracelsus Medical University, Salzburg, Austria

2 Department of Endocrinology Diabetology Nutrition, Jean Verdier Hospital, AP-HP, Paris-Nord University, CRNH-IdF, Bondy, France

${ }^{3}$ Department of Chronic Disease Prevention Diabetes Prevention Unit, National Institute for Health and Welfare (THL), Helsinki, Finland

${ }^{4}$ Diabetes Center, Institute for Endocrinology, Diabetes and Metabolic Diseases School of Medicine, Clinical Center of Serbia, University of Belgrade, Belgrade, Serbia

${ }^{5}$ Peninsula Medical School, University of Exeter, Exeter, United Kingdom

${ }^{6}$ European Centre on Health of Societies in Transition, London School of Hygiene and Tropical Medicine, London, United Kingdom

${ }^{7}$ Executive Office, International Diabetes Federation (IDF), Brussels, Belgium

${ }^{8}$ Diabetes Center, Laiko Hospital, Athens University Medical School, Athens, Greece

${ }^{9}$ Karl-Landsteiner Institute for Endocrinology and Metabolism, Vienna, Austria, Institute for Clinical Diabetology, German Diabetes Center, and Department of Metabolic Diseases, Heinrich-Heine University Düsseldorf, Düsseldorf, Germany

10 President Federation of European Nurses in Diabetes (FEND), London, United Kingdom

${ }^{11}$ Board member, International Diabetes Foundation-Europe (IDF-Europe), Brussels, Belgium

12 Vice-President, European Association for the Study of Obesity (EASO) and Obesity Research Unit, Helsinki University Central Hospital, Helsinki, Finland

${ }^{13}$ Hjelt Institute, Department of Public Health, University of Helsinki, Helsinki, Finland, and South Ostrobothnia Central Hospital, Seinäjoki, Finland, and Spanish Diabetes Foundation, Madrid, Spain

${ }^{14}$ Carl Gustav Carus Medical Faculty, Technical University of Dresden, Dresden, Germany

\section{References}

1 Cautinho M, Gerstein HC, Wang Y, Yusuf S. The relationship between glucose and incident cardiovascular events. A metaregression analysis of published data from 20 studies of 95,783 individuals followed for 12.4 years. Diabetes Care 1999; 22 (Suppl. 2): 233-240

2 Tominaga M, Eguchi H, Manaka H, Igarashi K, Kato T, Sekikawa A. Impaired glucose tolerance is a risk factor for cardiovascular disease, but not impaired fasting glucose. The Funagata Diabetes Study. Diabetes Care 1999; 22: 920-924

3 Galassi A, Reynolds K, He J. Metabolic syndrome and risk of cardiovascular disease: a meta-analysis. Am J Med 2006; 119: 812-819

4 Narayan KM, Boyle JP, Thompson TJ, Sorensen SW, Williamson DF. Lifetime risk for diabetes mellitus in the United States. JAMA 2003; 290: 1884-1890

5 The DECODE Study Group on behalf of the European Diabetes Epidemiology Group. Glucose tolerance and cardiovascular mortality: comparison of fasting and 2-hour diagnostic criteria. Arch Intern Med 2001; 161: 397-405

6 Shaw J. Epidemiology of childhood type 2 diabetes and obesity. Pediatr Diabetes 2007; 8 (Suppl. 9): 7-15

7 Rocchini AP. Childhood obesity and a diabetes epidemic. N Engl J Med 2002; 346: 854-855

8 Arslanian SA. Type 2 diabetes mellitus in children: pathophysiology and risk factors. J Pediatr Endocrinol Metab 2000; 13 (Suppl.6): 1385-1394

9 Cali AM, Caprio S. Prediabetes and type 2 diabetes in youth: an emerging epidemic disease? Curr Opin Endocrinol Diabetes Obes 2008; 15 : 123-127

10 Zimmet P, Alberti KG, Kaufman F, Tajima N, Silink M, Arslanian S, Wong G, Bennett P, Shaw J, Caprio S. The metabolic syndrome in children and adolescents - an IDF consensus report. Pediatr Diabetes 2007; 8: 299306 
11 Fagot-Campagna A. Emergence of type 2 diabetes mellitus in children: epidemiological evidence. J Pediatr Endocrinol Metab 2000; 13 (Suppl. 6): 1395-1402

12 Dimitrijevic-Sreckovic V, Colak E, Djordjevic P, Gostiljac D, Sreckovic B, Popovic S, Canovic F, Ilic M, Obrenovic R, Vukcevic V, Nikolic D, Nisic T, Milic $G$, Pejcic $G$. Prothrombogenic factors and reduced antioxidative defense in children and adolescents with pre-metabolic and metabolic syndrome. Clin Chem Lab Med 2007; 45: 1140-1144

13 Dietz WH. Health consequences of obesity in youth: childhood predictors of adult disease. Pediatrics 1998; 101: 518-525

14 Barnett AH, EffC, Leslie RD, Pyke DA. Diabetes in identical twins. A study of 200 pairs. Diabetologia 1981; 20: 87-93

15 Newman B, Selby JV, King MC, Slemenda C, Fabsitz R, Friedman GD. Concordance for type 2 (non-insulin-dependent) diabetes mellitus in male twins. Diabetologia 1987; 30: 763-768

16 Poulsen P, Kyvik KO, Vaag A, Beck-Nielsen H. Heritability of type II (noninsulin-dependent) diabetes mellitus and abnormal glucose tolerancea population-based twin study. Diabetologia 1999; 42: 139-145

17 Tattersall RB, Pyke DA. Discordant identical twins. IV. Diabetes mellitus. Practitioner 1972; 209: 569-573

18 Thomas F, Balkau B, Vauzelle-Kervroedan F, Papoz L. Maternal effect and familial aggregation in NIDDM. The CODIAB Study. CODIAB-INSERMZENECA Study Group. Diabetes 1994; 43: 63-67

19 Lyssenko V, Jonsson A, Almgren P, Pulizzi N, Isomaa B, Tuomi T, Berglund G, Altshuler D, Nilsson P, Groop L. Clinical risk factors, DNA variants, and the development of type 2 diabetes. N Engl J Med 2008; 359: 2220 2232

20 Carulli L, Rondinella S, Lombardini S, Canedi I, Loria P, Carulli N. Review article: diabetes, genetics and ethnicity. Aliment Pharmacol Ther 2005; 22 (Suppl. 2): 16-19

21 Wellcome Trust Case Control Consortium. Genome-wide association study of 14,000 cases of seven common diseases and 3,000 shared controls. Nature 2007; 447: 661-678

22 Frayling TM. Genome-wide association studies provide new insights into type 2 diabetes aetiology. Nat Rev Genet 2007; 8: 657-662

23 Saxena R, Voight BF, Lyssenko V, Burtt NP, de Bakker PI, Chen H, Roix JJ, Kathiresan S, Hirschhorn JN, Daly MJ, Hughes TE, Groop L, Altshuler D, Almgren P, Florez JC, Meyer J, Ardlie K, Bengtsson Bostrom K, Isomaa B, Lettre $G$, Lindblad $U$, Lyon HN, Melander 0 , Newton-Cheh C, Nilsson $P$, Orho-Melander M, Rastam L, Speliotes EK, Taskinen MR, Tuomi T, Guiducci C, Berglund A, Carlson J, Gianniny L, Hackett R, Hall L, Holmkvist J, Laurila E, Sjogren M, Sterner M, Surti A, Svensson M, Tewhey R, Blumenstiel B, Parkin M, Defelice M, Barry R, Brodeur W, Camarata J, Chia N, Fava M, Gibbons J, Handsaker B, Healy C, Nguyen K, Gates C, Sougnez C, Gage D, Nizzari M, Gabriel SB, Chirn GW, Ma Q Parikh H, Richardson D, Ricke $D$, Purcell $S$. Genome-wide association analysis identifies loci for type 2 diabetes and triglyceride levels. Science 2007; 316: 1331-1336

24 Sladek R, Rocheleau G, Rung J, Dina C, Shen L, Serre D, Boutin P, Vincent D, Belisle A, Hadjadj S, Balkau B, Heude B, Charpentier G, Hudson TJ, Montpetit A, Pshezhetsky AV, Prentki M, Posner BI, Balding DJ, Meyre D, Polychronakos C, Froguel P. A genome-wide association study identifies novel risk loci for type 2 diabetes. Nature 2007; 445: 881-885

25 Zeggini E, Scott LJ, Saxena R, Voight BF, Marchini JL, Hu T, de Bakker PI, Abecasis GR, Almgren P, Andersen G, Ardlie K, Bostrom KB, Bergman RN, Bonnycastle LL, Borch-Johnsen K, Burtt NP, Chen H, Chines PS, Daly MJ, Deodhar P, Ding CJ, Doney AS, Duren WL, Elliott KS, Erdos MR, Frayling TM, Freathy RM, Gianniny L, Grallert H, Grarup N, Groves CJ, Guiducci C, Hansen T, Herder C, Hitman GA, Hughes TE, Isomaa B, Jackson AU, Jorgensen T, Kong A, Kubalanza K, Kuruvilla FG, Kuusisto J, Langenberg C, Lango $H$, Lauritzen T, Li Y, Lindgren CM, Lyssenko V, Marvelle AF, Meisinger C, Midthjell K, Mohlke KL, Morken MA, Morris AD, Narisu N, Nilsson P, Owen KR, Palmer CN, Payne F, Perry JR, Pettersen E, Platou C, Prokopenko I, Qi L, Qin L, Rayner NW, Rees M, Roix JJ, Sandbaek A, Shields B, Sjogren $M$, Steinthorsdottir V, Stringham HM, Swift AJ, Thorleifsson G, Thorsteinsdottir U, Timpson NJ, Tuomi T, Tuomilehto J, Walker M, Watanabe RM, Weedon MN, Willer CJ, Illig T, Hveem $K, H u$ FB, Laakso M, Stefansson $K$, Pedersen O, Wareham NJ, Barroso I, Hattersley AT, Collins FS, Groop L, McCarthy MI, Boehnke M, Altshuler D. Meta-analysis of genome-wide association data and large-scale replication identifies additional susceptibility loci for type 2 diabetes. Nat Genet 2008; 40: 638-645

26 Zeggini E, Weedon MN, Lindgren CM, Frayling TM, Elliott KS, Lango H, Timpson NJ, Perry JR, Rayner NW, Freathy RM, Barrett JC, Shields B, Morris AP, Ellard S, Groves CJ, Harries LW, Marchini JL, Owen KR, Knight B, Cardon LR, Walker M, Hitman GA, Morris AD, Doney AS, McCarthy MI, Hattersley AT. Replication of genome-wide association signals in UK samples reveals risk loci for type 2 diabetes. Science 2007; 316 : 1336-1341

27 Stolerman ES, Florez JC. Genomics of type 2 diabetes mellitus: implications for the clinician. Nat Rev Endocrinol 2009; 5: 429-436

28 Fujimoto WY. Overview of non-insulin-dependent diabetes mellitus (NIDDM) in different population groups. Diabet Med 1996; 13: S7-10

29 Umpierrez GE, Gonzalez A, Umpierrez D, Pimentel D. Diabetes mellitus in the Hispanic/Latino population: an increasing health care challenge in the United States. Am J Med Sci 2007; 334: 274-282

30 Davis TM. Ethnic diversity in type 2 diabetes. Diabet Med 2008; 25 (Suppl. 2): 52-56

31 Abate N, Chandalia M. Ethnicity and type 2 diabetes: focus on Asian Indians. J Diabetes Complications 2001; 15: 320-327

32 American Diabetes Association. Gestational diabetes mellitus. Diabetes Care 2004; 27 (Suppl. 1): S88-90

33 American Diabetes Association. Executive summary: standards of medical care in diabetes - 2009. Diabetes Care 2009; 32 (Suppl. 1): S6-12

34 Ben-Haroush A, Yogev Y, Hod M. Epidemiology of gestational diabetes mellitus and its association with Type 2 diabetes. Diabet Med 2004; 21: 103-113

35 Bellamy L, Casas JP, Hingorani AD, Williams D. Type 2 diabetes mellitus after gestational diabetes: a systematic review and meta-analysis. Lancet 2009; 373: 1773-1779

36 Dooley SL, Metzger BE, Cho NH. Gestational diabetes mellitus. Influence of race on disease prevalence and perinatal outcome in a U.S. population. Diabetes 1991; 40 (Suppl. 2): 25-29

37 Ratner RE, Christophi CA, Metzger BE, Dabelea D, Bennett PH, Pi-Sunyer $X$, Fowler S, Kahn SE. Prevention of diabetes in women with a history of gestational diabetes: effects of Metformin and lifestyle interventions. J Clin Endocrinol Metab 2008; 93: 4774-4779

38 Metzger BE, Buchanan TA, Coustan DR, de Leiva A, Dunger DB, Hadden DR, Hod M, Kitzmiller JL, Kjos SL, Oats JN, Pettitt DJ, Sacks DA, Zoupas C. Summary and recommendations of the Fifth International WorkshopConference on Gestational Diabetes Mellitus. Diabetes Care 2007; 30 (Suppl. 2): S251-260

39 Norman RJ, Dewailly D, Legro RS, Hickey TE. Polycystic ovary syndrome. Lancet 2007; 370: 685-697

40 Dunaif A, Givens JR, Haseltine FP, eds. Diagnostic criteria for polycystic ovary syndrome: towards a rational approach. Chap.: Polycystic ovary syndrome. Boston: Blackwell Scientific Publications; 1992

41 Rotterdam ESHRE/ASRM-sponsored PCOS Consensus Workshop Group. Revised 2003 consensus on diagnostic criteria and long-term health risks related to polycystic ovary syndrome. Fertil Steril 2004; 81: 1925

42 Azziz R, Carmina E, Dewailly D, Diamanti-Kandarakis E, Escobar-Morreale $H F$, Futterweit $W$, Janssen $O E$, Legro $R S$, Norman $R J$, Taylor $A E$, Witchel SF. Positions statement: criteria for defining polycystic ovary syndrome as a predominantly hyperandrogenic syndrome: an Androgen Excess Society guideline. J Clin Endocrinol Metab 2006; 91: 42374245

43 Goodarzi MO, Azziz R. Diagnosis, epidemiology, and genetics of the polycystic ovary syndrome. Best Pract Res Clin Endocrinol Metab 2006; 20: 193-205

44 Broekmans FJ, Knauff EA, Valkenburg O, Laven JS, Eijkemans MJ, Fauser $B C$. PCOS according to the Rotterdam consensus criteria: Change in prevalence among WHO-II anovulation and association with metabolic factors. BJOG 2006; 113: 1210-1217

45 Dabadghao P, Roberts BJ, Wang J, Davies MJ, Norman RJ. Glucose tolerance abnormalities in Australian women with polycystic ovary syndrome. Med J Aust 2007; 187: 328-331

46 Ehrmann DA, Barnes RB, Rosenfield RL, Cavaghan MK, Imperial J. Prevalence of impaired glucose tolerance and diabetes in women with polycystic ovary syndrome. Diabetes Care 1999; 22: 141-146

47 Dunaif A. Hyperandrogenic anovulation (PCOS): a unique disorder of insulin action associated with an increased risk of non-insulin-dependent diabetes mellitus. Am J Med 1995; 98: 33S-39S

48 Laven JS, Imani B, Eijkemans MJ, Fauser BC. New approach to polycystic ovary syndrome and other forms of anovulatory infertility. Obstet Gynecol Surv 2002; 57: 755-767

49 Boomsma CM, Fauser BC, Macklon NS. Pregnancy complications in women with polycystic ovary syndrome. Semin Reprod Med 2008; 26: $72-84$

50 Boomsma CM, Eijkemans MJ, Hughes EG, Visser GH, Fauser BC, Macklon NS. A meta-analysis of pregnancy outcomes in women with polycystic ovary syndrome. Hum Reprod Update 2006; 12: 673-683 
51 Harris MI. Impaired glucose tolerance in the U.S. population. Diabetes Care 1989; 12: 464-474

52 DeFronzo RA, Ferrannini E. Insulin resistance. A multifaceted syndrome responsible for NIDDM, obesity, hypertension, dyslipidemia, and atherosclerotic cardiovascular disease. Diabetes Care 1991; 14: 173-194

53 Norris SL, Zhang X, Avenell A, Gregg E, Schmid CH, Lau J. Long-term nonpharmacological weight loss interventions for adults with prediabetes. Cochrane Database Syst Rev 2005: CD005270

54 Cummings DE, Flum DR. Gastrointestinal surgery as a treatment for diabetes. JAMA 2008; 299: 341-343

55 Colditz GA, Willett WC, Rotnitzky A, Manson JE. Weight gain as a risk factor for clinical diabetes mellitus in women. Ann Intern Med 1995; 122: 481-486

56 Chan JM, Rimm EB, Colditz GA, Stampfer MJ, Willett WC. Obesity, fat distribution, and weight gain as risk factors for clinical diabetes in men. Diabetes Care 1994; 17: 961-969

57 Meisinger C, Doring A, Thorand B, Heier M, Lowel $H$. Body fat distribution and risk of type 2 diabetes in the general population: are there differences between men and women? The MONICA/KORA Augsburg cohort study. Am J Clin Nutr 2006; 84: 483-489

58 Vazquez G, Duval S, Jacobs Jr DR, Silventoinen K. Comparison of body mass index, waist circumference, and waist/hip ratio in predicting incident diabetes: a meta-analysis. Epidemiol Rev 2007; 29: 115-128

59 Rana JS, Li TY, Manson JE, Hu FB. Adiposity compared with physical inactivity and risk of type 2 diabetes in women. Diabetes Care 2007; 30: 53-58

60 Hamman RF, Wing RR, Edelstein SL, Lachin JM, Bray GA, Delahanty L, Hoskin M, Kriska AM, Mayer-Davis EJ, Pi-Sunyer X, Regensteiner J, Venditti B, Wylie-Rosett J. Effect of weight loss with lifestyle intervention on risk of diabetes. Diabetes Care 2006; 29: 2102-2107

61 Tuomilehto J, Lindstrom J, Eriksson JG, Valle TT, Hamalainen H, IlanneParikka P, Keinanen-Kiukaanniemi S, Laakso M, Louheranta A, Rastas $M$, Salminen $V$, Uusitupa $M$. Prevention of type 2 diabetes mellitus by changes in lifestyle among subjects with impaired glucose tolerance. N Engl J Med 2001; 344: 1343-1350

62 Helmrich SP, Ragland DR, Leung RW, Paffenbarger Jr RS. Physical activity and reduced occurrence of non-insulin-dependent diabetes mellitus. $\mathrm{N}$ Engl J Med 1991; 325: 147-152

$63 \mathrm{Hu}$ FB, Sigal RJ, Rich-Edwards JW, Colditz GA, Solomon CG, Willett WC, Speizer FE, Manson JE. Walking compared with vigorous physical activity and risk of type 2 diabetes in women: a prospective study. JAMA 1999; 282: 1433-1439

$64 \mathrm{Hu}$ G, Lindstrom J, Valle TT, Eriksson JG, Jousilahti P, Silventoinen K, Qiao Q Tuomilehto J. Physical activity, body mass index, and risk of type 2 diabetes in patients with normal or impaired glucose regulation. Arch Intern Med 2004; 164: 892-896

65 Knowler WC, Barrett-Connor E, Fowler SE, Hamman RF, Lachin JM, Walker EA, Nathan DM. Reduction in the incidence of type 2 diabetes with lifestyle intervention or metformin. N Engl J Med 2002; 346: 393-403

66 Lynch J, Helmrich SP, Lakka TA, Kaplan GA, Cohen RD, Salonen R, Salonen $J T$. Moderately intense physical activities and high levels of cardiorespiratory fitness reduce the risk of non-insulin-dependent diabetes mellitus in middle-aged men. Arch Intern Med 1996; 156: 1307-1314

67 Manson JE, Nathan DM, Krolewski AS, Stampfer MJ, Willett WC, Hennekens $\mathrm{CH}$. A prospective study of exercise and incidence of diabetes among US male physicians. JAMA 1992; 268: 63-67

68 Pan XR, Li GW, Hu YH, Wang JX, Yang WY, An ZX, Hu ZX, Lin J, Xiao JZ, Cao $H B$, Liu PA, Jiang XG, Jiang YY, Wang JP, Zheng $H$, Zhang $H$, Bennett $P H$, Howard $B V$. Effects of diet and exercise in preventing NIDDM in people with impaired glucose tolerance. The Da Qing IGT and Diabetes Study. Diabetes Care 1997; 20: 537-544

69 Yamaoka K, Tango T. Efficacy of lifestyle education to prevent type 2 diabetes: a meta-analysis of randomized controlled trials. Diabetes Care 2005; 28: 2780-2786

70 Hales $C N$, Barker DJ. Type 2 (non-insulin-dependent) diabetes mellitus: the thrifty phenotype hypothesis. Diabetologia 1992; 35: 595-601

71 Valdez R, Athens MA, Thompson GH, Bradshaw BS, Stern MP. Birthweight and adult health outcomes in a biethnic population in the USA. Diabetologia 1994; 37: 624-631

72 Forsen T, Eriksson J, Tuomilehto J, Reunanen A, Osmond C, Barker D. The fetal and childhood growth of persons who develop type 2 diabetes. Ann Intern Med 2000; 133: 176-182

73 Phillips DI, Barker DJ, Hales CN, Hirst S, Osmond C. Thinness at birth and insulin resistance in adult life. Diabetologia 1994; 37: 150-154
74 Dyck RF, Klomp H, Tan L. From "thrifty genotype" to "hefty fetal phenotype": the relationship between high birthweight and diabetes in Saskatchewan Registered Indians. Can J Public Health 2001; 92: 340-344

75 Harder T, Rodekamp E, Schellong K, Dudenhausen JW, Plagemann A. Birth weight and subsequent risk of type 2 diabetes: a meta-analysis. Am J Epidemiol 2007; 165: 849-857

76 Hofman PL, Regan F, Jackson WE, Jefferies C, Knight DB, Robinson EM, Cutfield WS. Premature birth and later insulin resistance. N Engl J Med 2004; 351: 2179-2186

77 Hovi P, Andersson S, Eriksson JG, Jarvenpaa AL, Strang-Karlsson S, Makitie 0 , Kajantie E. Glucose regulation in young adults with very low birth weight. N Engl J Med 2007; 356: 2053-2063

78 Genuth S, Alberti KG, Bennett P, Buse J, Defronzo R, Kahn R, Kitzmiller J, Knowler WC, Lebovitz H, Lernmark A, Nathan D, Palmer J, Rizza R, Saudek C, Shaw J, Steffes M, Stern M, Tuomilehto J, Zimmet P. Follow-up report on the diagnosis of diabetes mellitus. Diabetes Care 2003; 26: 3160-3167

79 Kim SH, Chunawala L, Linde R, Reaven GM. Comparison of the 1997 and 2003 American Diabetes Association classification of impaired fasting glucose: impact on prevalence of impaired fasting glucose, coronary heart disease risk factors, and coronary heart disease in a community-based medical practice. J Am Coll Cardiol 2006; 48: 293-297

80 Alberti KG, Zimmet PZ. Definition, diagnosis and classification of diabetes mellitus and its complications. Part 1: diagnosis and classification of diabetes mellitus provisional report of a WHO consultation. Diabet Med 1998; 15: 539-553

81 Gerstein HC, Santaguida P, Raina P, Morrison KM, Balion C, Hunt D, Yazdi $H$, Booker $L$. Annual incidence and relative risk of diabetes in people with various categories of dysglycemia: a systematic overview and meta-analysis of prospective studies. Diabetes Res Clin Pract 2007; 78: 305-312

82 Santaguida PL, Bailon C, Hunt D, Morrison K, Gerstein H, Raina P, Booker $L$, Yazdi $H$. Diagnosis, prognosis, and treatmentof impaired glicose tolerance and impaired fasting glucose. AHRQ Evidence Reports and Summaries (2006); available at: http://www.ahrq.gov

83 de Vegt F, Dekker JM, Jager A, Hienkens E, Kostense PJ, Stehouwer CD, Nijpels $G$, Bouter LM, Heine RJ. Relation of impaired fasting and postload glucose with incident type 2 diabetes in a Dutch population: The Hoorn Study. JAMA 2001; 285: 2109-2113

84 Shaw JE, Zimmet PZ, de Courten M, Dowse GK, Chitson P, Gareeboo H, Hemraj F, Fareed D, Tuomilehto J, Alberti KG. Impaired fasting glucose or impaired glucose tolerance. What best predicts future diabetes in Mauritius? Diabetes Care 1999; 22: 399-402

85 Stern MP, Williams K, Haffner SM. (2002) Identification of persons at high risk for type 2 diabetes mellitus: do we need the oral glucose tolerance test? Ann Intern Med 2002; 136: 575-581

86 National Cholesterol Education Program (NCEP). Third Report of the National Cholesterol Education Program (NCEP) Expert Panel on Detection, Evaluation, and Treatment of High Blood Cholesterol in Adults (Adult Treatment Panel III) final report. Circulation 2002; 106: 31433421

87 Reaven GM. Banting lecture 1988. Role of insulin resistance in human disease. Diabetes 1988; 37: 1595-1607

88 Grundy SM. Does the metabolic syndrome exist? Diabetes Care 2006; 29: 1689-1692; discussion 1693-1686

89 Kahn R, Buse J, Ferrannini E, Stern M. The metabolic syndrome: time for a critical appraisal: joint statement from the American Diabetes Association and the European Association for the Study of Diabetes. Diabetes Care 2005; 28: 2289-2304

90 Oda $E$. The metabolic syndrome (emperor) wears no clothes: response to Kahn. Diabetes Care 2006; 29: 2566

91 Alberti KG, Eckel RH, Grundy SM, Zimmet PZ, Cleeman JI, Donato KA, Fruchart JC, James WP, Loria CM, Smith Jr SC. Harmonizing the metabolic syndrome: a joint interim statement of the International Diabetes Federation Task Force on Epidemiology and Prevention; National Heart, Lung, and Blood Institute; American Heart Association; World Heart Federation; International Atherosclerosis Society; and International Association for the Study of Obesity. Circulation 2009; 120: 1640-1645

92 Ford ES, Li C, Sattar N. Metabolic syndrome and incident diabetes: current state of the evidence. Diabetes Care 2008; 31: 1898-1904

93 Ford ES. Risks for all-cause mortality, cardiovascular disease, and diabetes associated with the metabolic syndrome: a summary of the evidence. Diabetes Care 2005; 28: 1769-1778 
94 Stern MP, Williams K, Gonzalez-Villalpando C, Hunt KJ, Haffner SM. Does the metabolic syndrome improve identification of individuals at risk of type 2 diabetes and/or cardiovascular disease? Diabetes Care 2004; 27: 2676-2681

95 Wilson PW, D'Agostino RB, Parise H, Sullivan L, Meigs JB. Metabolic syndrome as a precursor of cardiovascular disease and type 2 diabetes mellitus. Circulation 2005; 112: 3066-3072

96 Lorenzo C, Williams K, Hunt KJ, Haffner SM. The National Cholesterol Education Program - Adult Treatment Panel III, International Diabetes Federation, and World Health Organization definitions of the metabolic syndrome as predictors of incident cardiovascular disease and diabetes. Diabetes Care 2007; 30: 8-13

97 Lindstrom J, Peltonen M, Eriksson JG, Louheranta A, Fogelholm M, Uusitupa $M$, Tuomilehto J. High-fibre, low-fat diet predicts long-term weight loss and decreased type 2 diabetes risk: the Finnish Diabetes Prevention Study. Diabetologia 2006; 49: 912-920

98 Salmeron J, Ascherio A, Rimm EB, Colditz GA, Spiegelman D, Jenkins DJ, Stampfer MJ, Wing AL, Willett WC. Dietary fiber, glycemic load, and risk of NIDDM in men. Diabetes Care 1997; 20: 545-550

99 Salmeron J, Manson JE, Stampfer MJ, Colditz GA, Wing AL, Willett WC. Dietary fiber, glycemic load, and risk of non-insulin-dependent diabetes mellitus in women. JAMA 1997; 277: 472-477

100 Stevens J, Ahn K, Juhaeri, Houston D, Steffan L, Couper D. Dietary fiber intake and glycemic index and incidence of diabetes in African-American and white adults: the ARIC study. Diabetes Care 2002; 25: 17151721

101 Anderson JW, Baird P, Davis Jr RH, Ferreri S, Knudtson M, Koraym A, Waters $V$, Williams CL. Health benefits of dietary fiber. Nutr Rev 2009; 67: 188-205

102 Weickert MO, Pfeiffer AF. Metabolic effects of dietary fiber consumption and prevention of diabetes. J Nutr 2008; 138: 439-442

103 Meyer KA, Kushi LH, Jacobs Jr DR, Slavin J, Sellers TA, Folsom AR. Carbohydrates, dietary fiber, and incident type 2 diabetes in older women. Am J Clin Nutr 2000; 71: 921-930

104 Barclay AW, Petocz P, McMillan-Price J, Flood VM, Prvan T, Mitchell P, Brand-Miller JC. Glycemic index, glycemic load, and chronic disease risk - a meta-analysis of observational studies. Am J Clin Nutr 2008 87: 627-637

105 Thanopoulou AC, Karamanos BG, Angelico FV, Assaad-Khalil SH, Barbato AF, Del Ben MP, Djordjevic PB, Dimitrijevic-Sreckovic VS, Gallotti CA, Katsilambros NL, Migdalis IN, Mrabet MM, Petkova MK, Roussi DP, Tenconi MT. Dietary fat intake as risk factor for the development of diabetes: multinational, multicenter study of the Mediterranean Group for the Study of Diabetes (MGSD). Diabetes Care 2003; 26: 302-307

106 Vessby B, Aro A, Skarfors E, Berglund L, Salminen I, Lithell H. The risk to develop NIDDM is related to the fatty acid composition of the serum cholesterol esters. Diabetes 1994; 43: 1353-1357

107 Wang L, Folsom AR, Zheng ZJ, Pankow JS, Eckfeldt JH. Plasma fatty acid composition and incidence of diabetes in middle-aged adults: the Atherosclerosis Risk in Communities (ARIC) Study. Am J Clin Nutr 2003; 78: 91-98

108 Due A, Larsen TM, Hermansen K, Stender S, Holst JJ, Toubro S, Martinussen T, Astrup A. Comparison of the effects on insulin resistance and glucose tolerance of 6-mo high-monounsaturated-fat, low-fat, and control diets. Am J Clin Nutr 2008; 87: 855-862

109 van Woudenbergh GJ, van Ballegooijen AJ, Kuijsten A, Sijbrands EJ, van Rooij FJ, Geleijnse JM, Hofman A, Witteman JC, Feskens EJ. Eating fish and risk of type 2 diabetes: A population-based, prospective followup study. Diabetes Care 2009; 32: 2021-2026

110 Kaushik M, Mozaffarian D, Spiegelman D, Manson JE, Willett WC, Hu FB. Long-chain omega- 3 fatty acids, fish intake, and the risk of type 2 diabetes mellitus. Am J Clin Nutr 2009; 90: 613-620

111 Paniagua JA, de la Sacristana AG, Sanchez E, Romero I, Vidal-Puig A, Berral FJ, Escribano A, Moyano MJ, Perez-Martinez P, Lopez-Miranda J, Perez-Jimenez F. A MUFA-rich diet improves posprandial glucose, lipid and GLP-1 responses in insulin-resistant subjects. J Am Coll Nutr 2007; 26: 434-444

112 Salmeron J, Hu FB, Manson JE, Stampfer MJ, Colditz GA, Rimm EB, Willett $W C$. Dietary fat intake and risk of type 2 diabetes in women. Am J Clin Nutr 2001; 73: 1019-1026

113 Mente A, de Koning L, Shannon HS, Anand SS. A systematic review of the evidence supporting a causal link between dietary factors and coronary heart disease. Arch Intern Med 2009; 169: 659-669
114 Conigrave KM, Hu BF, Camargo Jr CA, Stampfer MJ, Willett WC, Rimm $E B$. A prospective study of drinking patterns in relation to risk of type 2 diabetes among men. Diabetes 2001; 50: 2390-2395

115 Stampfer MJ, Colditz GA, Willett WC, Manson JE, Arky RA, Hennekens $\mathrm{CH}$, Speizer FE. A prospective study of moderate alcohol drinking and risk of diabetes in women. Am J Epidemiol 1988; 128: 549-558

116 Ford ES, Mokdad AH. Fruit and vegetable consumption and diabetes mellitus incidence among U.S. adults. Prev Med 2001; 32: 33-39

117 Jiang R, Manson JE, Stampfer MJ, Liu S, Willett WC, Hu FB. Nut and peanut butter consumption and risk of type 2 diabetes in women. JAMA 2002; 288: 2554-2560

118 Smith B, Wingard DL, Smith TC, Kritz-Silverstein D, Barrett-Connor E. Does coffee consumption reduce the risk of type 2 diabetes in individuals with impaired glucose? Diabetes Care 2006; 29: 2385-2390

119 Mann JI, De Leeuw I, Hermansen K, Karamanos B, Karlstrom B, Katsilambros N, Riccardi G, Rivellese AA, Rizkalla S, Slama G, Toeller M, Uusitupa $M$, Vessby B. Evidence-based nutritional approaches to the treatment and prevention of diabetes mellitus. Nutr Metab Cardiovasc Dis 2004; 14: 373-394

120 Jinlin F, Binyou W, Terry C. A new approach to the study of diet and risk of type 2 diabetes. J Postgrad Med 2007; 53: 139-143

121 Luna B, Feinglos MN. Drug-induced hyperglycemia. JAMA 2001; 286 1945-1948

122 Franciosi M, De Berardis G, Rossi MC, Sacco M, Belfiglio M, Pellegrini F, Tognoni G, Valentini M, Nicolucci A. Use of the diabetes risk score for opportunistic screening of undiagnosed diabetes and impaired glucose tolerance: the IGLOO (Impaired Glucose Tolerance and LongTerm Outcomes Observational) study. Diabetes Care 2005; 28: 11871194

123 Jin H, Meyer JM, Jeste DV. Atypical antipsychotics and glucose dysregulation: a systematic review. Schizophr Res 2004; 71: 195-212

124 Tebas $P$. Insulin resistance and diabetes mellitus associated with antiretroviral use in HIV-infected patients: pathogenesis, prevention, and treatment options. J Acquir Immune Defic Syndr 2008; 49 (Suppl. 2): S86-92

125 Elliott RB. Diabetes - a man made disease. Med Hypotheses 2006; 67: 388-391

126 Elinder LS, Jansson $M$. Obesogenic environments - aspects on measurement and indicators. Public Health Nutr 2009: 12: 307-315

127 Wylie-Rosett J. The diabetes epidemic: what can we do? J Am Diet Assoc 2009; 109: 1160-1162

128 James WP. The epidemiology of obesity: the size of the problem. J Intern Med 2008; 263: 336-352

129 Chiolero A, Faeh D, Paccaud F, Cornuz J. Consequences of smoking for body weight, body fat distribution, and insulin resistance. Am J Clin Nutr 2008; 87: 801-809

130 Fagard RH, Nilsson PM. Smoking and diabetes - The double health hazard! Prim Care Diabetes 2009; 3 (4): 205-209

131 Jones OA, Maguire ML, Griffin JL. Environmental pollution and diabetes: a neglected association. Lancet 2008; 371: 287-288

132 Cranmer M, Louie S, Kennedy RH, Kern PA, Fonseca VA. Exposure to 2, 3 7, 8-tetrachlorodibenzo-p-dioxin (TCDD) is associated with hyperinsulinemia and insulin resistance. Toxicol Sci 2000; 56: 431-436

133 Lee DH, Lee IK, Jin SH, Steffes M, Jacobs Jr DR. Association between serum concentrations of persistent organic pollutants and insulin resistance among nondiabetic adults: results from the National Health and Nutrition Examination Survey 1999-2002. Diabetes Care 2007; 30: 622-628

134 Lee DH, Lee IK, Song K, Steffes M, Toscano W, Baker BA, Jacobs Jr DR. A strong dose-response relation between serum concentrations of persistent organic pollutants and diabetes: results from the National Health and Examination Survey 1999-2002. Diabetes Care 2006; 29: $1638-1644$

135 Porta M. Persistent organic pollutants and the burden of diabetes. Lancet 2006; 368: 558-559

136 Rylander L, Rignell-Hydbom A, Hagmar L. A cross-sectional study of the association between persistent organochlorine pollutants and diabetes. Environ Health 2005; 4: 28

137 Raikkonen K, Matthews KA, Kuller LH. Depressive symptoms and stressful life events predict metabolic syndrome among middle-aged women: a comparison of World Health Organization, Adult Treatment Panel III, and International Diabetes Foundation definitions. Diabetes Care 2007; 30: 872-877 
138 Lustman PJ, Clouse RE. Depression: a potentially modifiable risk factor for diabetes and its complications. Diabetes Spectrum 2004; 17: 147148

139 Williams MM, Clouse RE, Lustman PJ. Treating depression to prevent diabetes and its complications: understanding depression as a medical risk factor. Clinical Diabetes 2006; 24: 79-86

140 Knol MJ, Twisk JW, Beekman AT, Heine RJ, Snoek FJ, Pouwer F. Depression as a risk factor for the onset of type 2 diabetes mellitus. A metaanalysis. Diabetologia 2006; 49: 837-845

141 Rubin RR, Ma Y, Marrero DG, Peyrot M, Barrett-Connor EL, Kahn SE, Haffner SM, Price DW, Knowler WC. Elevated depression symptoms, antidepressant medicine use, and risk of developing diabetes during the diabetes prevention program. Diabetes Care 2008; 31: 420-426

142 Blane D, Smith GD, Bartley M. Social class differences in years of potential life lost: size, trends, and principal causes. BMJ 1990; 301: 429_ 432

143 Blaxter $M$. Evidence on inequality in health from a national survey. Lancet 1987; 2: 30-33

144 Brown AF, Ettner SL, Piette J, Weinberger M, Gregg E, Shapiro MF, Karter AJ, Safford M, Waitzfelder B, Prata PA, Beckles GL. Socioeconomic position and health among persons with diabetes mellitus: a conceptual framework and review of the literature. Epidemiol Rev 2004; 26: 6377

145 Kunst AE, Mackenbach JP. The size of mortality differences associated with educational level in nine industrialized countries. Am J Public Health 1994; 84: 932-937

146 Marmot MG, McDowall ME. Mortality decline and widening social inequalities. Lancet $1986 ; 2:$ 274-276

147 Rose G, Marmot MG. Social class and coronary heart disease. Br Heart J 1981; 45: 13-19

148 Woodward M, Shewry MC, Smith WC, Tunstall-Pedoe H. Social status and coronary heart disease: results from the Scottish Heart Health Study. Prev Med 1992; 21: 136-148

149 Brancati FL, Whelton PK, Kuller LH, Klag MJ. Diabetes mellitus, race, and socioeconomic status. A population-based study. Ann Epidemiol 1996; 6: 67-73

150 Choi BC, Shi F. Risk factors for diabetes mellitus by age and sex: results of the National Population Health Survey. Diabetologia 2001; 44: 1221-1231

151 Connolly V, Unwin N, Sherriff P, Bilous R, Kelly W. Diabetes prevalence and socioeconomic status: a population based study showing increased prevalence of type 2 diabetes mellitus in deprived areas. J Epidemiol Community Health 2000; 54: 173-177

152 Hjelm K, Isacsson A, Apelqvist J, Sundquist J, Nyberg P. Foreign- and Swedish-born diabetic patients - a population-based study of prevalence, glycaemic control and social position. Scand J Soc Med 1996; 24: 243-252

153 Ismail AA, Beeching NJ, Gill GV, Bellis MA. Capture-recapture-adjusted prevalence rates of type 2 diabetes are related to social deprivation. QJM 1999; 92: 707-710

154 Marmot MG, Smith GD, Stansfeld S, Patel C, North F, Head J, White I, Brunner E, Feeney A. Health inequalities among British civil servants: the Whitehall II study. Lancet 1991; 337: 1387-1393

155 Robbins JM, Vaccarino V, Zhang H, Kasl SV. Socioeconomic status and type 2 diabetes in African American and non-Hispanic white women and men: evidence from the Third National Health and Nutrition Examination Survey. Am J Public Health 2001; 91: 76-83

156 Stern MP, Rosenthal M, Haffner SM, Hazuda HP, Franco LJ. Sex difference in the effects of sociocultural status on diabetes and cardiovascular risk factors in Mexican Americans. The San Antonio Heart Study. Am J Epidemiol 1984; 120: 834-851

157 Whitford DL, Griffin SJ, Prevost AT. Influences on the variation in prevalence of type 2 diabetes between general practices: practice, patient or socioeconomic factors? Br J Gen Pract 2003; 53: 9-14

158 Haffner SM. Epidemiology of type 2 diabetes: risk factors. Diabetes Care 1998; 21 (Suppl. 3): C3-6

159 Harris MI. Diabetes in America: epidemiology and scope of the problem. Diabetes Care 1998; 21 (Suppl. 3): C11-14

160 Maty SC, Everson-Rose SA, Haan MN, Raghunathan TE, Kaplan GA. Education, income, occupation, and the 34-year incidence (1965-99) of Type 2 diabetes in the Alameda County Study. Int J Epidemiol 2005; 34: 1274-1281

161 Mokdad AH, Bowman BA, Ford ES, Vinicor F, Marks JS, Koplan JP. The continuing epidemics of obesity and diabetes in the United States. JAMA 2001; 286: 1195-1200
162 Larosa C, Sgueglia GA, Sestito A, Infusino F, Niccoli G, Lamendola P, Mariani $L$, Santangeli $P$, Lombardo A, Crea F, Lanza GA. Predictors of impaired heart rate variability and clinical outcome in patients with acute myocardial infarction treated by primary angioplasty. J Cardiovasc Med (Hagerstown) 2008; 9: 76-80

163 Mokdad AH, Ford ES, Bowman BA, Nelson DE, Engelgau MM, Vinicor F, Marks JS. Diabetes trends in the U.S.: 1990-1998. Diabetes Care 2000; 23: 1278-1283

164 Agardh EE, Ahlbom A, Andersson T, Efendic S, Grill V, Hallqvist J, Ostenson CG. Socio-economic position at three points in life in association with type 2 diabetes and impaired glucose tolerance in middle-aged Swedish men and women. Int J Epidemiol 2007; 36: 84-92

165 Lawlor DA, Patel R, Fraser A, Smith GD, Ebrahim S. The association of life course socio-economic position with diagnosis, treatment, control and survival of women with diabetes: findings from the British Women's Heart and Health Study. Diabet Med 2007; 24: 892-900

166 Lynch JW, Kaplan GA, Cohen RD, Kauhanen J, Wilson TW, Smith NL, Salonen JT. Childhood and adult socioeconomic status as predictors of mortality in Finland. Lancet 1994; 343: 524-527

167 Marmot M, Shipley M, Brunner E, Hemingway H. Relative contribution of early life and adult socioeconomic factors to adult morbidity in the Whitehall II study. J Epidemiol Community Health 2001; 55: 301-307

168 Vagero $D$, Leon $D$. Effect of social class in childhood and adulthood on adult mortality. Lancet 1994; 343: 1224-1225

169 Brunner E, Shipley MJ, Blane D, Smith GD, Marmot MG. When does cardiovascular risk start? Past and present socioeconomic circumstances and risk factors in adulthood. J Epidemiol Community Health 1999; 53: 757-764

170 Giskes K, Turrell G, van Lenthe FJ, Brug J, Mackenbach JP. A multilevel study of socio-economic inequalities in food choice behaviour and dietary intake among the Dutch population: the GLOBE study. Public Health Nutr 2006; 9: 75-83

171 Wannamethee SG, Whincup PH, Shaper G, Walker M. Influence of fathers' social class on cardiovascular disease in middle-aged men. Lancet 1996 ; 348: 1259-1263

172 Alberti KG, Zimmet P, Shaw J. International Diabetes Federation: a consensus on Type 2 diabetes prevention. Diabet Med 2007; 24: 451-463

173 Simmons RK, Harding AH, Jakes RW, Welch A, Wareham NJ, Griffin SJ. How much might achievement of diabetes prevention behaviour goals reduce the incidence of diabetes if implemented at the population level? Diabetologia 2006; 49: 905-911

174 Tabak AG, Jokela M, Akbaraly TN, Brunner EJ, Kivimaki M, Witte DR. Trajectories of glycaemia, insulin sensitivity, and insulin secretion before diagnosis of type 2 diabetes: an analysis from the Whitehall Il study. Lancet 2009; 373: 2215-2221

175 Lorenzo C, Okoloise M, Williams K, Stern MP, Haffner SM. The metabolic syndrome as predictor of type 2 diabetes: the San Antonio heart study. Diabetes Care 2003; 26: 3153-3159

176 Garber AJ, Handelsman Y, Einhorn D, Bergman DA, Bloomgarden ZT, Fonseca V, Garvey WT, Gavin 3rd JR, Grunberger G, Horton ES, Jellinger PS, Jones KL, Lebovitz H, Levy P, McGuire DK, Moghissi ES, Nesto RW. Diagnosis and management of prediabetes in the continuum of hyperglycemia: when do the risks of diabetes begin? A consensus statement from the American College of Endocrinology and the American Association of Clinical Endocrinologists. Endocr Pract 2008; 14: 933946

177 Mensink M, Feskens EJ, Saris WH, De Bruin TW, Blaak EE. Study on Lifestyle Intervention and Impaired Glucose Tolerance Maastricht (SLIM): preliminary results after one year. Int J Obes Relat Metab Disord 2003; 27: $377-384$

178 Roumen C, Corpeleijn E, Feskens EJM, Mensink M, Saris WHM, Blaak EE. Impact of 3-year lifestyle intervention on postprandial glucose metabolism: the SLIM study. Diabetic Medicine 2008; 25: 597-605

179 Gillies CL, Abrams KR, Lambert PC, Cooper NJ, Sutton AJ, Hsu RT, Khunt $K$. Pharmacological and lifestyle interventions to prevent or delay type 2 diabetes in people with impaired glucose tolerance: systematic review and meta-analysis. BMJ 2007; 334: 299

180 DECODE Study Group. Age- and sex-specific prevalences of diabetes and impaired glucose regulation in 13 European cohorts. Diabetes Care 2003; 26: 61-69

181 Harris MI, Flegal KM, Cowie CC, Eberhardt MS, Goldstein DE, Little RR, Wiedmeyer HM, Byrd-Holt DD. Prevalence of diabetes, impaired fasting glucose, and impaired glucose tolerance in U.S. adults. The Third National Health and Nutrition Examination Survey, 1988-1994. Diabetes Care 1998; $21: 518-524$ 
182 Qiao Q Hu G, Tuomilehto J, Nakagami T, Balkau B, Borch-Johnsen K, Ramachandran A, Mohan V, Iyer SR, Tominaga M, Kiyohara Y, Kato I, Okubo K, Nagai M, Shibazaki S, Yang Z, Tong Z, Fan Q Wang B, Chew SK, Tan BY, Heng D, Emmanuel S, Tajima N, Iwamoto Y, Snehalatha $C$, Vijay V, Kapur A, Dong Y, Nan H, Gao W, Shi H, Fu F.Age- and sex-specific prevalence of diabetes and impaired glucose regulation in 11 Asian cohorts. Diabetes Care 2003; 26: 1770-1780

183 Rasmussen SS, Glumer C, Sandbaek A, Lauritzen T, Borch-Johnsen K. Determinants of progression from impaired fasting glucose and impaired glucose tolerance to diabetes in a high-risk screened population: 3 year follow-up in the ADDITION study, Denmark. Diabetologia 2008; 51: 249-257

184 Li G, Zhang P, Wang J, Gregg EW, Yang W, Gong Q Li H, Li H, Jiang Y, An Y, Shuai Y, Zhang B, Zhang J, Thompson TJ, Gerzoff RB, Roglic G, Hu Y, Bennett $P H$. The long-term effect of lifestyle interventions to prevent diabetes in the China Da Qing Diabetes Prevention Study: a 20-year follow-up study. Lancet 2008; 371: 1783-1789

185 Lindstrom J, Ilanne-Parikka P, Peltonen M, Aunola S, Eriksson JG, Hemio $K$, Hamalainen $H$, Harkonen P, Keinanen-Kiukaanniemi S, Laakso M, Louheranta A, Mannelin M, Paturi M, Sundvall J, Valle TT, Uusitupa M, Tuomilehto J. Sustained reduction in the incidence of type 2 diabetes by lifestyle intervention: follow-up of the Finnish Diabetes Prevention Study. Lancet 2006; 368: 1673-1679

186 Ramachandran A, Snehalatha C, Mary S, Mukesh B, Bhaskar AD, Vijay V. The Indian Diabetes Prevention Programme shows that lifestyle modification and metformin prevent type 2 diabetes in Asian Indian subjects with impaired glucose tolerance (IDPP-1). Diabetologia 2006; 49: 289-297

187 Kosaka K, Noda M, Kuzuya T. Prevention of type 2 diabetes by lifestyle intervention: a Japanese trial in IGT males. Diabetes Res Clin Pract 2005; 67: 152-162

188 Gerstein HC, Yusuf S, Bosch J, Pogue J, Sheridan P, Dinccag N, Hanefeld M, Hoogwerf B, Laakso M, Mohan V, Shaw J, Zinman B, Holman RR. Effect of rosiglitazone on the frequency of diabetes in patients with impaired glucose tolerance or impaired fasting glucose: a randomised controlled trial. Lancet 2006; 368: 1096-1105

189 O’Dea K, Patel M, Kubisch D, Hopper J, Traianedes K. Obesity, diabetes, and hyperlipidemia in a central Australian aboriginal community with a long history of acculturation. Diabetes Care 1993; 16: 10041010

190 Lindstrom J, Tuomilehto J. The diabetes risk score: a practical tool to predict type 2 diabetes risk. Diabetes Care 2003; 26: 725-731

191 McNeely MJ, Boyko EJ, Leonetti DL, Kahn SE, Fujimoto WY. Comparison of a clinical model, the oral glucose tolerance test, and fasting glucose for prediction of type 2 diabetes risk in Japanese Americans. Diabetes Care 2003; 26: 758-763

192 Schmidt MI, Duncan BB, Bang H, Pankow JS, Ballantyne CM, Golden SH, Folsom AR, Chambless LE. Identifying individuals at high risk for diabetes: The Atherosclerosis Risk in Communities study. Diabetes Care 2005; 28: 2013-2018

193 Kanaya AM, Wassel Fyr CL, de Rekeneire N, Shorr RI, Schwartz AV, Goodpaster BH, Newman AB, Harris T, Barrett-Connor E. Predicting the development of diabetes in older adults: the derivation and validation of a prediction rule. Diabetes Care 2005; 28: 404-408

194 Norberg M, Eriksson JW, Lindahl B, Andersson C, Rolandsson O, Stenlund $H$, Weinehall $L$. A combination of HbA1c, fasting glucose and BMI is effective in screening for individuals at risk of future type 2 diabetes: OGTT is not needed. J Intern Med 2006; 260: 263-271

195 Balkau B, Hillier T, Vierron E, D'Hour A, Lepinay P, Royer B, Born C. Comment to: Borch-Johnsen K, Colagiuri S, Balkau B et al. Creating a pandemic of prediabetes: the proposed new diagnostic criteria for impaired fasting glycaemia (Diabetologia 2004; 47: 1396-1402). Diabetologia 2005; 48: 801-802

196 Hippisley-Cox J, Coupland C, Robson J, Sheikh A, Brindle P. Predicting risk of type 2 diabetes in England and Wales: prospective derivation and validation of ODScore. BMJ 2009; 338: b880

197 Tabaei BP, Herman WH. A multivariate logistic regression equation to screen for diabetes: development and validation. Diabetes Care 2002; 25: 1999-2003

198 Saaristo T, Peltonen M, Lindstrom J, Saarikoski L, Sundvall J, Eriksson JG, Tuomilehto J. Cross-sectional evaluation of the Finnish Diabetes Risk Score: a tool to identify undetected type 2 diabetes, abnormal glucose tolerance and metabolic syndrome. Diab Vasc Dis Res 2005; 2: 67-72

199 Bergmann A, Li J, Wang L, Schulze J, Bornstein SR, Schwarz PE. A simplified Finnish diabetes risk score to predict type 2 diabetes risk and dis- ease evolution in a German population. Horm Metab Res 2007; 39: 677-682

200 Glumer C, Carstensen B, Sandbaek A, Lauritzen T, Jorgensen T, BorchJohnsen K. A Danish diabetes risk score for targeted screening: the Inter99 study. Diabetes Care 2004; 27: 727-733

201 Griffin SJ, Little PS, Hales CN, Kinmonth AL, Wareham NJ. Diabetes risk score: towards earlier detection of type 2 diabetes in general practice. Diabetes Metab Res Rev 2000; 16: 164-171

202 Spijkerman A, Griffin S, Dekker J, Nijpels G, Wareham NJ. What is the risk of mortality for people who are screen positive in a diabetes screening programme but who do not have diabetes on biochemical testing? Diabetes screening programmes from a public health perspective. J Med Screen 2002; 9: 187-190

203 Park PJ, Griffin SJ, Sargeant L, Wareham NJ. The performance of a risk score in predicting undiagnosed hyperglycemia. Diabetes Care 2002; 25: 984-988

204 Spijkerman AM, Yuyun MF, Griffin SJ, Dekker JM, Nijpels G, Wareham NJ. The performance of a risk score as a screening test for undiagnosed hyperglycemia in ethnic minority groups: data from the 1999 health survey for England. Diabetes Care 2004; 27: 116-122

205 Heldgaard PE, Griffin SJ. Routinely collected general practice data aids identification of people with hyperglycaemia and metabolic syndrome. Diabet Med 2006; 23: 996-1002

206 Baan CA, Ruige JB, Stolk RP, Witteman JC, Dekker JM, Heine RJ, Feskens EJ. Performance of a predictive model to identify undiagnosed diabetes in a health care setting. Diabetes Care 1999; 22: 213-219

207 Schulze MB, Hoffmann K, Boeing H, Linseisen J, Rohrmann S, Mohlig M, Pfeiffer AF, Spranger J, Thamer C, Haring HU, Fritsche A, Joost HG. An accurate risk score based on anthropometric, dietary, and lifestyle factors to predict the development of type 2 diabetes. Diabetes Care 2007: 30: 510-515

208 Balkau B, Lange C, Fezeu L, Tichet J, de Lauzon-Guillain B, Czernichow S, Fumeron F, Froguel P, Vaxillaire M, Cauchi S, Ducimetiere P, Eschwege E. Predicting diabetes: clinical, biological, and genetic approaches: data from the Epidemiological Study on the Insulin Resistance Syndrome (DESIR). Diabetes Care 2008; 31: 2056-2061

209 Heikes KE, Eddy DM, Arondekar B, Schlessinger L. Diabetes Risk Calculator: a simple tool for detecting undiagnosed diabetes and pre-diabetes. Diabetes Care 2008; 31: 1040-1045

210 Mohan V, Deepa R, Deepa M, Somannavar S, Datta M. A simplified Indian Diabetes Risk Score for screening for undiagnosed diabetic subjects. J Assoc Physicians India 2005; 53: 759-763

211 Keesukphan P, Chanprasertyothin S, Ongphiphadhanakul B, Puavilai G. The development and validation of a diabetes risk score for high-risk Thai adults. J Med Assoc Thai 2007; 90: 149-154

212 Rathmann W, Martin S, Haastert B, Icks A, Holle R, Lowel H, Giani G. Performance of screening questionnaires and risk scores for undiagnosed diabetes: the KORA Survey 2000. Arch Intern Med 2005; 165 : 436-441

213 Al-Lawati JA, Tuomilehto J. Diabetes risk score in Oman: a tool to identify prevalent type 2 diabetes among Arabs of the Middle East. Diabetes Res Clin Pract 2007: 77: 438-444

214 Glumer C, Vistisen D, Borch-Johnsen K, Colagiuri S. Risk scores for type 2 diabetes can be applied in some populations but not all. Diabetes Care 2006; 29: 410-414

215 Ryan J, Velez F, Chung-Bridges K, Lewis JB, Schwartz R, Jennings T. Prevalence of undetected high risk for type 2 diabetes mellitus in primary care: a South Florida primary care practice-based research network study. Insulin 2007; 2: 109-117

216 Adriaanse $M$, Snoek $F$. The psychological impact of screening for type 2 diabetes. Diabetes Metab Res Rev 2006; 22: 20-25

217 Engelgau MM, Thompson TJ, Smith PJ, Herman WH, Aubert RE, Gunter EW, Wetterhall SF, Sous ES, Ali MA. Screening for diabetes mellitus in adults. The utility of random capillary blood glucose measurements. Diabetes Care 1995; 18: 463-466

218 Rohlfing CL, Little RR, Wiedmeyer HM, England JD, Madsen R, Harris MI, Flegal KM, Eberhardt MS, Goldstein DE. Use of GHb (HbA1c) in screening for undiagnosed diabetes in the U.S. population. Diabetes Care 2000; 23: 187-191

219 Mannucci E, Ognibene A, Sposato I, Brogi M, Gallori G, Bardini G, Cremasco F, Messeri G, Rotella CM. Fasting plasma glucose and glycated haemoglobin in the screening of diabetes and impaired glucose tolerance. Acta Diabetol 2003; 40: 181-186 
220 British Diabetes Association. Diabetes UK. Position statement: early identification of peolple with type 2 diabetes. Report. London, UK: Diabetes UK, British Diabetes Association; 2006

221 Haute Autorité de Santé. Agence nationale d'accréditation ete d'évaluation en santé A (2003). Principes de dépistage du diabète de type 2 . Report. Paris: Haute Autorité de Santé; 2003

222 ADA. Clinical practice recommendations 2008. Diabetes Care 2008; 31: S1-S110

223 Ealovega MW, Tabaei BP, Brandle M, Burke R, Herman WH. Opportunistic screening for diabetes in routine clinical practice. Diabetes Care 2004; 27 (1): 9-12

224 Cosson E, Nguyen MT, Ba H, Hamo-Tchatchouang E, Valensi P. Screening overweighed or obese subjects for prediabetes and diabetes: performing directly oral glucose tolerance test in selected patients may be beneficial and cost-effective. In: 5th World Congress on Prevention of Diabetes and its Complications. Helsinki: WCPD; 2008

225 Zimmet $P$, Thomas $C$. Genotype, obesity and cardiovascular disease has technical and social advancement outstripped evolution? J Intern Med 2003; 254: 114-125

226 Ryden L, Standl E, Bartnik M, Van den Berghe G, Betteridge J, de Boer MJ, Cosentino F, Jonsson B, Laakso M, Malmberg K, Priori S, Ostergren J, Tuomilehto J, Thrainsdottir I, Vanhorebeek I, Stramba-Badiale M, Lindgren P, Qiao Q Priori SG, Blanc JJ, Budaj A, Camm J, Dean V, Deckers J, Dickstein K, Lekakis J, McGregor K, Metra M, Morais J, Osterspey A, Tamargo J, Zamorano JL, Deckers JW, Bertrand M, Charbonnel B, Erdmann E, Ferrannini E, Flyvbjerg A, Gohlke H, Juanatey JR, Graham I, Monteiro PF, Parhofer K, Pyorala K, Raz I, Schernthaner G, Volpe M, Wood D. Guidelines on diabetes, pre-diabetes, and cardiovascular diseases: executive summary. The Task Force on Diabetes and Cardiovascular Diseases of the European Society of Cardiology (ESC) and of the European Association for the Study of Diabetes (EASD). Eur Heart J 2007; 28: 88-136

227 Pan XR, Li GW, Hu YH, Wang JX, Yang WY, An ZX, Hu ZX, Lin J, Xiao JZ, Cao HB, Liu PA, Jiang XG, Jiang YY, Wang JP, Zheng H, Zhang H, Bennett $P H$, Howard BV. Effects of diet and exercise in preventing NIDDM in people with impaired glucose tolerance. The Da Qing IGT and Diabetes Study. Diabetes Care 1997; 20: 537-544

228 Li G, Zhang P, Wang J, Gregg EW, Yang W, Gong Q Li H, Jiang Y, An Y, Shuai Y, Zhang B, Zhang J, Thompson TJ, Gerzoff RB, Roglic G, Hu Y, Bennett $P H$. The long-term effect of lifestyle interventions to prevent diabetes in the China Da Qing Diabetes Prevention Study: a 20-year follow-up study. Lancet 2008; 371: 1783-1789

229 Orchard TJ, Temprosa M, Goldberg R, Haffner S, Ratner R, Marcovina S, Fowler $S$. The effect of metformin and intensive lifestyle intervention on the metabolic syndrome: the Diabetes Prevention Program randomized trial. Ann Intern Med 2005; 142: 611-619

230 Ratner R, Goldberg R, Haffner S, Marcovina S, Orchard T, Fowler S, Temprosa $M$. Impact of intensive lifestyle and metformin therapy on cardiovascular disease risk factors in the diabetes prevention program. Diabetes Care 2005; 28: 888-894

231 Tuomilehto J, Lindström J, Eriksson JG, Valle TT, Hämäläinen H, IlanneParikka P, Keinänen-Kiukaanniemi S, Laakso M, Louheranta A, Rastas $M$, Salminen $V$, Uusitupa $M$. Prevention of type 2 diabetes mellitus by changes in lifestyle among subjects with impaired glucose tolerance. N Engl J Med 2001; 344: 1343-1350

232 Ilanne-Parikka P, Eriksson JG, Lindström J, Peltonen M, Aunola S, Hämäläinen H, Keinänen-Kiukaanniemi S, Laakso M, Valle TT, Lahtela J, Uusitupa M, Tuomilehto J. Effect of lifestyle intervention on the occurrence of metabolic syndrome and its components in the Finnish Diabetes Prevention Study. Diabetes Care 2008; 31: 805-807

233 Yach D, McKee M, Lopez AD, Novotny T. Improving diet and physical activity: 12 lessons from controlling tobacco smoking. BMJ 2005; 330: 898-900

234 The Diabetes Prevention Program Research Group. Reduction in the incidence of type 2 diabetes with lifestyle intervention or metformin. N Engl J Med 2002; 346: 393-403

235 Ramachandran A, Snehalatha C, Satyavani K, Sivasankari S, Vijay V. Metabolic syndrome does not increase the risk of conversion of impaired glucose tolerance to diabetes in Asian Indians - Result of Indian diabetes prevention programme. Diabetes Res Clin Pract 2007; 76 : 215-218

236 Sartor G, Schersten B, Carlstrom S, Melander A, Norden A, Persson G. Ten-year follow-up of subjects with impaired glucose tolerance. Prevention of diabetes by tolbutamide and diet regulation. Diabetes 1980; 29: 41-49
237 Jarrett RJ, Keen H, Fuller JH, McCartney M. Worsening to diabetes in men with impaired glucose tolerance ("borderline diabetes"). Diabetologia $1979 ; 16: 25-30$

238 Eriksson KF, Lindgärde F. Prevention of type 2 (non-insulin-dependent) diabetes mellitus by diet and physical exercise. The 6-year Malmö feasibility study. Diabetologia 1991; 34: 891-898.

239 Schwarz PE, Lindstrom J, Kissimova-Scarbeck K, Szybinski Z, Barengo $N C$, Peltonen M, Tuomilehto J. The European perspective of type 2 diabetes prevention: diabetes in Europe - prevention using lifestyle, physical activity and nutritional intervention (DE-PLAN) project. Exp Clin Endocrinol Diabetes 2008; 116: 167-172

240 Wein P, Beischer N, Harris C, Permezel M. A trial of simple versus intensified dietary modification for prevention of progression to diabetes mellitus in women with impaired glucose tolerance. Aust N Z J Obstet Gynaecol 1999; 39: 162-166

241 Swinburn BA, Metcalf PA, Ley SJ. Long-term (5-year) effects of a reduced-fat diet intervention in individuals with glucose intolerance. Diabetes Care 2001; 24: 619-624

242 Davey Smith G, Bracha Y, Svendsen KH, Neaton JD, Haffner SM, Kuller $L H$. Incidence of type 2 diabetes in the randomized multiple risk factor intervention trial. Ann Intern Med 2005; 142: 313-322

243 Bo S, Ciccone G, Baldi C, Benini L, Dusio F, Forastiere G, Lucia C, Nuti C, Durazzo M, Cassader M, Gentile L, Pagano G. Effectiveness of a lifestyle intervention on metabolic syndrome. A randomized controlled trial. J General Intern Med 2007; 22: 1695-1703

244 Barlow SE, Dietz WH. Obesity evaluation and treatment: Expert Committee recommendations. The Maternal and Child Health Bureau, Health Resources and Services Administration and the Department of Health and Human Services. Pediatrics 1998; 102: E29

245 Krebs NF, Jacobson MS. Prevention of pediatric overweight and obesity. Pediatrics 2003; 112: 424-430

246 Dietz WH, Gortmaker SL. Preventing obesity in children and adolescents. Annu Rev Public Health 2001; 22: 337-353

247 Gillies CL, Abrams KR, Lambert PC, Cooper NJ, Sutton AJ, Hsu RT, Khunti $K$. Pharmacological and lifestyle interventions to prevent or delay type 2 diabetes in people with impaired glucose tolerance: systematic review and meta-analysis. BMJ 2007; 334: 299-307

248 Bantle JP, Wylie-Rosett J, Albright AL, Apovian CM, Clark NG, Franz MJ, Hoogwerf BJ, Lichtenstein AH, Mayer-Davis E, Mooradian AD, Wheeler $M L$. Nutrition recommendations and interventions for diabetes: a position statement of the American Diabetes Association. Diabetes Care 2008; 31 (Suppl. 1): S61-78

249 Richelsen B, Tonstad S, Rossner S, Toubro S, Niskanen L, Madsbad S, Mustajoki P, Rissanen A. Effect of orlistat on weight regain and cardiovascular risk factors following a very-low-energy diet in abdominally obese patients: a 3-year randomized, placebo-controlled study. Diabetes Care 2007; 30: 27-32

250 Torgerson JS, Hauptman J, Boldrin MN, Sjostrom L. XENical in the prevention of diabetes in obese subjects (XENDOS) study: a randomized study of orlistat as an adjunct to lifestyle changes for the prevention of type 2 diabetes in obese patients. Diabetes Care 2004; 27: 155-161

251 Van Gaal LF, Scheen AJ, Rissanen AM, Rossner S, Hanotin C, Ziegler 0. Long-term effect of CB1 blockade with rimonabant on cardiometabolic risk factors: two year results from the RIO-Europe Study. Eur Heart J 2008; 29: 1761-1771

252 Nilsson PM. Is weight loss beneficial for reduction of morbidity and mortality? What is the controversy about? Diabetes Care 2008; 31 (Suppl. 2): S278-283

253 Buchwald H, Estok R, Fahrbach K, Banel D, Jensen MD, Pories WJ, Bantle $J P$, Sledge I. Weight and type 2 diabetes after bariatric surgery: systematic review and meta-analysis. Am J Med 2009; 122 (3): 248-256, e5

254 Colquitt JL, Picot J, Loveman E, Clegg AJ. Surgery for obesity. Cochrane Database Syst Rev 2009: CD003641

255 Chiasson JL, Josse RG, Gomis R, Hanefeld M, Karasik A, Laakso M. Acarbose for prevention of type 2 diabetes mellitus: the STOP-NIDDM randomised trial. Lancet 2002; 359: 2072-2077

256 Chiasson JL, Josse RG, Gomis R, Hanefeld M, Karasik A, Laakso M. Acarbose treatment and the risk of cardiovascular disease and hypertension in patients with impaired glucose tolerance: the STOP-NIDDM trial. JAMA 2003; 290: 486-494

257 Sawicki PT, Kaiser T. Response to Chiasson et al.: Acarbose for the prevention of Type 2 diabetes, hypertension and cardiovascular disease in subjects with impaired glucose tolerance: facts and interpretations concerning the critical analysis of the STOP-NIDDM Trial data. Diabetologia $2004 ; 47$ : 976-977 
258 Eriksson JG, Lehtovirta M, Ehrnstrom B, Salmela S, Groop L. Long-term beneficial effects of glipizide treatment on glucose tolerance in subjects with impaired glucose tolerance. J Intern Med 2006; 259: 553 560

259 Jarrett RJ, Keen H, McCartney P. The Whitehall Study: ten year followup report on men with impaired glucose tolerance with reference to worsening to diabetes and predictors of death. Diabet Med 1984; 1 : 279-283

260 The Diabetes Prevention Program Research Group.The Diabetes Prevention Program: baseline characteristics of the randomized cohort. The Diabetes Prevention Program Research Group. Diabetes Care 2000; 23: 1619-1629

261 Knowler WC, Hamman RF, Edelstein SL, Barrett-Connor E, Ehrmann DA, Walker EA, Fowler SE, Nathan DM, Kahn SE. Prevention of type 2 diabetes with troglitazone in the Diabetes Prevention Program. Diabetes 2005; 54 : 1150-1156

262 Buchanan TA, Xiang AH, Peters RK, Kjos SL, Marroquin A, Goico J, Ochoa C, Tan S, Berkowitz K, Hodis HN, Azen SP. Preservation of pancreatic beta-cell function and prevention of type 2 diabetes by pharmacological treatment of insulin resistance in high-risk hispanic women. Diabetes 2002; 51: 2796-2803

263 Xiang AH, Peters RK, Kjos SL, Marroquin A, Goico J, Ochoa C, Kawakubo $M$, Buchanan TA. Effect of pioglitazone on pancreatic beta-cell function and diabetes risk in Hispanic women with prior gestational diabetes. Diabetes 2006; 55: 517-522

264 Bosch J, Yusuf S, Gerstein HC, Pogue J, Sheridan P, Dagenais G, Diaz R, Avezum A, Lanas F, Probstfield J, Fodor G, Holman RR. Effect of ramipril on the incidence of diabetes. N Engl J Med 2006; 355: 1551-1562

265 Andraws $R$, Brown DL. Effect of inhibition of the renin-angiotensin system on development of type 2 diabetes mellitus (meta-analysis of randomized trials). Am J Cardiol 2007; 99: 1006-1012

266 Jandeleit-Dahm KA, Tikellis C, Reid CM, Johnston CI, Cooper ME. Why blockade of the renin-angiotensin system reduces the incidence of new-onset diabetes. J Hypertens 2005; 23: 463-473

267 Freeman DJ, Norrie J, Sattar N, Neely RD, Cobbe SM, Ford I, Isles C, Lorimer AR, Macfarlane PW, McKillop JH, Packard CJ, Shepherd J, Gaw A. Pravastatin and the development of diabetes mellitus: evidence for a protective treatment effect in the West of Scotland Coronary Prevention Study. Circulation 2001; 103: 357-362

268 Collins R, Armitage J, Parish S, Sleigh P, Peto R. MRC/BHF Heart Protection Study of cholesterol-lowering with simvastatin in 5963 people with diabetes: a randomised placebo-controlled trial. Lancet 2003; 361: 2005-2016

269 Sever PS, Dahlof B, Poulter NR, Wedel H, Beevers G, Caulfield M, Collins $R$ Kjeldsen SE, Kristinsson A, McInnes GT, Mehlsen J, Nieminen M, O’Brien E, Ostergren J. Prevention of coronary and stroke events with atorvastatin in hypertensive patients who have average or lower-than-average cholesterol concentrations, in the Anglo-Scandinavian Cardiac Outcomes Trial - Lipid Lowering Arm (ASCOT-LLA): a multicentre randomised controlled trial. Lancet 2003; 361: 1149-1158

270 The LIPID Study Group. Prevention of cardiovascular events and death with pravastatin in patients with coronary heart disease and a broad range of initial cholesterol levels. The Long-Term Intervention with Pravastatin in Ischaemic Disease (LIPID) Study Group. N Engl J Med 1998; 339: 1349-1357

271 Sjostrom L, Narbro K, Sjostrom CD, Karason K, Larsson B, Wedel H, Lystig T, Sullivan M, Bouchard C, Carlsson B, Bengtsson C, Dahlgren S, Gummesson A, Jacobson P, Karlsson J, Lindroos AK, Lonroth H, Naslund I, Olbers T, Stenlof K, Torgerson J, Agren G, Carlsson LM. Effects of bariatric surgery on mortality in Swedish obese subjects. N Engl J Med 2007; 357: 741-752

272 WHO. WHO Study Group, Primary Prevention of Diabetes Mellitus. Geneva: Technical Report Series 1994: No. 844

273 Schwarz PE, Schuppenies A, Gruhl U, Hoffmann R, Bornstein SR, Schulze $J$, Landgraf $R$. [Prevention of type 2 diabetes in Germany. Ideas, evidence, implementation]. Med Klin (Munich) 2006; 101: 730-736

274 Saaristo T, Peltonen M, Keinanen-Kiukaanniemi S, Vanhala M, Saltevo J, Niskanen L, Oksa H, Korpi-Hyovalti E, Tuomilehto J. National type 2 diabetes prevention programme in Finland: FIN-D2D. Int J Circumpolar Health 2007; 66: 101-112

275 Wang J, Luben R, Khaw KT, Bingham S, Wareham NJ, Forouhi NG. Dietary energy density predicts the risk of incident type 2 diabetes: the European Prospective Investigation of Cancer (EPIC)-Norfolk Study. Diabetes Care 2008; 31: 2120-2125
276 Rosenbloom AL, Silverstein JH, Amemiya S, Zeitler P, Klingensmith GJ. Type 2 diabetes in children and adolescents. Pediatr Diabetes 2009; 10 (Suppl. 12): 17-32

277 Carnethon MR. Diabetes prevention in US ethnic minorities: role of the social environment. J Am Diet Assoc 2008; 108: 942-944

278 Cramer JS, Sibley RF, Bartlett DP, Kahn LS, Loffredo L. An adaptation of the diabetes prevention program for use with high-risk, minority patients with type 2 diabetes. Diabetes Educ 2007; 33: 503-508

279 Azjen I. The theory of planned behavior. OBHDP 1991; 50 (2): 179211

280 Miller WR, Rollnick S. Motivational interviewing: Preparing people for change, 2nd ed. New York: Guildford Press; 2002

281 Bandura A. Social foundations of thought and action: A social cognitive theory. Englewood Cliffs, NJ: Prentice-Hall; 1986

282 Leventhal $H$, Nerenz DR, Steele DJ. Illness representations and coping with health threats. In: Baum A, Taylor SE, Singer JE, eds. Handbook of psychology and health, Vol. 4. Hillsdale, NJ: Lawrence Erlbaum Associates; 1984: 219-252

283 Oxman $A D$, Guyatt $G H$. Validation of an index of the quality of review articles. J Clin Epidemiol 1991; 44: 1271-1278

284 Kreuter $G$. Health program planning: an educational and ecological approach. New York: McGraw-Hill; 2005

285 Bartholomew LK, Parcel GS, Kok G, Gottlieb NH. Intervention mapping: a process for designing theory- and evidence-based health education programs. Mountain View: Mayfield; 2001

286 Anonymous. Management of diabetes: A national clinical guideline. Edinburgh: Scottish Intercollegiate Guidelines Network Publication; 2001: No. 55

287 Chow CK, Lock K, Teo K, Subramanian SV, McKee M, Yusuf S. Environmental and societal influences acting on cardiovascular risk factors and disease at a population level: a review. Int J Epidemiol 2009; DOI: $10.1093 / \mathrm{ije} / \mathrm{dyn} 258$

288 Nolte E, Knai C, McKee M, eds. Managing chronic conditions: An introduction to the experience in eight countries. Copenhagen: European Observatory on Health Systems and Policies; 2008

289 Nolte E, McKee M, eds. Caring for people with chronic conditions. A health system perspective. Maidenhead: Open University Press; 2008

290 Dubois C-A, McKee M, Nolte E, eds. Human resources for health in Europe. Buckingham: Open University Press; 2005

291 Rechel B, Dubois C-A, McKee M, eds. The health care workforce in Europe: learning from experience. Copenhagen: European Observatory on Health Systems and Policies; 2006

292 Saltman RB, Busse R, Figueras J. Social health insurance systems in western Europe. Maidenhead: Open University Press; 2004

293 Saltman RB, Rico A, Boerma WGW. Primary care in the driver's seat? Maidenhead: Open University Press; 2005

294 Bodenheimer T, Wagner EH, Grumbach K. Improving primary care for patients with chronic illness. JAMA 2002; 288: 1775-1779

295 Swinburn B, Egger G, Raza F. Dissecting obesogenic environments: the development and application of a framework for identifying and prioritizing environmental interventions for obesity. Prev Med 1999; 29 : 563-570

296 Swinburn B, Egger G. Preventive strategies against weight gain and obesity. Obes Rev 2002; 3: 289-301

297 Saelens BE, Sallis JF, Black JB, Chen D. Neighborhood-based differences in physical activity: an environment scale evaluation. Am J Public Health 2003; 93: 1552-1558

298 Ewing R, Brownson RC, Berrigan D. Relationship between urban sprawl and weight of United States youth. Am J Prev Med 2006; 31: 464-474

299 Morland K, Diez Roux AV, Wing S. Supermarkets, other food stores, and obesity: the atherosclerosis risk in communities study. Am J Prev Med 2006; 30: 333-339

300 Boehmer TK, Lovegreen SL, Haire-Joshu D, Brownson RC. What constitutes an obesogenic environment in rural communities? Am J Health Promot 2006; 20: 411-421

301 Kumanyika SK, Obarzanek E, Stettler N, Bell R, Field AE, Fortmann SP, Franklin BA, Gillman MW, Lewis CE, Poston 2nd WC, Stevens J, Hong Y. Population-based prevention of obesity: the need for comprehensive promotion of healthful eating, physical activity, and energy balance: a scientific statement from American Heart Association Council on Epidemiology and Prevention, Interdisciplinary Committee for Prevention (formerly the expert panel on population and prevention science). Circulation 2008; 118: 428-464

302 Ståhl T, Wismar M, Ollila E, Lahtinen E, Leppo K, eds. Health in all policies: prospects and potentials. Helsinki: STAKES; 2007 
303 Morsanutto A, Berto P, Lopatriello S, Gelisio R, Voinovich D, Cippo PP, Mantovani LG. Major complications have an impact on total annual medical cost of diabetes: results of a database analysis. J Diabetes Complications 2006; 20: 163-169

304 Norlund A. Cost of illness of adult diabetes mellitus underestimated if comorbidity is not considered. J Intern Med 2001; 250: 57-65

305 Unwin N, Whiting D, Gan D, eds. International Diabetes Federation, IDF Diabetes Atlas, 4th edition. 2009; available online: www.eatlas.idf.org

306 Zhang P, Zhang X, Betz Brown J et al. International Diabetes Federation. Economic impact of diabetes. 2009; available online: www.eatlas.idf. org (Background paper of the IDF Diabetes Atlas fourth edition)

307 Eddy DM, Schlessinger L, Kahn R. Clinical outcomes and cost-effectiveness of strategies for managing people at high risk for diabetes. Ann Intern Med 2005; 143: 251-264

308 NICE. Obesity guidance on the prevention, identification, assessment and management of overweight and obesity in adults and children. London, UK: National Institute for Health and Clinical Excellence; 2006

309 Gillies CL, Lambert PC, Abrams KR, Sutton AJ, Cooper NJ, Hsu RT, Davies MJ, Khunti K. Different strategies for screening and prevention of type 2 diabetes in adults: cost effectiveness analysis. BMJ 2008; 336: 11801185

310 Lauritzen T, Borch-Johnsen K, Sandbaek A. Is prevention of Type-2 diabetes feasible and efficient in primary care? A systematic PubMed review. Prim Care Diabetes 2007; 1: 5-11

311 Hernan WH, Brandle M, Zhang P, Williamson DF, Matulik MJ, Ratner RE, Lachin JM, Engelgau MM. Costs associated with the primary prevention of type 2 diabetes mellitus in the diabetes prevention program. Diabetes Care 2003; 26: 36-47

312 Ramachandran A, Snehalatha C, Yamuna A, Mary S, Ping Z. Cost-effectiveness of the interventions in the primary prevention of diabetes among Asian Indians: within-trial results of the Indian Diabetes Prevention Programme (IDPP). Diabetes Care 2007; 30: 2548-2552

313 Lindgren P, Lindstrom J, Tuomilehto J, Uusitupa M, Peltonen M, Jonsson $B$, de Faire $U$, Hellenius $M L$. Lifestyle intervention to prevent diabetes in men and women with impaired glucose tolerance is cost-effective. Int J Technol Assess Health Care 2007; 23: 177-183

314 Tan-Torres Edejer T, Baltussen R, Adam T, Hutubessy R, Acharya A, Evans DB, Murray CJLs. Making choices in health. WHO guide to costeffectiveness analysis. Geneva: WHO; 2003

315 Gold MR SJ, Russell LB, Weinstein MC. Cost-effectiveness in health and medicine. New York: Oxford University Press; 1996
316 Garber AM, Phelps CE. Economic foundations of cost-effectiveness analysis. J Health Econ 1997; 16: 1-31

317 Herman WH, Hoerger TJ, Brandle M, Hicks K, Sorensen S, Zhang P, Hamman RF, Ackermann RT, Engelgau MM, Ratner RE. The cost-effectiveness of lifestyle modification or metformin in preventing type 2 diabetes in adults with impaired glucose tolerance. Ann Intern Med 2005; 142: 323-332

318 Jacobs-van der Bruggen MA, Bos G, Bemelmans WJ, Hoogenveen RT, Vijgen SM, Baan CA. Lifestyle interventions are cost-effective in people with different levels of diabetes risk: results from a modeling study. Diabetes Care 2007; 30: 128-134

319 Herman WH, Smith PJ, Thompson TJ, Engelgau MM, Aubert RE. A new and simple questionnaire to identify people at increased risk for undiagnosed diabetes. Diabetes Care 1995; 18: 382-387

320 Lindström J, Louheranta A, Mannelin M, Rastas M, Salminen V, Eriksson J, Uusitupa M, Tuomilehto J. The Finnish Diabetes Prevention Study (DPS): Lifestyle intervention and 3-year results on diet and physical activity. Diabetes Care 2003; 26: 3230-3236

321 Lindström J, Ilanne-Parikka P, Peltonen M, Aunola S, Eriksson JG, Hemiö $K$, Hämäläinen $H$, Härkönen P, Keinänen-Kiukaanniemi S, Laakso $M$, Louheranta A, Mannelin M, Rastas M, Sundvall J, Valle TT, Uusitupa M, Tuomilehto J. Sustained reduction in the incidence of type 2 diabetes by lifestyle intervention: The follow-up results of the Finnish Diabetes Prevention Study. Lancet 2006; 368: 1673-1679

322 Orchard TJ, Temprosa M, Goldberg R, Haffner S, Ratner R, Marcovina S, Fowler S, for the Diabetes Prevention Program Research $G$. The effect of Metformin and intensive lifestyle intervention on the metabolic syndrome: The Diabetes Prevention Program Randomized Trial. Ann Intern Med 2005; 142: 611-619

323 Avenell A, Broom J, Brown TJ, Poobalan A, Aucott L, Stearns SC, Smith WCS, Jung RT, Campbell MK, Grant AM. Systematic review of the longterm effects and economic consequences of treatments for obesity and implications for health improvement. Health Technology Assessment 2004; 8 (21): iii - iv, 1-182

324 McTigue KM, Harris R, Hemphill B, Lux L, Sutton S, Bunton AJ, Lohr K. Screening and interventions for obesity in adults: summary of the evidence for the U.S. Preventive Services Task Force. Ann Intern Med 2003; 139: 933-949

325 Shaw KA, O'Rourke P, Del Mar C, Kenardy J. Psychological interventions for overweight or obesity. Cochrane Database of Systematic Reviews 2005; CD003818 
Appendix 1

\section{Oral Glucose Tolerance Test (OGTT)}

$\nabla$

The oral glucose tolerance test (OGTT) is recommended by the WHO for diagnosis of T2DM.

\section{Preparation and cautions}

The OGTT should be performed in the morning, after at least three days of unrestricted carbohydrate intake (more than $150 \mathrm{~g}$ of carbohydrate daily). The test should not be done during an acute illness, as the results may not reflect the patient's glucose metabolism when healthy. A full test dose of glucose for adults should not be given to a person weighing less than $43 \mathrm{~kg}$, due to the fact excessive amount of glucose may produce a false positive result.

\section{The OGTT procedure}

The test should be implemented after an overnight fast of 10 to 16 hours (water is allowed). Smoking or physical activity is not permitted during the test. Usually the OGTT is scheduled to begin in the morning (7-9 am) as glucose tolerance exhibits a diurnal rhythm with a significant decrease in the afternoon. At baseline, the blood sample for glucose determination is taken. The patient is then given a glucose solution to drink. The standard dose is $75 \mathrm{~g}$ of glucose in 250-300 $\mathrm{ml}$ of water. It should be ingested within 5 minutes. For children, the test load should be $1.75 \mathrm{~g}$ per $\mathrm{kg}$ of body weight, up to a maximum of $75 \mathrm{~g}$ of glucose, The next blood sample is collected at $120 \mathrm{~min}$ after the glucose load.

\section{Plasma glucose measurement in blood samples}

The processing of the samples after collection is important to ensure accurate measurement of plasma glucose. This requires rapid separation of the plasma after collection. Laboratory measurements rely upon the use of separated plasma and only immediate separation can prevent the lowering of the glucose in the sample. Only if the plasma separation is completely impossible to be done immediately upon collection, glycolysis inhibitors, e.g. sodium fluoride ( $6 \mathrm{mg}$ per $\mathrm{ml}$ of the whole blood) can be used. Rapid cooling of the sample may also be helpful in reducing the loss of glucose if the plasma cannot be immediately separated. In this case, the sample should be placed immediately after collection into ice-water but the plasma separation should occur within 30 minutes. The plasma should be frozen until the glucose concentration can be measured.

International Federation of Clinical Chemistry (IFCC) recommended that all glucose measuring devices report the results in plasma values. The reason for this recommendation is the fact that plasma glucose values are approximately $11 \%$ higher than the values of whole blood glucose measured in the same sample. Moreover, WHO recommendation is that venous plasma glucose should be the standard method for measuring and reporting. However, it should be noted if one converts from venous to capillary plasma glucose the conversion is different in the case of fasting or post-load glucose values. Fasting values for venous and capillary plasma glucose are identical, while the conversion is necessary only for post-load glucose.
Appendix 2

\section{Methods and Procedures}

\section{$\nabla$}

\section{Methods}

The IMAGE project is described in detail on its website (http:// www.image-project.eu/). Briefly, the development of this guideline followed a pre-defined step-wise procedure addressing:

(i) Stakeholder involvement: the IMAGE guideline development group included diabetes specialists, public health and primary care health professionals, behavioural and social scientists, epidemiologists, patients' organisations, health professional organisations, multidisciplinary, health economists, and health promotion, health policy and health services researchers (for details see Acknowledgements and website). All stakeholders were consulted at numerous stages including the design of the project, definition of the scope and purpose, identification of relevant evidence and developing and refining drafts and final versions of the guideline.

(ii) Scope and purpose: the overall objectives of the guideline were developed through consultation with all stakeholders by email, teleconference and a 2-day symposium. By this process, the clinical questions and target population covered by the guideline were defined and separate working groups established to synthesise the evidence under the following headings: definitions of risk and target population; screening tools, diagnosis and detection; prevention of T2DM and its comorbidities; supporting change in lifestyle behavior for adults at risk of T2DM; models of care and economic aspects of T2DM prevention; and recommendations for economic evaluation of T2DM prevention strategies.

(iii) Evidence identification and review: systematic methods were used to identify relevant evidence using defined search strategies appropriate to the specific topic (see Methodology sections), use of multiple databases, follow up of cited references, and consultation with experts in the field. Criteria for selecting and evaluating the quality of the evidence were based only on publications in peer-reviewed scientific journals and are described in detail (see Methodology sections). Throughout the guideline, SIGN guidance was used to define the criteria for levels (quality) of evidence and grades of the resulting recommendation, which are provided at the end of each chapter. Health benefits, side effects, and risks were considered in formulating these recommendations which were linked to the supporting evidence. Prior to publication, experts externally reviewed the guideline. A procedure for updating the guideline is to be defined.

(iv) Clarity and presentation: the recommendations were reviewed to ensure they are specific and unambiguous. Contextually specific issues arising in each participating European country were discussed to minimise any misunderstanding or misinterpretation. Different options for management are clearly presented and the key recommendations are easily identifiable. The guideline is supported by tools and materials for its application (see website).

(iv) Implementation and dissemination: Potential organizational barriers to applying the recommendations were discussed and addressed where possible. The potential cost implications of applying the recommendations were considered (recognising that 
precise values will depend on national circumstances such as mix of inputs and unit costs) and the guideline presents key review criteria for monitoring and/or audit purposes. A plan for disseminating the guideline to relevant professional groups and persons with increased diabetes risk is in development.

(v) Editorial independence: The guideline is editorially independent from the funding body. Conflicts of interest of guideline development members have been recorded in the Acknowledgements.

\section{Procedures}

At the initial meeting of the guideline development group (Munich, November 2007), the partners discussed the overall project strategies and, based on their specific expertise, assigned themselves to the different working groups. Working group leaders were decided by consensus within each group. Communication occurred within and across the working groups by email, intranet and face-to-face meetings. During a 2-day meeting (Vienna, March 2008), the available information was pre-screened, exclusion and inclusion criteria defined, methodology for evidence identification, grading and recommendation development was further discussed and additional partners allocated to the working groups. Drafts on specific topics were circulated by email and discussed at a further 1-day meeting (Helsinki, June 2008) and across the WPs at a further 2-day meeting (Mallorca, November 2008). In January 2009, the completed drafts were disseminated as a first version of the completed guideline to all stakeholders via email and intranet. After consensus was reached on the contents, the guideline was shortened and edited. Consensus on the final version of the guideline, authors list and publication strategies was achieved during the final 2-day IMAGE meeting (Lisbon, October 2009).

\section{Strengths and limitations}

The evidence-based guideline focuses primarily on the European environment. It does not address specific requirements for ethnic minority groups and people with different social and cultural backgrounds. Although the working groups took note of the specific need for prevention of obesity and diabetes in children with metabolic risk factors, it was determined that this laid outside the scope of this guideline. Although many of the interventions identified can be expected to have similar effects in children, the metabolic, psychosocial, behavioural and medical requirements may be different. Despite these limitations, the IMAGE guideline applies to more than $80 \%$ of people with increased metabolic risk in Europe. Further work is necessary to extend the scope of the guideline and to address the needs of children and specific ethnic groups. 